In-corporeal Diagrams:

Drawing from Dance to Architecture

\title{
Renée Charron
}

A Thesis

In

The Department

Of

Art Education

Presented in Partial Fulfillment of the Requirements

For the Degree of Masters of Art (Art Education) at Concordia University Montreal, Quebec, Canada

May 2017

(C) Renée Charron, 2017 


\section{CONCORDIA UNIVERSITY}

School of Graduate Studies

This is to certify that the thesis prepared

By: Renée Charron

Entitled In-corporeal Diagrams: Drawing from Dance to Architecture

and submitted in partial fulfillment of the requirements for the degree of

Master of Arts (Art Education)

complies with the regulations of the University and meets the accepted standards with respect to originality and quality.

Signed by the final Examining Committee:

Examiner
Lorrie Blair
Erançois Morelli
Examiner
Supervisor
MJ Thompson

Approved by

Chair of the Department or Graduate Program Director 2017

Dean of Faculty 


\section{Abstract \\ In-corporeal Diagrams: \\ Drawing from Dance to Architecture}

Renée Charron

This thesis examines drawing's potential to revive the role of the body in architectural practices, by unveiling forces and processes that compose our bodies and intertwine with the corporeality of architecture. It establishes drawing as a form of dance and notation capable of inscribing the kinesthetic vitality of the live body into architecture. It looks at Frank Gehry's sketches as dynamic tracings of embodied gestures that mediate body and landscape, interior and exterior. The sketches are addressed as the residue of forces generating potential bodies of space, as well as formative diagrams that operate as a prehension of the coming into being of building. Drawing's heuristic role is substantiated by pedagogical and epistemological theories of dance, drawing and architecture education, which situate the affective/haptic kinesthetic body at the center of all in-corporeal experience, perception and conception. The thesis concludes by advancing potential heuristic approaches to embodied drawing in architecture education that could inform processes of conceptualization and enrich the act of sketching as a vital interface between body and architecture. 


\section{Dedication}

To my loving pitbull, Mishka, through whom I have had the privilege of rediscovering the primal vitality of movement, affect, and attunement. 


\section{Acknowledgements}

I would like to thank Erin Manning for her many references that have enable this thesis to emerge. I thank Michel for his support, and patience in proof reading my texts. And of course, many thanks to MJ for her insightful feedback, encouragement and enthusiasm. Thanks also to my committee members: François Morelli and Lorrie Blair. 


\section{Table of Contents}

Signature Page $\quad$ ii

Abstract iii

Dedication $\quad$ iv

Acknowledgments $\quad$ V

Table of Contents $\quad$ vi

List of Drawings viii

INTRODUCTION 1

0.1 Statement of Research Intent $\quad 1$

0.2 Theoretical and Practical Justifications 2

$\begin{array}{ll}0.3 \text { Methodology } & 7\end{array}$

0.4 Study: The Drawing Practice of Frank Gehry 10

0.5 Chapter Outline $\quad 12$

Chapter ONE: Dance as a Tool of Inquiry for Architecture $\quad 13$

1.1 The Phenomenological Body: Fraleigh and the Lived Body 13

1.2 Poststructuralist Views: Langer, Gil, Lepecki and the Space of the Body 15

1.3 Experiencing Stillness: The Towers of Frank Gehry 17

1.4 Mobiüs Skins: The Walt Disney Concert Hall 24

1.5 Living Architecture: The Choreography of Noémie Lachance 29

$\begin{array}{ll}1.6 \text { Conclusion } & 31\end{array}$

\begin{tabular}{ll} 
Chapter TWO: Drawing as Notation & 32 \\
\hline
\end{tabular}

2.1 Formative Form: Nancy on Drawing 32

2.2 Inscribing Dance: Derrida's Trace 34

2.3 Embodied Drawing: Trisha Brown and the Venice Gateway Complex 36

2.4 In-corporeal Diagrams: The Lewis Residence 40

2.5 Drawing as Notation: Louppe on Scripting 47

$\begin{array}{ll}2.6 \text { Conclusion } & 49\end{array}$ 
Chapter THREE: Implications for Architecture Education

3.1 Multi-sensory Perception in Architecture: Pallasmaa's Critique of Ocularcentrism 51

3.2 Duration and Virtualities: Grosz on Space as Duration 54

3.3 Suspension of Perception: Crary and the Paradigm of Attention 56

3.4 Kinetic Bodily Logos: Sheets-Johnstone on Movement 58

3.5 Vitality and Affect Attunement: Stern on Dynamic Forms of Vitality 60

3.6 Body as Locus of Conception: Johnson and Lakoff on Embodied Meaning 62

3.7 Drawing as a Heuristic Tool: Projections 65

$\begin{array}{ll}3.8 \text { Conclusion } & 69\end{array}$

\begin{tabular}{ll} 
CONCLUSION & 70 \\
\hline
\end{tabular}

$\begin{array}{ll}\text { References } & 72\end{array}$

Appendix A: An Embodied Approach to Drawing in Architecture Education $\quad \mathbf{7 5}$

A.1 Seeing and Perceiving: The Urban Context 76

$\begin{array}{ll}\text { A.2 Proprioception: Body and Anatomy } & 79\end{array}$

A.3 Visualizing: Creating and Remembering Space 82

A.4 Improvising: Working with a Dancer 83

A.5 Drawing in Space: Interventions $\quad 85$

A.6 Scoring: Writing Movement 86

A.7 Duration: Tracing Time 88

$\begin{array}{ll}\text { Bibliography (appendix A) } & 89\end{array}$ 


\section{List of Drawings}

Figure 1

Astor Place Hotel (New York / 2001)

Source: H. Bredekamp \& M. Rappolt, (Eds.). (2004). In Gehry Draws (p. 459). London: The MIT Press.

Figure 2

22

Astor Place Hotel

Source: H. Bredekamp \& M. Rappolt, (Eds.). (2004). In Gehry Draws (p. 458). London: The MIT Press.

Figure 3

Astor Place Hotel

Source: H. Bredekamp \& M. Rappolt, (Eds.). (2004). In Gehry Draws (p. 461). London: The MIT Press.

Figure 4

Walt Disney Concert Hall (Los Angeles / 1987-2003)

Source: H. Bredekamp \& M. Rappolt, (Eds.). (2004). In Gehry Draws (p. 339). London: The MIT Press.

Figure 5

Walt Disney Concert Hall

Source: H. Bredekamp \& M. Rappolt, (Eds.). (2004). In Gehry Draws (p. 335). London: The MIT Press.

Figure 6

Walt Disney Concert Hall (interior of hall)

Source: H. Bredekamp \& M. Rappolt, (Eds.). (2004). In Gehry Draws (p. 333). London: The MIT Press.

Figure 7

Noémie Lafrance (Rapture / 2008)

http://sensproduction.org/rapture

Figure 8

Trisha Brow (It's a Draw / 2008)

http://www.trishabrowncompany.org/content/images/image web8 351.jpg 
Figure 9

Detail of Venice Gateway Complex (Marco Polo Airport, Italy / 1998)

Source: H. Bredekamp \& M. Rappolt, (Eds.). (2004). In Gehry Draws (p. 483). London: The MIT Press.

Figure 10

37

Venice Gateway Complex

Source: H. Bredekamp \& M. Rappolt, (Eds.). (2004). In Gehry Draws (p. 465). London: The MIT Press.

Figure 11

39

Venice Gateway Complex

Source: H. Bredekamp \& M. Rappolt, (Eds.). (2004). In Gehry Draws (p. 468). London: The MIT Press.

Figure 12

42

Lewis Residence (Ohio / 1989-1995)

Source: H. Bredekamp \& M. Rappolt, (Eds.). (2004). In Gehry Draws (p. 131). London: The MIT Press.

Figure 13

43

Lewis Residence

Source: H. Bredekamp \& M. Rappolt, (Eds.). (2004). In Gehry Draws (p. 112). London: The MIT Press.

Figure 14

43

Lewis Residence

Source: H. Bredekamp \& M. Rappolt, (Eds.). (2004). In Gehry Draws (p. 125). London: The MIT Press.

Figure 15

45

Lewis Residence

Source: H. Bredekamp \& M. Rappolt, (Eds.). (2004). In Gehry Draws (p. 133). London: The MIT Press.

Figure 16

46

Lewis Residence

Source: H. Bredekamp \& M. Rappolt, (Eds.). (2004). In Gehry Draws (p. 117). London: The MIT Press. 


\section{1}

\section{Statement of Research Intent}

Contemporary architectural practice predominantly underestimates the role of the corporeal in conceptualizing and animating space. An kinesthetic (embodied) awareness of space is essential to an architecture that is to be attuned to its inhabitants and environment. Could exploring drawing as a form of dance facilitate an embodied (affective/tactile-kinesthetic ${ }^{1}$ ) approach to architecture and, by extension, the conception of more vital buildings? This thesis looks at the drawings of architect Frank Gehry and attempts to show how his freehand drawing practice embodies dynamic forms of vitality that thrive on enactive experience and generate an infinite potentiality for imagining other flows of living. Literatures of dance studies, drawing and architecture education will help support this inquiry.

\section{INTRODUCTION}

Contemporary drawing has undergone many metamorphoses in the last decades that have expanded its field of practices in response to technological evolutions and changing cultures. Recent developments have brought about alternative ways of thinking about drawing, moving away from observation towards exploration. Drawing, as premise to this thesis is above all an act and a process that thrives on incompleteness and ambiguity and that operates on the boundaries of categorical definitions. It is the incarnation of the in between; not simply representation, expression or communication but rather a gesture, a movement into space, the trace of passage, the in-corporeal ${ }^{2}$ diagramming of forces, the formative act of drawing: ephemeral movement and incipient thought.

This thesis aims to examine the temporal and relational dimensions of drawing and its potential, often underestimated role in architecture education. It endeavors to weave a field of

\footnotetext{
1 Sheets-Johnstone (2011) coined this expression to designate the felt qualitative dynamics of movement that is bound with affect and that together enable us to make sense of the world.

${ }^{2}$ The hyphen is used here to suggest multiple forms of connection: First, it is from with-in the corporeal that we will attempt to connect bodies and architecture; corporeality and materiality; dance, drawing and architecture. The incorporeal will also constitute the "direction or trajectory that orients a movement of concepts or thought, that constitutes the possibility of a process of understanding, that enables the creation of [drawing]....as the emergence from and an entwinement with a material order... beyond us, and a world of objects, things, processes, and events that constitute materiality on earth". (Grosz 2017, 250) It will constitute the framework from which architecture is acted upon and becomes transformable and expandable in its virtual potential activated in drawing.
} 
relations between various disciplines to form the dynamic framework for an inquiry into the potentialities of drawing as threshold and vital source of new insights into architecture. Inferring from a range of literatures and practices, it aims to reinstate the primacy of architecture's essential and primary motive: the live, sentient human body, always in the act.

My research turns to dance and choreography as an idiomatic discourse through which drawing in architecture might acquire a fresh impetus in a world overcome by technology. The inquiry will revolve around the question of sketching: How can sketching as an embodied, spatializing and generative practice inform the process of architectural design? Can drawing as amodal, partaking in movements, rhythms and vitality affects, bridge the intervals between dance (the kinetic body), and architecture? Is architectural sketching, as I aim to illustrate primarily through the work of the architect Frank Gehry, inscribed in a continuous cycle in which the body gives to drawing what drawing gives to architecture and architecture back to the body? The final objective of this thesis is ultimately to open other venues in the practice of drawing in architecture education that will sustain forms of implicit relational knowing that draw on tacit bodily logos.

\section{2}

\section{Theoretical and Practical Justifications}

I enrolled as a student in architecture in the mid eighties subsequent to studies in fine arts. The only art related course in the architecture curriculum was a compulsory (mostly model) drawing course given every session and summer throughout the program. It was generally perceived as the odd course (in an otherwise conventional functionalist and engineer-based architecture curriculum), the pertinence of which was rarely questioned or understood by students. I attended those courses with an attitude of abandonment and freedom because they were considered of subsidiary relevance to the prestigious design studio courses. It is perhaps precisely because of the unfocused attention given to this subject matter that it could come to have a transformational effect on my awareness of architecture. Throughout the years I began to understand intuitively that studying and working with live models correlated with and enriched my embodied apprehension and comprehension of architecture. Line as an everchanging mediating interface between vital body and space, interior and exterior, became a living analogy for the permeable potential of architectural boundaries. My conception of space, which until then had been that of an 'empty container' conceived through formalist and 
pragmatic concerns and devoid of human affect, began to transform. Architectural space started to appear as an intervallic space between the pulsating, animate and sentient body and its environment: one that recalls the Japanese concept of "Ma" ${ }^{3}$ I gradually began to intuitively perceive the elements of architecture as malleable, resilient membranes responding to forces and energies and modulated by the interplay of my living, feeling body and the changing elements of the landscape or cityscape. Breathing body and breathing landscapes met and merged in the interval that permeable architectural boundaries attempted to invoke and mediate in my own design practice. Architecture began to make more sense and to become much more exciting and meaningful as I played that interval in attunement with my own affects.

This conception was enforced by, and continued to evolve as I acquired implicit bodily knowledge, derived from an ongoing embodied experience of drawing from/with the human body in it's relation to space, light and matter. I found myself particularly engaged in gesture drawing in which the gestures of the moving body and those of the drawing hand correlated in a form of relational dance in a wondering of affective space that engaged directly in an exploration of time. The moving body of flesh offered another understanding of boundaries as living vibrating skin highly responsive to micro-movements and inner (felt) forces as they interacted with the environment. Nothing appeared fixed anymore, nor body, nor space: not even in stillness. My conception of the body, space and architecture as developed in this thesis, is a natural extension of this experience.

Since then, the pedagogical situation has significantly changed. Drawing courses in the same university have been reduced to one only, in the first session of the program. The architecture school in which I have been teaching drawing for over a decade has similarly reduced its only drawing course to a lighter thirty-hour version. What ensues on the part of certain students is no longer abandonment but rather, disinterest. On the other hand, I am constantly reminded by students, year after year, that the majority, despite ongoing scepticism within the discipline, are moved and inspired by the shift away from cognitive emphasis into new territories. Unfortunately, those students will likely never have the opportunity to

3 On the concept of 'Ma' Buci-Glucksman (2001) writes: " $\mathrm{Ma}$ is at once interval, void and spacing, 'between' in its fullest sense. It separates, links, and sets a breathing, a fluctuation and an incompleteness which engenders a relation of time to infinity specific to Japan. For the interval establishes at once a distance and a dynamics, a void and a plurality of senses." (36, my translation) 
experience the state of freedom that emerges from long-term practice, as I have experienced as a student. Yet, pressure is increasingly applied by the faculty, to return to more practical objectives: to eliminate the live model and place more emphasis on the representational in architecture. More recently, I have been informed that the school is reconsidering the pertinence of the course in the program altogether. As with many art disciplines today, the burden of epistemological proof is left to its proponents, to justify its role and pertinence in education. This thesis, in its distinctive way, attempts to layout various points of entry into such an undertaking.

Architecture education is a discipline that has long evolved primarily through representation. Practical learning takes place through visual studies and various conventions of drawing, model making and now virtual spatial simulation often generated by computational processes. Tools and practices of exploration and representation have a direct influence on the perception of space and the development of projects within the discipline. Practices currently in effect seem to reflect a prevalent design attitude in which freehand drawing and the live, kinesthetic body, as medium for spatial exploration and perception, is often set aside in favour of conceptual and digital processes of design.

For centuries the role of the human figure has mainly been representative and symbolic within the discipline; it has predominantly been depicted as an inanimate measuring device, establishing scale, proportion and depth in static architectural representations, or at best, as a superficial analogy for architecture itself. Recent practices have shown a renewed interest in bringing the animate body back into design processes by engaging with the potentiality of movement and transformation through theories of emergence ${ }^{4}$ as in the work of Greg Lynn or Lars Spuybroek. Others, such as Liebeskind and Diller + Scofidio, address issues of embodiment by exploiting participative or interactive performative strategies ${ }^{5}$. I believe, however, that most underlying design processes continue to engage with the body from an intellectual and conceptual perspective that sustains a chasm between theory and practice, text and body.

\footnotetext{
4 Emergence theory normally appears in architecture in relation to generative or interactive computational systems. The system generates processes that interact with given parameters (often gleaned from patterns of bodily movements or social behaviour) to produce organizational complexes that are then translated into built form. (Ednie-Brown, 2007)

5 Sam Spurr has elaborated on these practices in her doctoral thesis entiltled "Performative Architecture" (2007).
} 
Bodies are absent in architecture, but they remain architecture's unspoken condition...To merely say that there is a body is not yet to deal with it. Bodies are there in a way that architects don't want, or can't afford to recognize. But the body is there in an incontrovertible way. The point is to affirm that it's there, and to find the right kind of terms and values by which to make it profitable for architecture to think its own in investments of corporeality. ${ }^{6}$ (Grosz 2001, 14)

Grosz argues that architecture has neglected the dimension of time and duration and has reduced temporality to its quantifiable measure: to space. She insists that architecture must engage with time, change and emergence as an integral aspect of (space and) the processes of design. The philosophical perspective that sustains this essay reaches beyond a purely cognitive and linguistic understanding of the conceptual process by emphasizing the importance of sensorimotor and visceral relations in our experience of the environment and the other as the primary source of all conceptualisation. The thesis argues the need to reconsider and enforce complementary practices that could inform and substantiate prevalent conceptual approaches by reinstating the moving body in processes that engage directly with an exploration of time, embodiment and sensory-kinetic experience in architecture education. I contend that a heightened awareness of embodied perception, through enactive experience, can only enrich students' ability to conceive of and manipulate the complex potentialities of movement and consequently of body-space dynamics as well as the thinking-drawing process underpinning architectural conception. Merleau Ponty (1962) regards the motility of the body as constitutive of our sense of spatiality:

it is clearly in action that the spatiality of our body is brought into being...by considering the body in movement, we can see better how it inhabits space (and, moreover, time) because movement is not limited to submitting passively to space and time, it actively assumes them, it takes them up in their basic significance which is obscured in the commonplaceness of established situation. (102)

This inquiry, therefore, aspires to look into the possibilities and ways of heightening one's corporeal awareness of space through drawing-as-dance ${ }^{7}$. It looks to dance and choreography

\footnotetext{
${ }^{6}$ Grosz is referring here to the sexualized and rationalized nature of embodiment, but I am applying this quote more broadly as I believe her arguments could be extended to the context of my thesis.

${ }^{7}$ Drawing-as-dance aspires to engender a mode of doing/thinking that draws on different modalities across various fields of rhythmic activity and sensibility to explore the dynamic interval between/across cognitive and bodily knowledge. Dance is, in the context of this thesis, above all an analogy that anticipates the potentialities of drawing; it seeks to open venues onto alternate drawing practices enabling the exploration of tacit bodily knowledge implicit in dance to shed light on the kinetic body's relation to space.
} 
and their pedagogical potential as both a sensory action-based paradigm for drawing and as a window into an understanding of lived space. By engaging with modes of thinking in/as movement it seeks to explore the collaborative potential of dance and drawing to generate intersubjective experiences of implicit relational $\mathrm{knowing}^{8}$. In dance space is embodied and becomes a medium perceived through and shaped by bodily gestures: relations of spatial forces and tensions (in excess of the sensorimotor). Dance engages with the essence of movement that is the very basis of the possibility of its spatial modulation and that reveals dynamic forms of vitality emerging from authentic embodied experience as a result of creativity, responsiveness and intentionality. Drawing-as-dance, by appropriating inherent dynamic qualities of dance as improvised performance and as notation, will attempt to seize the temporality of intangible (spatial) intervals in its formless tracings of bodily movements so as to provide insights into the nature of vital space. In the following statement, Pirson (2011) evokes a sense of the spatial affinities of dance to architecture that will stand as a point of departure for a drawing inquiry:

Dance and architecture are two ways of capturing space from the fugacity of one to the stability of the other. What we perceive stretches between the instant and the durable. In dance, bodies in movement activate sequences of spaces that follow each other over time. Any form is born of the disappearance of the previous form and in turn germinates the next. In architecture, the play of voids and fully articulate sequences of spaces that coexist and are experienced in the passage from one to the other thus generate the sense of inside and outside. What is played on in the coming and going between the two disciplines, and with a view to habitation, is finally the always greater relativity of the references and possibilities of moving towards other signatures of space, where the question of the flows of the living would dominate those of the forms of the material. (175, my translation)

This thesis, consequently, addresses the potential of drawing as improvisation and trace, as a tool, as a place of productivity: as a discursive exploration, a site of conception and as a thinking process that can sustain the creative impetus of architectural practice. Drawing-asdance I will argue not only involves a form of kinetic thinking but may also inform the process of conceptual thinking that is itself constituted of movements, rhythms and tensions meaningful primarily as a projection of our corporeal experience.

\footnotetext{
${ }^{8}$ Implicit relational knowing constitutes, according to Stern (2010), concepts and abstractions that occur when one enacts an aspect of a relationship in a new way without it being reflected upon and verbalized.
} 


\section{3}

\section{Methodology}

Given the nature of the topic, a qualitative research approach will prevail throughout my inquiry. The thesis will rely primarily on phenomenological and poststructuralist interpretation of written and drawn documentation using hermeneutic phenomenology as a methodology in order to justify a pedagogical critique of existing attitudes toward drawing in architecture education and to valorize the heuristic potential of alternate drawing approaches. A study of Frank Gehry's sketches will concurrently examine his drawing practice through the lens of dance and choreography. The results will be set against Noémie Lafrance's experience ${ }^{9}$ of the architect's built project, to introduce an alternate understanding of his buildings and to establish how the building performs the sketches.

Phenomenology and poststructuralism will serve as philosophical frameworks from which to examine and describe the structure or essence of lived experience of both drawing and dance as well as their point of contact situated in the body as locus of embodied experience. Phenomenology emphasizes the enactive and interacting body-subject as the embodiment of consciousness: it is through the non-dualistic mind-body that we know the world. Phenomenologists contend that our pre-reflective experience of the world is the basis of all understanding and knowledge; our sensorimotor experience, grounded on our feelings and our visceral relation to the environment constitutes the foundation of all meaning. Herein lies the premise of this thesis: it seeks to foreground an understanding of architecture based on bodies, space and being rather than materiality and function. Phenomenology, like poststructuralism, challenges traditional models of objectivity and disrupts the modern privileged role of science as the paradigm of knowledge. The former views science as a second-order expression of experience whereas the latter situates it among a multiplicity of interpretations of reality. Unlike phenomenology that strives to extrapolate universal statements from certain realities, however, poststructuralism seeks to resist and work against settled truths or oppositions by opening up many different situations and structures to new possibilities often hidden within apparent fixities. It invites varieties of different interpretations and creative responses and embraces the unknown and the ungraspable. (Williams 2014)

\footnotetext{
${ }^{9}$ Montreal dancer and choreographer Noémie Lafrance created a site-specific choreography on the rooftops of Gehry's Fisher Center in New York.
} 
As a methodology, I look to hermeneutic phenomenology. Unlike the phenomenologist, the hermeneutic researcher does not seek to bracket him/herself out of the study to eliminate biases and values. Biases, assumptions and preunderstandings are, on the contrary, embedded and essential to the interpretive process.

The interpretive process includes explicit statements of historical movements or philosophies that are guiding interpretation as well as the presuppositions that motivate the individuals who make the interpretations. (Laverty 2003, 27)

It also welcomes the insights of others and those stemming from multidimensional contexts. Experience is, therefore, understood from particular philosophical perspectives, which in the context of this inquiry are primarily those of phenomenology and poststructuralism. One of the key aspects of the hermeneutic methodology is the use of imagination and creativity to see the phenomenon in a new light and to integrate this vision into new semantic contexts. (Laverty 2003)

A preliminary collection of data will consist of a selection of Gehry's sketches; phenomenological and poststructuralist literature pertaining to drawing, dance and architecture education; qualitative descriptions of Lafrance's performative experience of the architect's building; as well as my own experience as a student and teacher in architecture. Analysis will proceed from description and interpretation of data as well as from themes and concepts that will emerge throughout this mediation. Themes will be organized analytically (from meaning that arises from interpretation of phenomena: its enigmatic nature, its qualitative or kinetic characteristics, etc.) exegetically (by weaving my own interpretations and experiences with notions or concepts of philosophy), exemplificatively (by discerning core structures and diverse perspectives on a theme) and existentially (in relation to lived existentials of time, space and body) always with a view to architecture. (McNamara 1999) However, in the spirit of poststructuralism, the methodology aspires to remain an active, transformative and creative process that responds to emerging insights and questions, prompts further reflection, and opens new interpretive possibilities. The aim of this analysis is ultimately to better understand how considering drawing through the lens of dance theory might unveil its untapped heuristic potential, and enrich the conception of sketching as a vital interface between the body and architecture.

More specifically, my thesis will examine architectural sketching through the language of dance and from the perspective of notation or scoring. At its origin, notation was envisioned as a form of writing, documentation and depiction of actions dominated by an archival logic 
that Rebecca Schneider equates with a "fixation on the bare bones of a skeleton [of dance] devoid of its flesh". (Van Imschoot 2010) It consisted of representational systems of sorts that denoted the underlying structure of dance without acknowledging its qualitative dimension. But its role has since expanded to address the evanescent nature of dance and to emphasize its value as flesh, "not as a passive matter, but as a physicalized relational field of interaction, intensities, techniques, histories, traces, and relics of experienced information". (6) My inquiry aims to reexamine the nature of architectural drawing, particularly sketching in the stages of exploration and conception, as a form of improvisation and idiosyncratic notation or trace of the presence of the absent body. I have chosen to look at Gehry's sketches because of the very distinctive manner in which they explore the qualitative dimensions of buildings. The pertinence of scoring in this context lies, as Van Imschoot expresses it, in its capacity to "link us back to the body and its modes of enactment". (13)

Many interesting attempts have been made to incorporate the body and movement into architecture by considering drawing as score, map or diagram, and leaving behind representational traditions. In her doctoral thesis and in a paper entitled Drawing the Body in Architecture, Sam Spurr (2009) examines the endeavors of several architects to encompass the kinetic dimensions of space in their drawings ${ }^{10}$. Although I find these interpretations of the choreographic script very compelling, I hope to invoke a divergent conception of scoring. The scripting practices surveyed by Spurr, all seem to rely on a cognitive reading of the event. They depict architectural elements and/or the (possibilities of) flows between them but fail to expose the vital and qualitative dimension of the interval in which they meet: the space in which their forces are felt in the bodily experience of the liminal. They also, for the most part, address architecture as secluded from its environment, by examining space as abstract selfsufficient fragments. Rather than examining the idea of notation as the narrative or conceptual abstract spaces of geometrical inscriptions, I aim to do so as the organic residue of the improvising body, through which the energetic flows of vitality are spontaneously projected in their immediacy as a trace of the enactive body in architecture. What I am proposing is to bring

\footnotetext{
${ }^{10}$ For example, and at the risk of oversimplifying: Bernard Tschumi's Manhattan Transcripts used cinematic techniques, multiple notation systems and movement diagrams to develop the eventmental sequential dimension of space. Daniel Libeskind's drawings of juxtaposed fragments of architectural spaces proposed alternate understandings of space by hinting at potential spatial experiences. His Endscape drawings were later used by the dancer/choreographer, William Forsythe, as scores or spatial instigators in his performances. John Hedjuk's Masques are reminiscent of choreographic scores that engage the poetic imagination by proposing possibilities in the liminal space of the theatre. And earlier, Bauhaus artist Oscar Schlemmer had produced his stereometry of space by creating drawings from movements of dancers and reusing their geometries as instigators for the three-dimensional form of costumes.
} 
in a primal dimension of experience that might underlie and vitalize other views of embodied spatial experience and that could open them up to alternate spatiotemporal virtualities that acknowledge the affective/tactile kinesthetic nature of movement.

The title of this thesis alludes to the score as in-corporeal diagram; a concept I have borrowed from Deleuze (2002) as he developed it in relation to the paintings of Francis Bacon. The diagram, he writes, is an "operative set of asignifying lines and zones... that mark out the possibilities of fact but do not yet constitute a fact". (83) They are traits of intensities in the making and sensations that remain as always potential future force fields. The tracing of these marks and lines arise "as if the hand assumed an independence, and began to be guided by other forces, making marks that no longer depend on either our will or our sight." (82) For Deleuze, the diagram is a catastrophe or chaos (relative to the figurative and representational) in which a new order or rhythm germinates and becomes the invisible haptic force of the work. It is this poststructuralist perspective, among others, of Gehry's sketches, at times veiled behind somewhat representational forms, which I aspire to expose and examine.

As a result of this research I hope to inspire alternate forms of drawing (as dance) that could be improvised and expanded on in the context of architecture education so as to nourish the practice of sketching as a process of thinking-with-the-body. These drawing practices might explore for example: improvisations with a moving dancer where dance and drawing participate in a kinetic dialogue; drawing as the tracing of one's simultaneous kinesthetic experience through space; or build on many of the contemporary practices of dancing/notation that explore the corporeal kinetics of tracing ${ }^{11}$. Annexed to the thesis, an archive of drawing approaches and exercises will attempt to illustrate the potential and significance of rethinking current practices in architecture education.

\section{4}

\section{Study}

The Drawing Practice of Frank Gehry

The architect Frank Gehry provides an exceptionally apt choice for a study, to explore my concerns and to speculate on the implications for architectural pedagogy because of the centrality of drawing to his architectural practice. Despite, and perhaps because of the highly

\footnotetext{
${ }^{11}$ For examples see Appendix A.
} 
sophisticated technological tools he has at his disposal to work out the pragmatics of building, he is able to exploit freehand drawing as a means to move beyond the formal, functional and technical preoccupations of architecture to in-corporeal dimensions of space. Unlike those of most architects, his sketches seem to explore the vitality of the project, its range of intensities and potentialities, rather than only working out form, fixing boundaries or diagramming functions. His production of imagery is unusually abundant and intervenes continually throughout the design process of each project; it is his key method of investigation and transformation. The proliferation of drawings and their richness in diversity has made it extremely difficult for me to privilege certain specimens at the expense of others, and yet it is this very diversity that imbues his practice with transformative potential. There has been considerable documentation and interpretation of his drawings but I have yet to come across a reading that does justice to the idiosyncrasies of his work. I believe that it is through the language and practice of dance that I can best unveil the specificity of his practice. Gehry's drawings and the traces they leave (perhaps also on his buildings ${ }^{12}$ ) reflect a conception of space that distances itself from that of the passive receptacle of fixed content. Space, not unlike that of dance, emerges as a qualitative extension of the motions that unfold and actualize it. Space partakes of duration as "a multiplicity of succession, heterogeneity, differences in kind and qualitative differentiations. It is continuous and virtual". (Grosz 2002, 113)

Noémie Lafrance's site-specific choreography Rapture, engages with the rooftops of Gehry's Fisher Center in New York. Her dancers use the building's curving and flowing surfaces to initiate their own soaring movements in space, both reflecting and defeating the buildings inherent movements. Lafrance's intervention reveals a conception of time in Gehry's project that is not linear or successive but complex, indeterminate and heterogeneous; it reconfigures architecture as an "opening up to other spaces, not regulating processes and events so much as accompanying them". (Grosz 2002, 119) Research into Lafrance's experience of Gehry's project, will enable me to compare my analysis of his drawings to her perceptual and kinesthetic experience of the building to determine how one translates into the other.

\footnotetext{
${ }^{12}$ It is important to note that my inquiry will be restricted uniquely to his drawing practice. I may point to his buildings as bodies but cannot, in the scope of this thesis, delve into any substantial exploration of the translation of his drawings into built form/event (except in the atypical case of Lafrance). Drawing is examined as, and is, inherently architectural process, not product.
} 


\section{5}

\section{Chapter Outline}

The thesis will be structured in three chapters. A first chapter looks at dance from a phenomenological and poststructural perspective as a tool of inquiry for architecture. It attempts to provide an alternative way of thinking and perceiving space and the role of drawing in architecture. The second chapter examines the act of drawing and more specifically sketching as notation or trace. It seeks to demonstrate how drawing as a form of embodied scripting can reveal temporal and qualitative dimensions of architecture absent in conventional types of architectural representations. The third chapter outlines the historical causes that have contributed to the privileging of disembodied forms of knowledge and establishes the primacy of bodily logos in contemporary architecture and its underestimated role in education. It demonstrates how the body is central in thinking and experiencing the vitality of space and, hence, in the conceptualization of meaningful buildings. This final chapter will further introduce potential heuristic drawing practices that could sustain an embodied approach to architecture education. An analysis of the sketches of Frank Gehry will weave through each chapter as a means to substantiate my thesis and illustrate its premise. 


\section{Chapter ONE \\ Dance as a Tool of Inquiry for Architecture}

This chapter sets the philosophical premise of my inquiry by establishing the role of the body in our experience of space through the lens of dance theory. It introduces a phenomenological view of the body primarily through dance theories of Sondra Fraleigh, as well as poststructuralist outlooks of Susan Langer, José Gil and André Lepecki, often grounded in Deleuzian concepts. The drawings of Frank Gehry are interpreted from the perspective of these theories and practices. The chapter concludes by examining the nature of his sketches as a resonance of Noémie Lafrance's dance choreography, Rapture, in which she appropriates the rooftops of one of his buildings as site and collaborative event for her performance.

\section{1}

\section{The Phenomenological Body}

Fraleigh and the Lived Body

The most evident link between thought, dance, drawing and architecture is that they are all founded in lived and experiential values. The lived body (i.e. the experiencing body) assumes the unity of body and mind: a non-dualistic conception of the body advocated by phenomenology. In Dance and the Lived Body, Fraleigh (1987) develops this phenomenological conception of the lived body as a body-of-action wherein action is the negation of dualism and movement, the actualization of embodiment. Space is perceived and experienced through the body on a kinesthetic and experiential level. Fraleigh examines dance from the perspective of the sentient or feeling-body as well as an affirmation of the vital body. Sentient life consists of the subjective, live and tactile/affective qualities of our own experiences that are distinctive in sensation. Our body is a body of feeling through which we live sentience, and dance involves every possible feeling as potential vitality affect. "When we value dance as an expression of the vital body, we value the lived source of dance; we illuminate and intensify its inmost defining condition." (56) She rejects the objectifying idea of dance as "an art that has movement as its medium, and uses the body as instrument", and contends rather that " dancing requires a concentration of the whole person as a minded body, not a mind in command of something separable, called body". (9) This minded body is the body that subtends this thesis throughout. 
Fraleigh distinguishes the precognitive body-subject from the cognitive body-object in her account of the body. The former, she states, "is a temporal concept, describing the time in which consciousness is present centered, or pre-reflective"; the latter "describes a conscious, intentional position taken toward the body as an object of attention". (14) The objectivity in which "science" indulges must, however, be differentiated from a phenomenological understanding of the objective body in terms of intentional consciousness, whereby 'intentiveness is implicated in will and freedom as it is realized in action'. In other words, the body-object that interests us here does not refer to the material body-as-object, but rather to the body as object of (self) awareness, or to a reflective attitude towards the sentient body. This body is moreover "coextensive with the poetry of the world, sounds, its colors, textures, and especially its movements." (72) It is in this coextensivity that the body is experienced as our immediate source of meaning; and in contemporary performance, the dancing body allows its significance to emerge. This idea of the body's interactive relation to its surroundings will constitute the framework from which alternate spatial conceptions will evolve and shed light on Gehry's drawings.

On the concepts of space and time, phenomenology accounts for a body integrally of space and time; movement is an undivided lived duration. Building on Bergson's contribution to phenomenology Fraleigh quotes:

Between positions and a displacement there is not the relation of parts to the whole, but that of a diversity of possible viewpoints to the real indivisibility of the object. (179)

Movement in duration does not inhabit a succession of spaces in time but an indivisible continuity of qualitative change. She continues:

We simply live time and space through the qualitative values of the time-space of our movement...When we rehearse a dance, we are trying to embody (incorporate) the ideal time-space in which the particular dance (movement) lives for us. (180)

The implications of phenomenology for architecture and for understanding Gehry's drawing practice are numerous. I will return to some of these implications in subsequent chapters. Suffice it to say for now, that understanding sketching as a form of dance requires us to draw from certain tenets of phenomenology. Drawing is an embodied gesture. It requires the receptive, sentient and pre-reflective body to respond to an external world while allowing the present moment to vacillate in the interval of the mnemonic and the imaginary. Through this kinesthetic act of sketching, meaning emerges as a movement of embodied thinking. As I will argue in the following chapters, drawing is the incarnation of a potentiality that thrives on 
qualitative sensations and vitality affects. Gehry's drawing practice distinguishes itself from most, in that it subsumes both vitality and duration as process. Vitality is understood here as the sensing of forces of variation brought about by rhythmic changes in line weight, intensity, speed, direction, duration, etc. that drives the experience of drawing for both its author and the viewer. Gehry does not engage in sketching as successive spatial fragments experienced optically over time in a cinematic fashion, in the manner of le Corbusier. As I hope to elucidate, his sketching partakes of duration by tracing time as a vibrating energy that resounds as space, in numerous drawings of diverse intensities. Juxtaposed, these drawings embody a temporal density, a fluctuating flow of intensities invested with dynamic vitality affects.

\section{2}

\section{Poststructuralist Views}

Langer, Gil, Lepecki and the Space of the Body

Phenomenology's contribution, therefore, lies in its consideration of the sentient, perceiving body in the world and its role in constituting situated meaning. But certain shortfalls are brought forth by dance critics that contend that phenomenology is unable to account for the dancing body's energy (invoked in Langer's concept of virtual power) and the body's spacetime (Gil \& Lepecki's understanding of the space of the body). Suzanne Langer (1953) develops the concept of virtual power through which all the vital movements of dancers responding and interacting in a performance are generated from forces that seem to operate beyond their physical gestures. In experiencing a performance we perceive not only the continuum of physical movements of dancers but the display of forces of volition that magnetize, push and pull, orient, drive and whirl the bodies. The relation between the dancers is not a spatial one but rather a field of forces that make up the virtual powers of dance. The dance is an appearance or apparition that unfolds from what the dancers do and yet manifests itself beyond them. These forces that exist only for perception are virtual and yet real.

The prototype of these purely apparent energies is not the 'field of forces' known to physics, but the subjective experience of volition and free agency...The consciousness of life, the sense of vital power, even of the power to receive impressions, apprehend the environment, and meet changes, is our most immediate self-consciousness. This is the feeling of power; and the play of such 'felt' energies is as different from any system of physical forces as psychological time is from clock-time, and psychological space from the space of geometry. (176) 
In The Dancer's Body, José Gil (2002) takes up this virtual plane of movement to designate his concept of the plane of immanence in dance. Deleuze characterizes the plane of immanence as the direction, orientation, the binding force that enables thought and body to connect, relate, converge and diverge, create alliances and tensions whose intensities are ever-changing. It can be understood as the virtual and continually actualizing potential of the existence of concepts, affects, percepts and prospect. (Grosz 2017, 136) On this plane of utmost intensity "thought and body dissolve into one another", body and mind become one, or paraphrasing Deleuze: 'what moves as a body returns as the movement of thought'. It is this virtual plane that ensures the continuity of gestures and movements by incorporating them into a virtual continuity. The paradoxical space of Gil's dancer is therefore very different from, yet imbricated in objective space. Space is created by, or emerges from the movements of the body. This space, which Gil \& Lepecki (2006) call the space of the body, is an intensified one, invested with affects ${ }^{13}$ and forces that imbue it, and the objects within it, with a diversity of textures and emotions. For them, the space of the body is a "skin extending itself into space; it is skin becoming space...that prolongs the body's limits beyond its visible contours" (22). This extension, which he refers to as the first natural prosthesis of the body, forms a virtual space that enables the actualization of movement. Throughout their essay, the authors emphasize the importance of reversibility of internal and exterior space: the dancer transfers the energy of his inner space to external space until it is infused with its textures so as to become one coextensive whole, and external space then turns back onto internal space sustaining it in return. In a sense the body must become space, it is no longer in space but, as Merleau-Ponty points out, 'of' space. The space of the body therefore provides interior (proprioceptive) and exterior (virtual) points of contemplation for the dancer. Points of view emerging from the intimacy of internal energy flows and those revealed by distanced but intensified exterior extensions and reflections coalesce into a multiplicity of virtual images with which the dancer engages in continual dialogue. In Paradoxical Body, Gil \& Lepecki conceive of the body as a

meta-phenomenon, simultaneously visible and virtual, a cluster of forces, a transformer of space and time, both emitter of signs and trans-semiotic, endowed by an organic interior ready to be dissolved as soon as it reaches the surface. A body [or BwO] inhabited by and inhabiting - other bodies and other minds, a body existing at the same time at the opening toward the world... and in the seclusion of its singularity...(28)

\footnotetext{
${ }^{13}$ Affects (a concept first introduced by Spinoza) are visceral forces or intensities that drive us towards action, thought and continually changing relations; they are modes of connection between an interior and exterior that orient us to the world by enabling us to feel it. Affects are the vital powers of the body and mind to act with and within things, to make connections and to expand them. (Grosz 2017)
} 
A phenomenological view of the body and its relation to space has strongly been acknowledged as indispensable to an embodied understanding of architecture. Dance, as Fraleigh demonstrates, incarnates the phenomenological body in an insightful manner. But understanding the concepts of the space of the body, and the virtual power that generates it, I will argue, is also key to grasping the potential vital quality of the spatial interval that relates architecture to the body, and that sheds light on the nature of Gehry's sketches. The dancer explores the extensity of the space of his/her moving body and in doing so enables one to perceive the limits at which intensities culminate or fade thereby exposing the potential virtual interfaces with which architecture can engage to maximize vital energies. In its own manner, architecture (as body) can reverberate, absorb, amplify or to some degree silence these energies and produce force fields, vibrations and affects in interaction with the body and the landscape. Looking at the drawings of Frank Gehry, we sense that his line probes this intervallic space in which architecture comes to life, much in the manner of the skin evoked by Gill \& Lepecki. The drawings are the manifestation of an intensified space that emerges as an extension of the architect's enactive minded body. The tracing constitutes the plane of imminence in which body and thought merge together and open onto a multiplicity of virtual images. Examining conceptions of space and drawing, as this thesis aspires to do, from the perspective of dance and the body, introduces new perspectives from which to perceive and think of architecture in its most vital manifestation.

\section{3}

\section{Experiencing Stillness}

The Towers of Frank Gehry

To set the tone for my exploration of Gehry's sketches I will begin with the study of one of his projects that might at first seem improbable as the embodiment of dance: the Astor Place Hotel, an indweller of New York City. In order to distance myself from a dynamic interpretation that could easily fall into a formal analysis of movement as the result of evocative ocular forces on the pictorial surface of his drawings (i.e. a two-dimensional interpretation of movement), I will first examine the tower through the concept of stillness as the precondition of dance. This perspective will serve as an entry point into the interpretation of other, more visibly dynamic project sketches. 
Stillness in dance theory encompasses more than a spontaneous, natural movement embracing gravity and downward motions; it stands in-between arrest and motion. It is, as Lepecki (2000) establishes, nor pose/pause nor fixity but a "still point which, at the moment, appears to possess all the vibratile contours of a fluttering punctum ${ }^{14}$... propelling signification into vertiginous motion while it stays put, vibrating, there". (334) As he goes on to explain, within pre-modern traditions stillness was perceived as non-dance; it was a disturbing element that menaced the very impetus of flight and fell outside the gestural flows considered as dance. With Nijinski ${ }^{15}$ stillness acquired a new significance as the invisible generative potential for any perceptual and kinetic transformation; it was acknowledged as the originator of dance, a conception also known as the anacrusis of dance. Not until the 1970's through the improvisation approaches of dancer Steve Paxton did stillness acquire its full status as a "threshold of sensorial perceptions that can be intensified by means of microscopy". (344) Stillness, Paxton contends does not exist per se, because it consists in itself of many layers of internal micro-movements or vibratile intensities. In other words, to stand still, the body must perform an in-visible dance. This provides an insight, as we will see below, into the relationship between the live body and the building as a reflection of its implicit bodily knowledge.

I will first diverge to architecture for a moment to develop a parallel transformation in our perception of buildings that might inform us as to Gehry's kinetic sense of architecture. Architecture has always evoked the notion of stability, fixity and permanence, inscribed in the condition of stillness somewhat like that of traditional dance. But in the advent of new technologies and the introduction of steel structures freeing buildings of their outer skins, this vision has since transformed, as might be epitomized in part by the following anecdote: During my studies in architecture, the school organized a trip to New York so as to visit the city and its architectural landmarks. The World Trade Center being the highest building at that time was of course part of the agenda. We made our way up to the upper floors of one of the twin towers and upon arrival the teacher explained that at the altitude at which we were standing, the building physically swung seven feet to one side and seven feet to the other in a regular pendulum motion. Without such flexibility, the tower would collapse. At that moment my whole perception of the building and of architecture in general suddenly transformed. I began to hear

\footnotetext{
${ }^{14} \mathrm{He}$ is referring here to Roland Barthe's concept of punctum and applying it to performance for its 'metonymic power of expansion'.

${ }^{15}$ Vaslav Nijinski was a Russian choreographer and dancer known for his performance of Stravinsky's Le Sacré du printemps in 1913.
} 
and feel the rumblings of the elevators, the ventilation running through its veins, the wind against the panes of glass, the city resonating in its structure; and the building suddenly came to life. It is perhaps at this point that I also began to intuit physiologically how our understanding of architecture is derived from our kinesthetic perception of space and the changing relations it engenders. My perception of liveliness as emanating solely from my centered body shifted to that of architecture. Buildings as breathing bodies actively modulating space, displacing light and leaving traces of faded shadows on its path; no longer an empty container passively absorbing its living environment but interacting with it, transforming it and creating its own movements. Architecture as mobiüs skin mediating interior and exterior: its own, its inhabitants', and the landscape's. The following passage from Fraleigh (1987) reveals another insightful view of building as lived experience:

We live [space] wholly, as embodied space. The arch of the dancer's back imparts a totally different feeling than an arch of steel, plastic or concrete. The arch of a dancer's back is formed of our own body-of-space. We feel the lifting and arching through our own embodiment - through which, in our lifted, back-arched leaning we also feel the upward soaring and backward leaning arch of steel. Our body-of-space is the origin for our perception and understanding of space in general. (181)

Gehry's gestural sketches of towers seem to embody the vibratile intensities that both Lepecki evokes in his conception of stillness, and that I experienced in the stillness of the dancing Twins. In order to enter the space of his drawings, I believe one must approach them as the incarnation (or the transposition) of the architect's dancing/drawing body into the dancing body of architecture. The reversibility of inner/outer space of which Lepecki speaks, and which is experienced in the introspective and proprioceptive immersion into the site of the projects, is what infuses the body of space of the architect with textures. This body of space is then inscribed, as corporeal residue, into the drawings of the potential space of the body of architecture. This infolding and unfolding of the body implies an opening onto the world as well as an excavation of the depths of imaginary and mnemonic worlds: worlds cast in a web of internal, visceral intensities in continual flux and channelled through kinesthetic impulses. Line in other words, is the trace of a chiasmic crossing, mediating the interval that activates relations between internal and external forces. To address Gehry's sketches, therefore, requires an attunement to the felt vitality of forces at play behind and beyond the purely visual. Gehry's lines are traces that need to be reawakened as qualitative conducting vectors of internal/external drives that generate and respond to these forces. As Lepecki points out, Merleau-Ponty (1968) emphasizes this intertwining of the visible and the invisible: 
Meaning is invisible, but the invisible is not the contrary of the visible: the visible itself has an invisible inner framework (membrure), and the in-visible is the secret counterpart of the visible, it appears only within it, it is the Nichturpräsentierbar which is presented to me as such within the world - one cannot see it there and every effort to see it there makes it disappear, but it is in the line of the visible, it is its virtual focus, it is inscribed within it. (215)

Gehry's sketches of the tower project, as of any other, cannot, in my opinion, be comprehensively seized in isolation. His multiple drawings constitute a sort of choreography in the making that seems to densify with each repetition (drawing) and culminate in an archive of its own process. It is by examining a series of sketches in juxtaposition that we begin to get a sense of the inner and outer forces and intensities at work in his modulation of time-space. By layering the multiplicity of elusive force fields developed over time, from drawing to drawing, we start to grasp the possibilities of flows, tensions, and concentrations of energy that comprise the essence, and more importantly the permeability and malleability of a skin in continual flux and reminiscent of the affective skin of Gil and Lepecki's (2006) space of the body:

Skin attracts them [affects] and impregnates them...Skin itself is in mutation, it changes nature, it wrinkles, it dilates - it searches for ways to become a new map for new intensities. It allows exterior and interior to penetrate it. It becomes an extremely porous interface, diaphanous, allowing all sorts of exchanges, confusing inside and outside. Skin no longer delimits the body-proper, but extends beyond it across exterior space: it is the space of the body. (33)

Gehry's line appears as trace or extension of nerve fibres embedded within morphing skins and conducting forces as they sound the possibilities of intensified spatiotemporal relations. Three inseparable phrasings seem to emerge from the gestural dance of his sketching hand, of which his towers are born (figs. 1-3). The first phrasing corresponds to the base of the building, the second to its body, and the third to its pinnacle. All seem to spring from the first: the footing of his sketches, which perhaps best taps into the vitality of the architect's experience of New York as lived place. The staggering, jagged lines that coalesce at the base of the building seem to deflect off the ubiquitous undercurrents of city life somewhat like seismographic cords that resonate between moving bodies and vibratile stillness (fig. 1). The polyrhythmic movement brought about by confrontational impulses that at once challenge and echo the city's urban spatial tempo seems to generate the tensile force 
sustaining the line's impetus. The implosion of lines in this spatial node reinforces the porous nature of its in-visible membrane that in turn reveals a multiplicity of potential connections, ruptures, and points of entry. It is also this volatile center that at once galvanizes and transfers the perpetual flux of potential force fields into the body of the building. The rhizomic nature of this footing sets both a movement into the depths of the body as well as on its surface; it enables ruptures to sprout in new directions, in new lines of flight or bifurcations, and to open onto other flows and rhythmic continuities elsewhere in the body of the towers.

I stand feet grounded to the floor, my weight shifting faintly from the ball of my foot to the heel, its arch contracting and dilating as I imagine the rumblings and tremors below me resonating loudly up into my trembling ankles and into my knees, through the tensed fibres of my calves. ${ }^{16}$
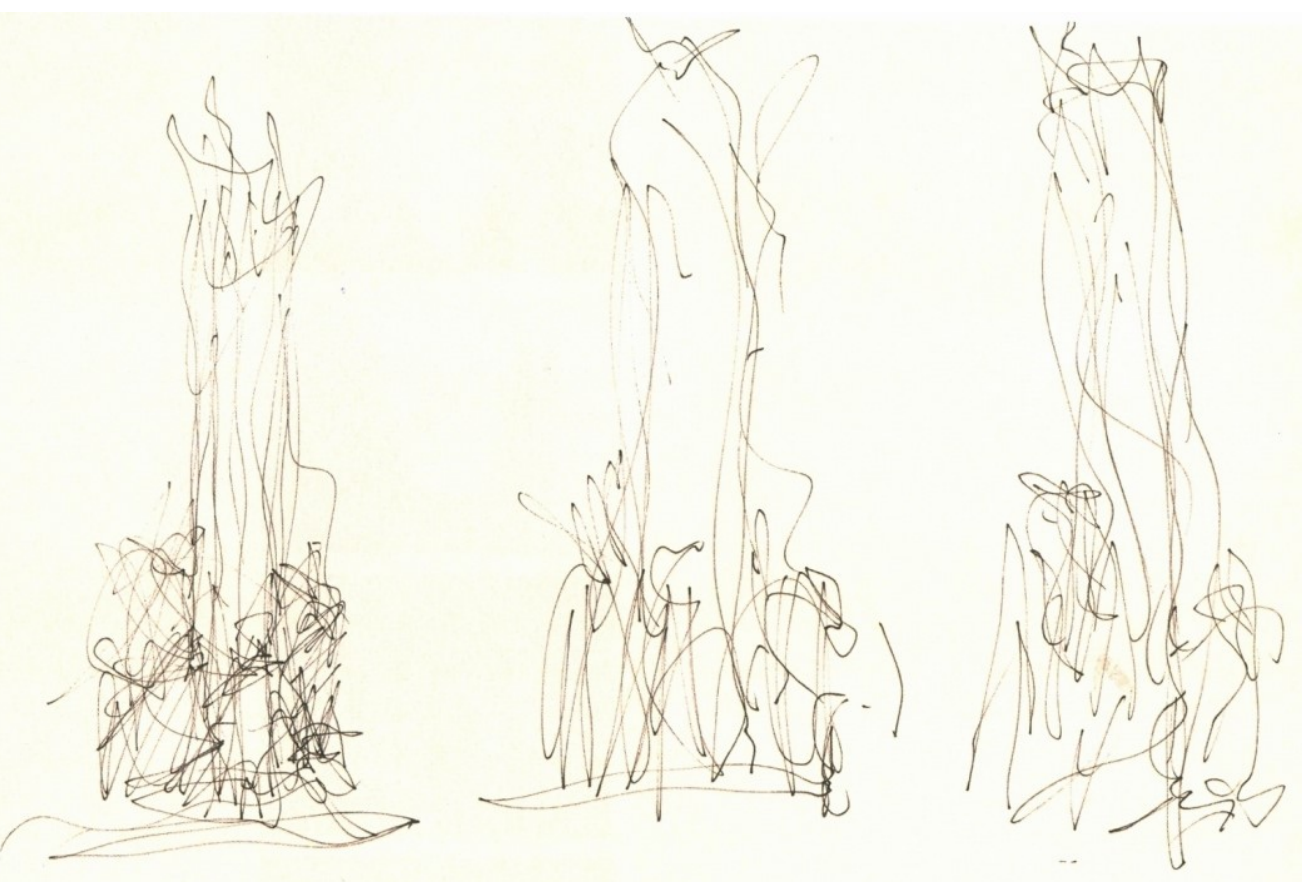

$$
\text { Buen avbi } 2007
$$

Figure 1: Astor Place Hotel (New York, 2001) In Gehry Draws (2004, 459).

\footnotetext{
${ }^{16}$ These insertions correspond to my own experience of standing as a way of relating to the forces at play in the towers.
} 
In the second phrasing, the precariousness of verticality is explored in the midsection of the building. "All movement is a deferred fall", Louppe (2010) contends, "and it is from the manner in which this fall (elsewhere fully embraced) is deferred that gestures are born". (66) Stillness is the vibratile deferral of the impulse to fall and this impulse is what symbolizes the relation of inside to outside. In Gery's sketches, time seems suspended in vertical vertiginous free-falling flows or in elastic tensile filaments that respond to in-visible forces of deferral: a bending, twisting, or vibrating lattice reverberating between breathing body and breathing landscapes, invoking and mediating potential permeable architectural membranes; landscapes in which whirling vortexes and the rugged edges of invisible tectonic matrices shape the internalexternal relation of space.

I stand swaying effortlessly to-and-fro my center of gravity in barely perceptible micro-movements, bones and vertebrae gently swivelling in each other's hollows as they compose their equilibrium.

Figure 2: Astor Place Hotel In Gehry Draws (2004, 461).

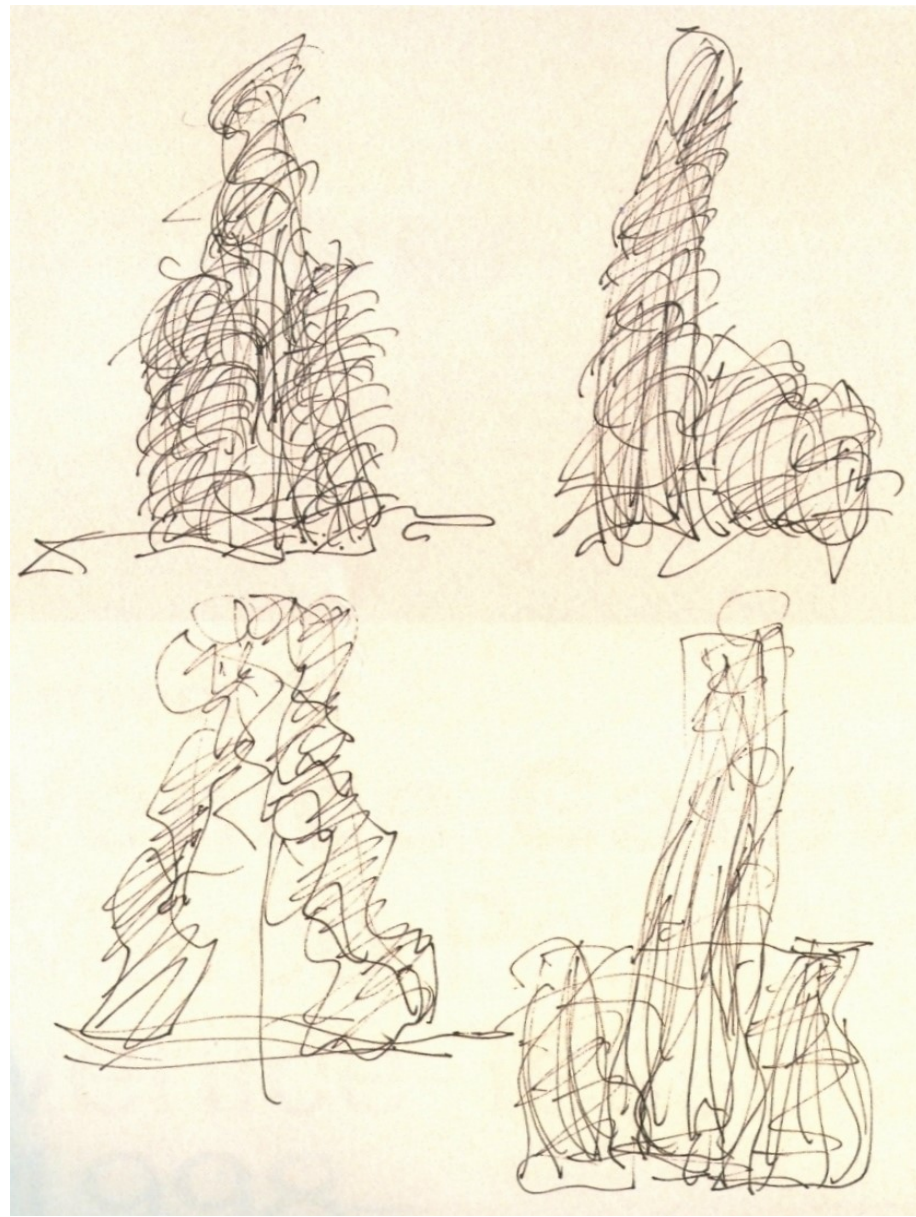


In the third phrasing, at the vertex of the building or the limit of its vertical extensity, forces both culminate and dissipate in what could be one of the many crescendos or nerve endings of New York City, blurring time and interrupting space. As they emerge from the depth of materiality/corporeality: dissolving energy, propelling it into virtuality, absorbing or weighing it back down through oscillating or pulsating inner-channels, the lines seem to extinguish, hover, or withdraw; loosing their impetus and purposiveness. Extending their ascending thrust into aerial landscapes, the lines seem to fade into ethereal mists leaving behind a residue of indeterminacy.

Still standing, skull precariously balanced on the tip of my spine, vacillating ambivalently between incipient thought and feeling.

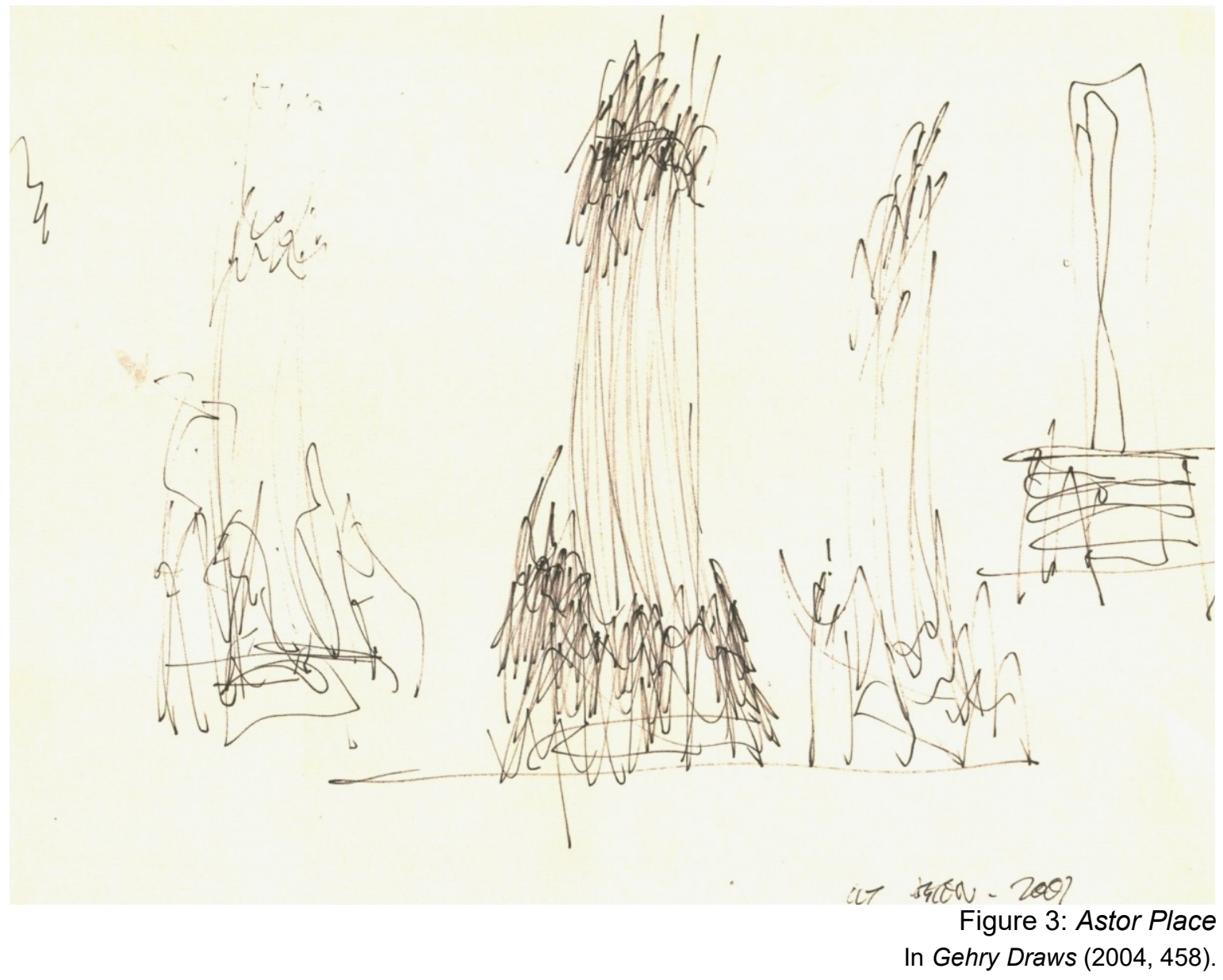


As I turn to other sketches, I discover yet other tempos, flows, modulations and intensities that transform the vitality of the drawings and the potential spatio-temporal engagement they unveil for architecture: the potential they have for vibrating with the music of the world.

Each drawing abounds in, liberates an ensemble of correspondences, a network of equivalences, triggering exchanges between the inanimate and the living, the near and the far, the miniscule and the immense. (Luc Richir, "Drawing")

Gehry's tower drawings are sensations of the intensity of stillness, of the metamorphosis of the interval into an apparition of depth and vitality, at the infra-thin point of vibratile equilibrium.

Gesture is the meeting of at least two confronting movements - those of the body and the aerial - producing, at the point of their equilibrium, a zone of arrest, of immobility, of syncopation. A sort of silence of gesture. (Didi-Huberman 2006, 114, my translation)

\section{4}

\section{Mobiüs Skins}

The Walt Disney Concert Hall

In dance and architecture - both bearing on weight - spatial apprehension begins with our most elementary relation to the ground. "The supporting-ground is an interface between the force of gravity and the experience of the body". (Louppe 2010, 137) In drawing, the paper or support also takes on the role of ground as interface between the hand's muscular-sensory tonicity and the feeling, minded-body. Our standing body's vertical axis locates us between sky and earth as a signpost for our orientation in space. "In these ascending-descending spaces an image forms in contemporary choreographic imaginary which is that of flight". (140) Our desire to fly, to free ourselves of the burden of weight and to experience the sensation of weightlessness propels us to move: to gallop, to bounce, to soar and to dance. Vibratile impulses burst into gestural surges. This inclination to dance is ubiquitous in Gehry's drawings and projects. The sketches I will examine next are those of the Walt Disney Concert Hall in Los Angeles (fig. 4-6).

In a survey of Gehry's drawing practice Bredekamp's (2004) interprets his sketches from a dynamic perspective which, albeit not entirely convincingly, sets the serpentine line as 
the premise of his analysis. He traces the use of this line in drawing, back to Leon Battista Alberti and through to Albrecht Dürer, William Hogarth and others right up to Paul Klee establishing its changing significance. But perhaps more relevant is Merleau-Ponty's (1964) commentary on da Vinci's insight into the serpentine line as he expounded in his Treatise on Painting. The artist states:

the secret of the art of drawing is to discover in each object the particular way in which a certain flexuous line, which is, so to speak, its generating axis, is directed through its whole extent. (72)

This lead to the realization that there are no visible lines in objects or figures, as MerleauPonty suggests: "[The lines] are always between or behind whatever we fix our eyes upon: they are indicated, implicated, and even very imperiously demanded by the things, but they themselves are not things".

From Klee onward it was then a 'matter of freeing the line, of revivifying its constituting power' (or virtual power); as Klee put it himself: " The line no longer imitates the visible: it renders visible; it is the blueprint of a genesis of things". (74) The relation of the 'invisible' serpentine line to formative movement may find its kinetic basis in the theories of movement in dance. Rouquet (1999), in her studies of dance, contends that movement is constituted as the internal spiral organization of the body's force fields. These internal spirals, structured as möbius strips, are present in all the motor apparatus of the body from the workings of the spinal cord down to the smallest molecules of DNA. They function through a dynamics of opposing forces always in an act of rebalancing that constitutes movement. It is through these structures that energy is absorbed and released, that volumes expand and retract and that fluids circulate. They enable flexion and extension in movements of torsion and rotation; expiration and inspiration in breathing rhythms; they constitute a space of passage between oppositions and the flow of relations between polarities. The spiral is also evoked by many dancers and choreographers as the primary spatio-temporal structure of all movement: it is inherent in Laban's ${ }^{17}$ icosahedron, a structure that encompasses all possible movements; in Ninjinski's choreographies that make of the universe a moving spiral in incessant organic

\footnotetext{
${ }^{17}$ A dance artist and theorist, Laban proposed theories of movement in the early twenties that remain influential in contemporary dance and movement analysis.
} 
metamorphoses. (Louppe, 1991, 103) Gil and Lepecki (2006) take up the concept of the möbius strip to refer to the reversibility of the interior on the exterior of the dancing body:

The body becomes a kind of...Mobiüs strip that forms itself as it absorbs interior affectforces and makes them circulate at the surface...That the dancer, through movement, transforms his body into a Mobiüs surface results from the very constitution of the body: covered by a single skin, it simulates on its back a quasi-obverse of the front - an opposition that rotation immediately annihilates, thus forging a single "frontal" surface, so to speak. (34)

Gehry's sinuous lines are perhaps not all mobiüs strips per se but they are made of the same stuff: they allow the flow of impulses to pass from back to front, from interior to exterior, absorbing interior affect-forces as they circulate through the line. In describing the movement of a dancer Louppe goes to the heart of what one perceives while examining Gehry's sketch (fig. 4) of the concert hall:

movement, weighted and fluidly curving, travels sequentially in her body from one place to another. It is this that gives her dance the billowing, self-generating quality, and its fluid, swinging, quasi-nonchalant aspect. The furling and unfurling is not impeded by a will to shape it...the impact of the flow of weight produces slight syncopations set in train by vast anacruses. Oceanic music of a broad, indolent, billowing body. (144)

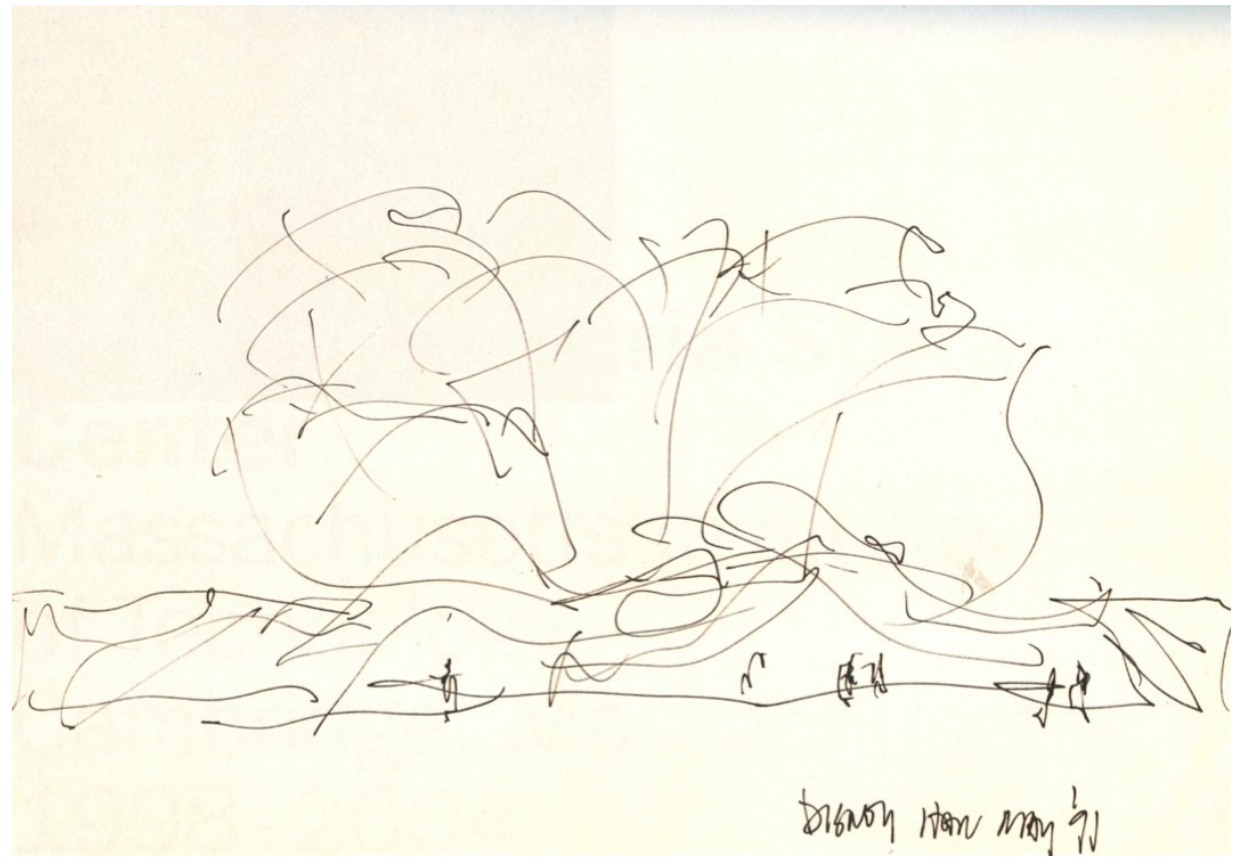

Figure 4: Walt Disney Concert Hall (Los Angeles / 1987-2003)

In Gehry Draws (2004, 339). 
What appears in this sketch to be an exploration of the sensation of grounding in a rolling, swaying movement of the drawing hand, drifts or springs upward into a body of nebular mass through multiple shifting centers of movement: a perpetually wandering and metamorphosing body of energy, circulating from inside to outside and forming its own vital spatiality. We sense in these flowing lines the extension of a dancing body within, or perhaps it is itself a body of skin (embodied in Gehry's resounding gestures) mediating the forces of the body and those of the landscape. Either way, it is a space of body. Yet again, when one examines other sketches (fig. 5), the affect-forces change entirely, other intensities emerge from the changing tempos and fluxes; Gehry sounds the spectrum of his inner impulses and vitality charges in the virtual spaces of multiple drawings.

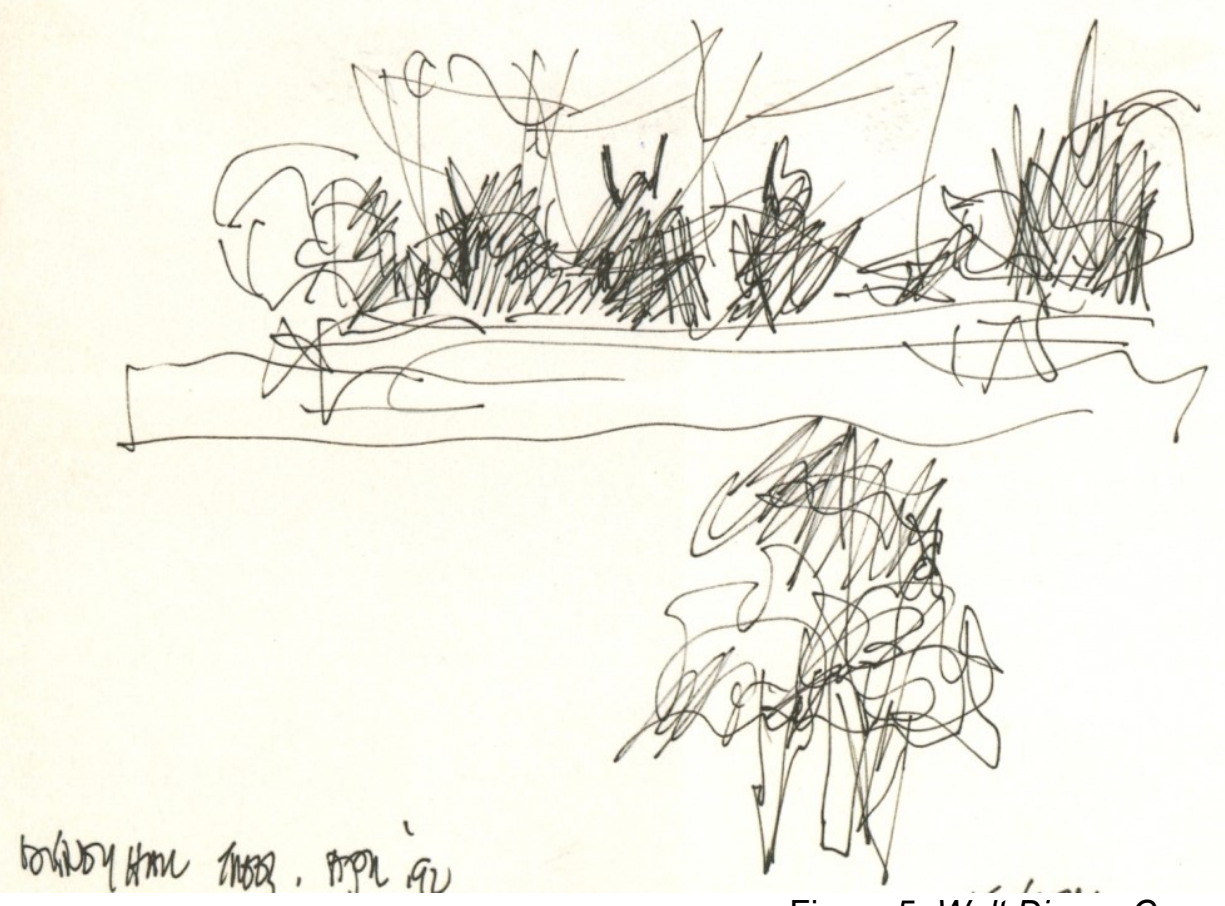

Figure 5: Walt Disney Concert Hall In Gehry Draws (2004, 335).

This thesis, as has been well established, is not concerned with the direct formal relation of drawing to building; nor do I have access to sufficient drawn documentation to attempt such an endeavour. Sketches of interiors are much more difficult to come by and to 
situate relative to the process of the architect. However I would like to bring attention to a sketch of the interior of the concert hall, with its orchestra pit and what appears to be an elevation of the organ (fig. 6). Juxtaposed into the first drawing of the 'external' space-of-body of architecture (fig. 4), we sense how this resonating formless core could infuse the skin of the building with its tempos, rhythms and flows, and generate the vitality of the drawing. Gehry is not attempting to form a material enclosure or container but rather to engender the texture of intensified space through the possibilities of felt reverberations that perpetually activate the space and echo within us. We feel within the thickness of our own hollows the vibratile energy of his gestures as motions of affect. From Lepecki's (2006) perspective, we might speak of a body-without-organs (BWO) ${ }^{18}$ : not the

habitual body (the body-organism) formed by organs that impede free circulation of energy...[in which] energy is invested and fixated on the organism's system of organs... [but] another body where intensities may be taken to their highest degrees. (31)

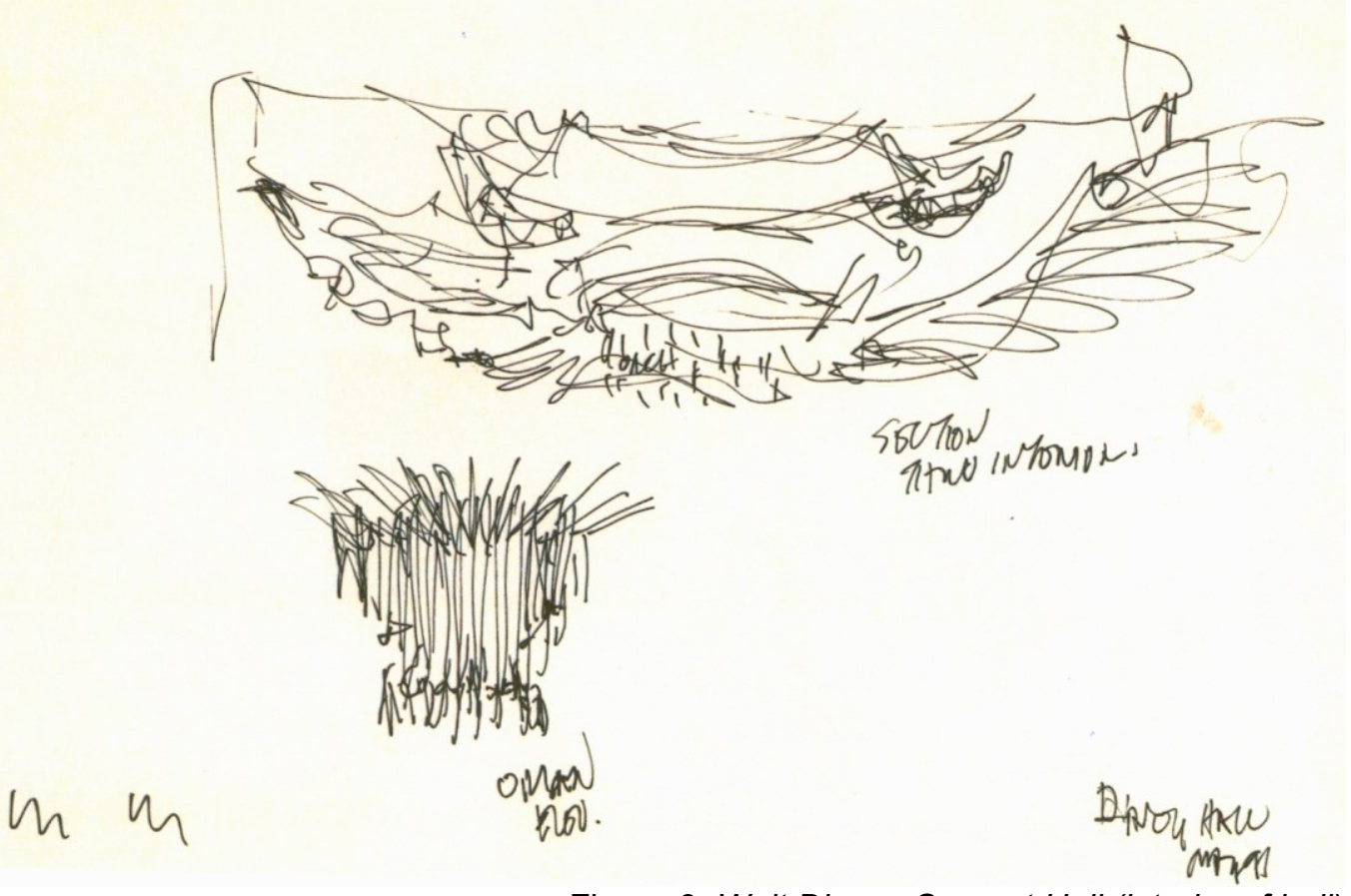

Figure 6: Walt Disney Concert Hall (interior of hall) In Gehry Draws (2004, 333).

${ }^{18}$ Lepecki, of course, borrows the concept of BWO from Deleuze \& Guattari. 


\section{5}

\section{Living Architecture}

The Choreography of Noémie Lachance

The final project I will present in this chapter is Gehry's Fischer Center for the Performing Arts in New York. But I will examine this project from a different angle, reflecting on his drawings through Noémie Lafrance's site-specific choreography Rapture, on the rooftops of Gehry's building (fig. 7). Dancers perform the aerial choreography suspended from cables that are in turn controlled through the synchronous performance of concealed riggers. The event is a very compelling incarnation of Lepecki's concept of reversibility of the skin of interior-exterior space. What is initially perceived as the exterior membrane of the body of architecture (i.e. its roof), suddenly transforms into interiority as it metamorphoses into a topographic membrane that takes on the simultaneous and changing role of wall, ceiling and floor. The dancers indulge in a duet with architecture. Performers (riggers) working from inside the membrane affect and respond to those who circulate on its the outer surface, bringing the inner-surface to life. Gehry's rooftops also mediate the interval in which the dancers move by re-sounding the fluid rolling landscape, which they echo. The spatial interval being played between dancers, architecture and landscape, is intensified by the intertwining of their respective virtual powers. Architecture at last participates in the dance with a heightened vitality that shatters our all too engrained corporeal habits, by reviving our sense of gravity, our kinetic potential, and our sensorial thresholds! Flesh of the body and flesh of architecture enter into a paradoxical relationship, at once defying and reflecting each other as they merge into a single body of space. This movement of space fluctuating with the reciprocal forces of push and pull of bodies seems to embody the generating drive of Gehry's drawings. When one observes the performers dancing across the rooftops, traces of Gehry's sketching hand, sounding the flows and rhythms of his improvised gestures are immediately evoked. Traces of the dancing bodies are deferred to traces of drawings, which defer back to the internal movements of the architect's dynamic, vital flows. 

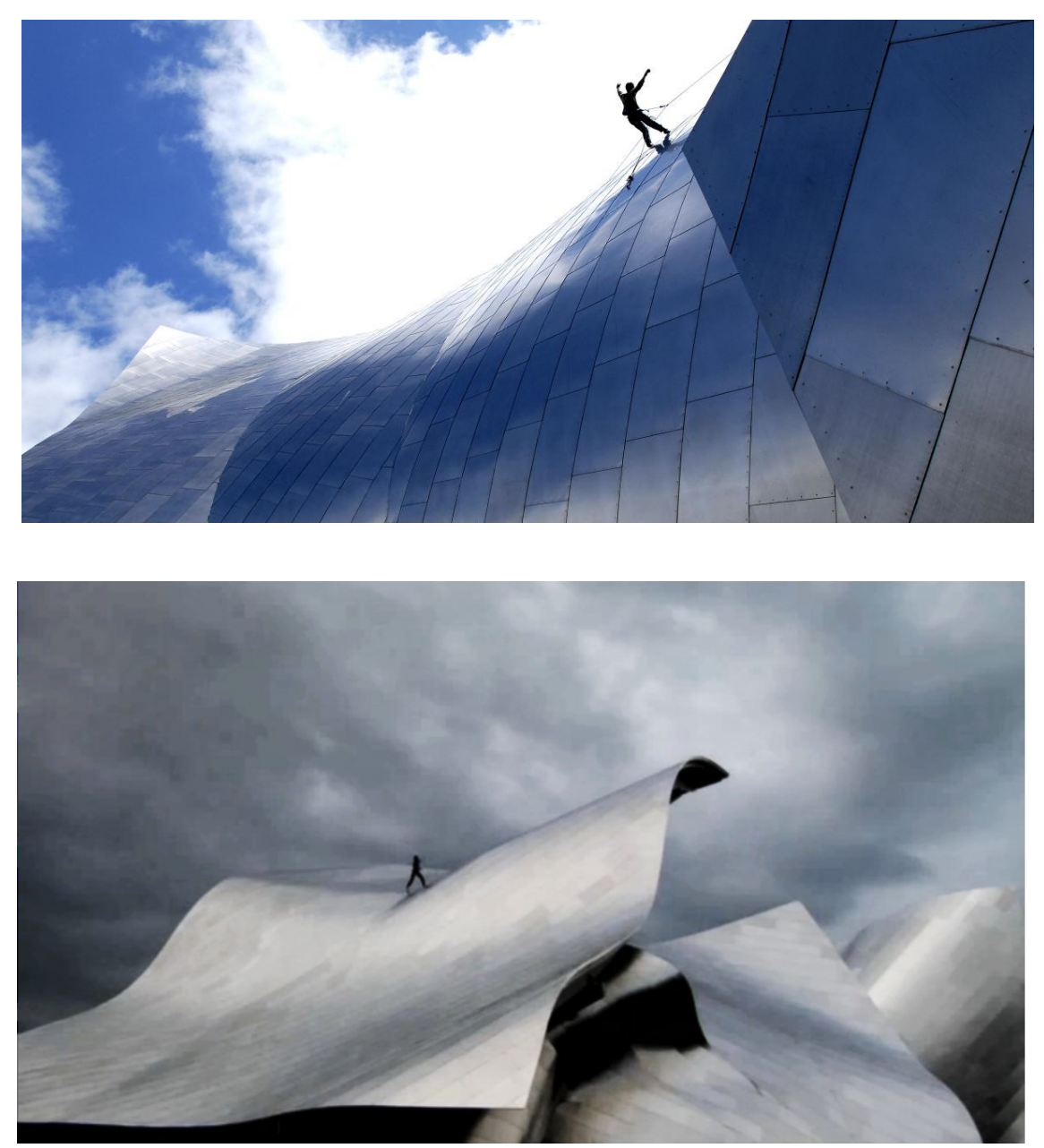

Figure 7: Rapture by Noémie Lafrance (2008) http://sensproduction.org/rapture

The perceptual experience of the performance and by extension, of Gehry's sketches is corroborated by Lafrance's (2008) own experiential account. The traces of the dancers she explains, "resonate the very unique textures and musicality of the architecture and reflect it in movement. Revealing the unique sensation that these buildings transpire." (2) The building not only embodies the state of transformation, she claims, but fulfills the dream of every dancer to experience the sensation of flight: "Suspended between two states, two places or two moments, the dancer's movements are transcending the architecture's inherent motion." (3) Lafrance's performance seems to respond to Grosz' call for a reinvestment in temporality and corporeality in architecture. Architecture realizes the virtual double (and the multiplicity inherent to doubles) of the dancer; by contemplating itself from the place of the other it becomes the other's dancing energy. The choreographer turns architecture inside out for a moment if only to rattle our preconceptions and actualize a potential for imagining and dreaming other flows of living, and possibilities of inhabiting. 


\section{6}

\section{Conclusion}

In this chapter I began by sketching out the nature of the phenomenological body and the way it lives space extensively and intensively. Dance's very subsistence not only depends on the actualization of embodiment through movement but also thrives on exploring its infinite potentiality. A phenomenological awareness is also fundamental to a heightened sensitivity to architecture. Having examined poststructuralist views of space through dance theories, we realise that vitality emerges from the activation of space as a result of the felt virtual extensity of bodily movement. Architecture can directly contribute to this dynamic vitality by participating in a duet with the body: by instilling dynamic relations that open onto living flows and heterogeneous, indeterminate possibilities of inhabiting time-space: a space that makes things happen, as we have seen in Lafrance's performance with architecture. Stillness is not synonymous with immobility or fixity and is no pretext for lifeless inhabitation. Gehry demonstrates how drawing can explore dynamic forms of vitality in architecture by inscribing his kinetic bodily logos into the drawing process. Drawing therein emerges as the prehension of architecture's coming into being. 


\section{Chapter TWO \\ Drawing as Notation}

This chapter examines Frank Gehry's sketches from the perspective of notation, as a manner of interface between the body and the projected space of architecture. Based on a text of Jean-Luc Nancy, it looks first at sketching as an interminable formative act that exposes infinite potentialities and that operates beyond the confines of intention. It then surveys the concept of trace developed by Derrida and translated into dance theory by Lepecki. Trace is introduced as the motion of appearance-disappearance that embodies the ephemerality of movement and the dissolution of the body in dance. The chapter then shifts to theories of Gilles Deleuze as advanced in his analysis of Francis Bacon's paintings. His concept of diagram addresses sketching as an operative force at work in the act of creation, which I will argue, also sustains Gehry's process of conception. Laurence Louppe's historical exposé of the practice of notation will be presented as an analogous spectrum from which I will draw parallels with various conventions of drawing in architecture and elicit how the theories designated above contribute to our understanding of sketching as notation.

\section{1}

\section{Formative Form}

Nancy on Drawing

Reflecting on his practice, Gehry states:

Architecture is so cluttered with problems of function, things that the painter confronting the white canvas doesn't have to deal with, that architects hide behind a lot of these things and develop rationales based upon functional issues... all these things are very important; I don't intend to demean them. But how do we go further? (Bredekamp 2004, 48, my italics)

Pushing the limits of architecture beyond its formal intentions and purposes, sketching concerns a single process:

That of rendering an event (circonstance) of the world (a volume, a displacement, a weight, a mixture, an inflection, etc.) to its pure, originary possibility, to an uprising (surgissement) that owes nothing more to any use or perception than its coming, its sudden arising (survenue), which does nothing but make further demands on itself. (Nancy 2013, 94) 
Sketching is a mode of drawing and investigation that anticipates the materialization of the architectural project. It is a manner of working through and beyond predetermined intentionalities often blinded by the desire for completeness and formal definition at the expense of heuristic processes that seek intuitive exploration, spontaneity and discovery of the infinite potential entries and relations hidden at the heart of any lived experience and design situation. Drawing, as addressed throughout this thesis, is not about the making of form but rather about the coming into appearance, the becoming of form: what Nancy (2013) calls the formative form:

The thought of a non-conforming and unverifiable form, the thought of form forming itself ...the element, moment, or dimension not of formalized but formative, ostensive, and dynamic thought across all artistic fields. (12)

The essence of drawing consists here entirely in the manner or mode of the gesture: the force of its movement, the weight and tonicity of its line. In developing Kant's concept of purposiveness without purpose Nancy insists that this gesture must not be governed by causes, anterior intentions, purpose or assigned ends in themselves. Purposiveness, according to him is the interminable pursuit of extension and expansion rather than intention. (91) Line, says Nancy:

is not a poor resource for designating as its origin this point of contact between thought and a gesture, between a sensibility and an activity, this indivisible and mobile point where a form and with it a manner are born - all the maneuverability and joint manipulations of what is put into action, in other words, bringing into appearance what is not hidden or given but invents itself in its gesture. (101)

It is here, in the feeling or sensing of gesture, in the gesture as formative form/space, that drawing finds its common grounds with dance. Dance by nature always formative, always being of the coming into appearance and disappearance of form, seems a kindred ally for shedding light onto the formative nature of Gehry's sketching. And it is precisely this alliance in drawing-as-dance (in its perpetual incompleteness and potentiality) that enables it to explore, in an embodied manner, the generative forces or virtual power at play in the process of conception in architecture. 


\section{2}

\section{Inscribing Dance}

\section{Derrida's Trace}

Drawing-as-dance is at once gesture and trace; both partake in the ephemeral nature of movement. In Inscribing Dance, Lepecki (2004) examines the relation of dance to writing or of body to text and the space that either connects or separates them throughout the history of dance notation. At the center of the dilemma was precisely the problem of the ephemerality of dance where the passing of movement implies its very disappearance and the constant dissolution of the body. Notation first appeared as a way of preserving, transmitting, producing or re-presenting movement and materializing the absent presence of the body. This form of writing brought to light the very problems of dance's inscription. The various codes enabled a process of creation of dance devoid of the presence of the body. The body could be injected into the dance post factum as a machine for execution. But more importantly, it brought forth the impossibility of arresting dance's ungraspable excess; it shaped an understanding of dance as ephemeral in which disappearance constitutes its very presence. Dance could be perceived "as the fleeting trace of an always irretrievable, never fully translatable motion: neither into notation, nor into writing". (127) This problematic lack provoked new attitudes and ways of reformulating the relationship between dance and writing.

Of particular interest in the context of this thesis is the concept of trace and its elusive dynamics first developed by Derrida. Derrida's focus lies in liberating philosophy from the burden of (making visible) presence or subject. In order to achieve this he introduces the notion of trace as an act of disappearance, self-erasure and, hence, of erasure of one's own presence. Trace becomes synonymous with 'ephemerality-as-disappearance', it is the absence of presence; it implies the lack or absence that is the condition of thought and experience in that every experience contains a motion toward what is not the experience. Consequently, "trace emerges as that which allows the possibility of writing along (as opposed to "against") ephemerality". (132) This new outlook enabled dance to free itself from the requirement of arresting visibility that had always haunted the discipline, or of understanding dance in terms of the visual alone. "Derrida's notion of writing as difference offered dance studies a set of signs as elusive as those dance steps to which they referred. Both writing and dance plunged into ephemerality". (133) The play of différence ${ }^{19}$ sets in motion an endless

\footnotetext{
${ }^{19}$ Derrida coined this neographism to refer to the always fleeting deferral of the signifying movement of the trace. (134)
} 
referral of all 'signs' to others: of traces to traces of traces, or of presence to presence of absences. For Derrida, "movement is the motion of deferment, the tracing of the trace, the writing under erasure, the slipping of the tracing". (138) Tracing as the motion of deferral, partakes in the movement of both dance and writing, of that which has already disappeared at the moment it appears. This notion of trace as différance opened up a whole realm of possibilities in writing, beyond dance's spatio-temporal mobility, to spaces of the symbolically charged imaginary. But others later pointed out the limits of Derrida's concept and his insistence on eliminating the subject—-these authors argued for the importance of embodiment and of the historical materiality of the dancing body, thereby reviving the notion of presence. They claimed that the very condition of dance's embodiment puts the dancer's historically subjectified, cultured and gendered body at play in the trace. ${ }^{20}$ Presence returned "with the mark of history on the edge of its own withdrawal...such history inscribed itself on the body, thus making dance and writing one". Dance's presence became multiple, pointing "toward yet unthinkable ontological coimpossibilities of pastness, presentness, and futurity". (136) Dance and writing, body and text were then reunited in a rich complicity and ongoing dialogue.

The codependence of dance and writing embodied in the concept of trace might at the very least inform that of gesture and sketching, of body and line. Most conventional architectural drawings (orthogonal and perspectival representations) tend to take on the role of documentation: insisting on the centrality of presence for the sake of history (and more often devoid of the body), or of traditional scripting: encoding information and instructions for execution. Sketches, although more explorative, generally stem from this tradition of seeing and depicting that, consequently, predetermines the nature of the relatively fixed process of conception. Gehry's sketches (as trace), on the other hand, seem to project the ephemerality of drawing-as-dance into the process of conception by inscribing the vital body directly through the gesture. The body/gesture responds to the forces that condition the coming into being of architecture, with a tracing of the line. The affects and intensities that emerge from the encounter of place and body (both the architect's actual and virtual body immersed in the event of drawing, and the buildings body of space as it forms itself) set the rhythm of drawing as the hand wanders and wonders the world of possibilities. His sketches thus script something altogether different that extends beyond the fixed parameters of building, and therefore become a useful tool for understanding other temporal and qualitative dimensions of architecture.

\footnotetext{
${ }^{20}$ Lepecki's position also calls for an acknowledgment of the transitory and historical conditionality of dance more globally: as a movement sentenced to pastness.
} 


\section{3}

\section{Embodied Drawing}

Trisha Brown and the Venice Gateway Complex

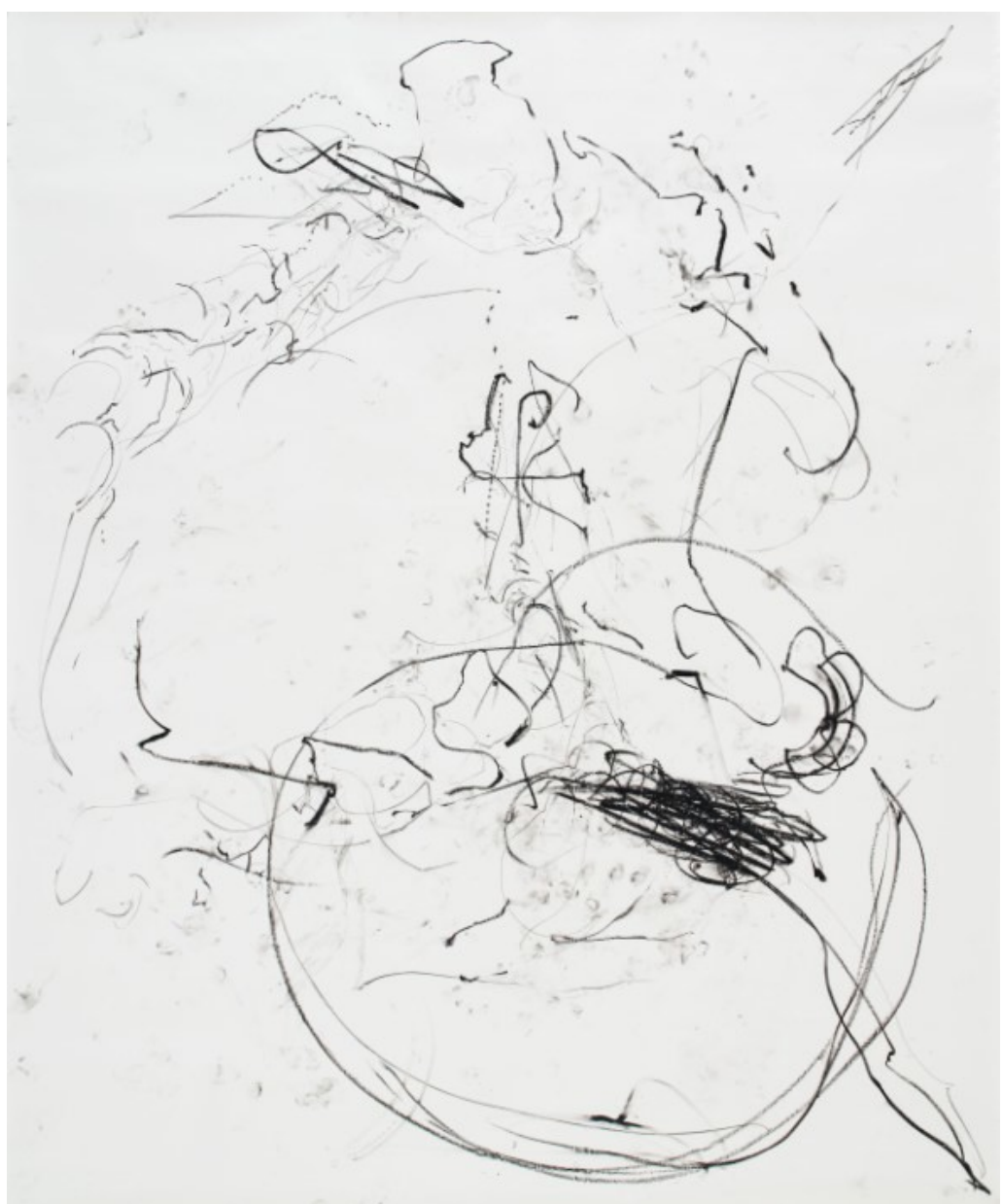

Figure 8: Trisha Brow (It's a Draw / 2008) http://www.trishabrowncompany.org/content/images/image

To exemplify the specificity of this dimension of Gehry's sketching practice, I will begin by diverging to the dance practice of dancer/choreographer Trisha Brown and particularly, to her work entitled It's a Draw (fig. 8). In this series, she explores the relation of dance motion to drawing by embodying movement directly in the trace. Holding pastels and charcoal chalks between her toes and fingers she marks her actions over time on floor and walls of her performance space in a translation of her bodily perceptions and insights. Dancer and drawer become one as actions and their traces emerge simultaneously in a dynamic dialogue between body and line in their relation to space. (Eleey 2008) As Simone Forti has written in 
relation to her own work of the same nature: “...making drawing as a bridge to embodying. The eyes move, the hand moves. The body embodies, the hand moves and the body's embodiment shows in the drawn line". (Louppe 2010, 250) Add to this image not only the hand and the feet that draw, but every other part of the body as it smears, erases, blurs, fades, absorbs, drags, breathes on, and dissolves the pastel powder on the surface of the paper. The skin of the body takes on the role of interface between inner impulses and exterior environment, between ephemeral movement and its residual trace; and trace, the interface between skin of the body and skin of the paper. On drawing as score Louppe (1994) writes:

The leaves of paper... [are] mirrors without a doubt, but also membranes, skins, the interface of porous spaces. The site of the illusory transaction between inside and outside, the metaphor of that final bodily envelope which is the surface of inscription....and which is the only prolongation of the cutaneous and intercutaneous elements determining the conjunctive territories of the imaginary...the ultimate skin where the body reads the limit of its own sensation...(23)

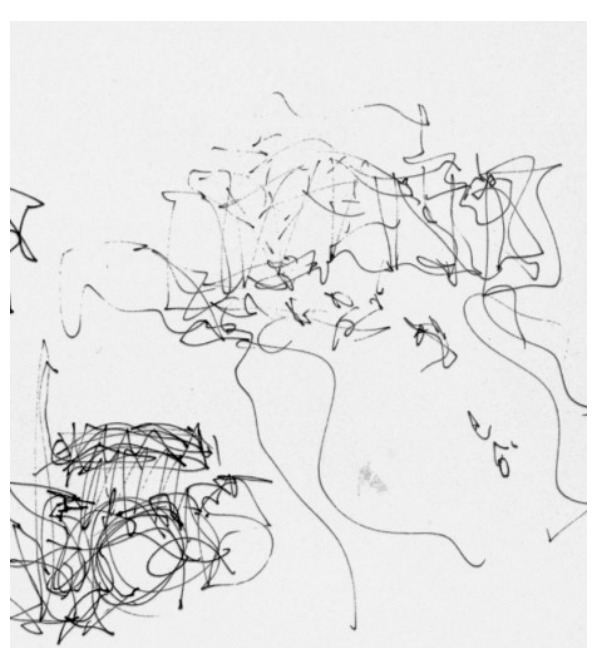

Figure 9: Venice Gateway Complex

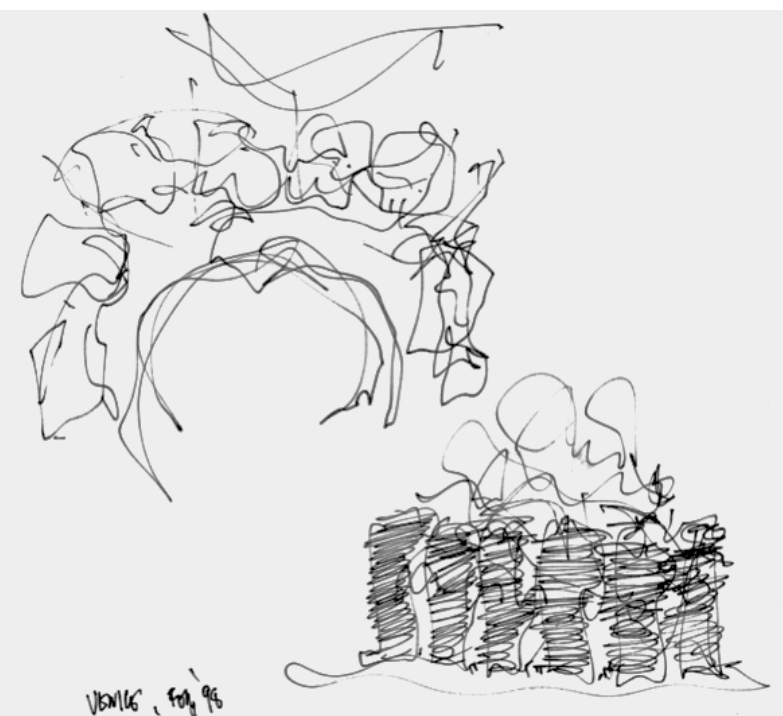

Figure 10: Detail of Venice Gateway Marco Polo Airport, Italy / 1998) In Gehry Draws (2004, 465). 
Unlike Brown's use of charcoal, Gehry draws with an ink medium that leaves little corporeal residue of the weight and tonal nuances of his corporeal gestures on the paper ${ }^{21}$. However if one compares his drawings (figs. 9-10) to those of Brown, constellations of similar kinetic, spatial and visceral sensibilities and energies seem to appear and disappear on the surfaces of the paper, both are enacted through corporeal impulses. That the gestures arise from a mingling of inside and outside is also manifested in these drawings in the way they explore the vital spatiality of circularity. We perceive a dialogue between center and periphery in both Brown's direct exploration of space and Gehry's exploration in plan. Centrifugal forces generated from a distinctive central curving line circumscribing the body, dissolve into a resounding, spasmodic, tortuous, twisted, frayed and broken line on the outer peripheries of the space. We sense in Brown's drawing, the extensity of her body-of-space, that point at which virtual forces begin to diffuse and linger in the viscosity of space, at which the space begins to vibrate with a diversity of textures and sensations. In a similar manner, Gehry's hand coalesces and channels the whole body's felt kinetic energies and logos. As in dance,

The hand, the wrists are...the completion of the breathed central movement, they complete a movement integrated into a whole form. They participate in articulating the movement language (langage gestuel) [of the body]. (Louppe 2010, 73)

This very acute qualitative attunement, lived in its immediacy, is what I believe distinguishes Gehry's practice from that of other architects. And it is from this perspective that I will further examine his drawings as notation: formative act, trace, and corporeal diagram.

I will pursue with an interpretation of another sketch page of the Venice Gateway Complex (fig. 11). Conveying a point of exchange between aerial and nautical transportation services, these sketches retain the dynamic, energetic and incipient force of ostentive formation of a nodal event. Virtual powers seem to mobilize labile waves rolling one onto another, linking center and periphery in a continual reversal of movement. Billowing gestures erupt from deep inner sensations that unfold and enfold onto and into the surface, swelling into a vibrant hub of emergent affects; a flow of osmotic movement recovering the thickness of a felt and visceral imaginary via the murky waters of the Venetian Lagoon. The drawings indulge in feeling, as Nancy (2013) so eloquently evokes,

\footnotetext{
${ }^{21}$ I have unfortunately not succeeded in accessing his drawings directly and must therefore work from reproductions. I would no doubt discover other markings of the body were I to examine the material drawings.
} 
not as a sensory faculty that records information but a sensing (ressentir), in other words, a faculty of making sense, or letting it be formed. The sense formed cannot be exhausted by any sensoriality or sensibility but, on the contrary, exhausts and exceeds them in drawing them to the limit of their potential intensity. (21)

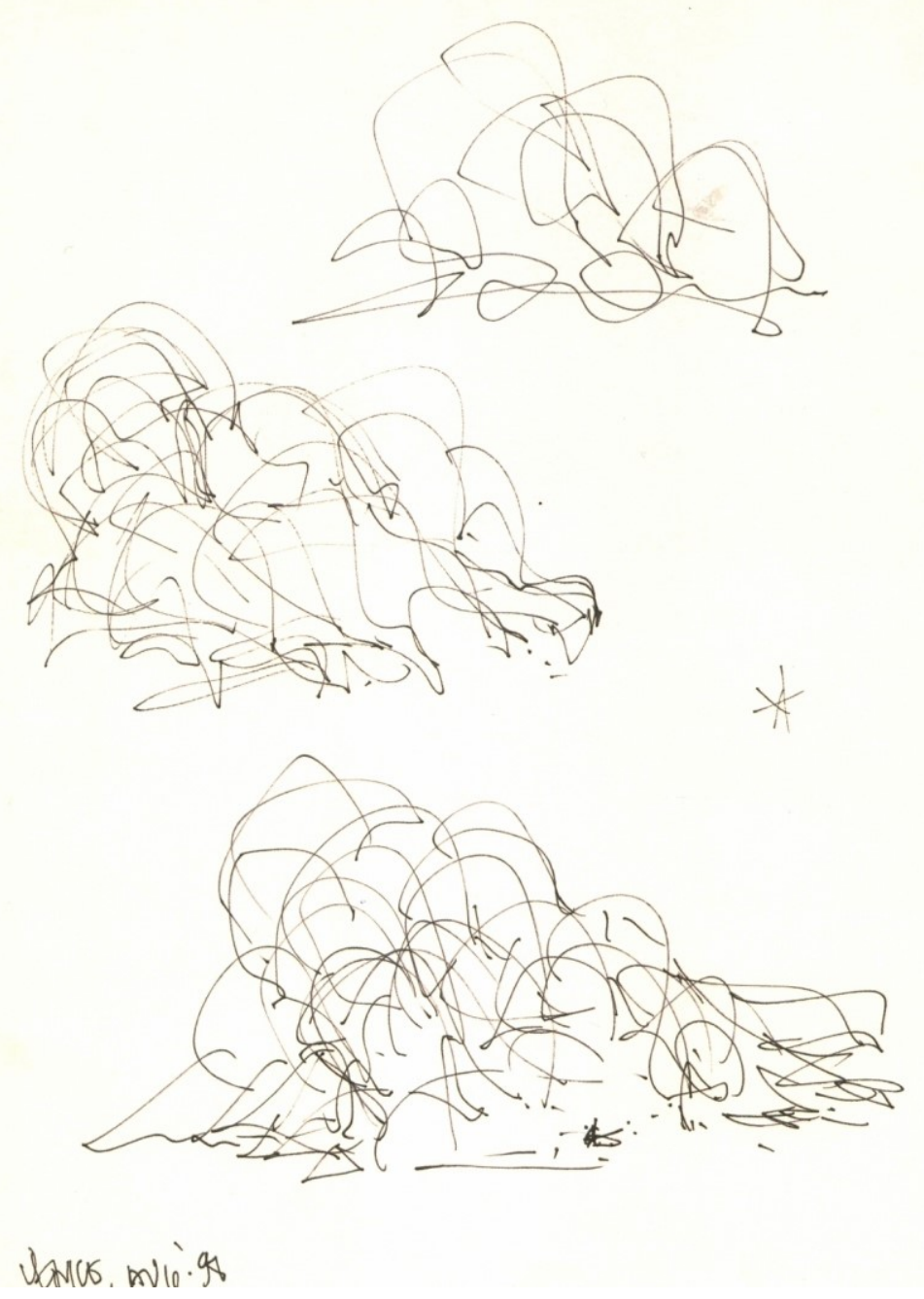

Figure 11: Venice Gateway Complex In Gehry Draws $(2004,468)$.

These drawings embody the infinity of becoming visible, not in the sense of the being that has appeared, since this is finite, but in the logic of that which sustains a potential visibility: the gesture (corporeal and affective); the attunement (with place); the sensations emerging from the tracing of the line. This gesture Nancy contends, is an immanent significance, not as a sign pointing to the signified but as a sense that is 'offered right at the body'; a sensing or a trait of 
sensation that "thrust open that through which all relations and distinctions are opened". (41) Gesture is the differential relation, the movement of deferral, on which everything depends.

Line here rides on the very impetus of gestures that sound the potential virtual forces (and perhaps affordances) at work in the formation of place. Gesture as impulse: a thrust of thought and experience mobilized in the body, gives birth to formative force; 'summoning, discovering, self-forming, informing itself' while opening space up to its own possibilities. The sketches as trace, grasp the ephemerality of a process and of the coming into being of the architectural event exposing a temporal dimension and vitality that will continue to drive and permeate forces of creation. In the very manner of the trace, the lines are the residue of the movement of deferral to other presences and absences, to that which is absent and yet present between and beyond them, pointing to other possibilities and 'coimpossibilities of pastness, presentness and futurity'. They are in a sense, a score or intimate partition of inner rhythms, a topography of intensities and qualitative flows that trigger the spatial imaginary while bringing us back to corporeal modes of attunement.

\section{4}

\section{In-corporeal Diagrams}

\section{The Lewis Residence}

The body in Gehry's sketches is experienced as a movement of sensation. Most architects' drawings enter the body through the brain, but Gehry's act directly onto the nervous system, as sensation. Sensation, writes Deleuze (2002):

has one face turned toward the subject (the nervous system, vital movement, 'instinct', 'temperament' ...), and one face turned toward the object (the 'fact', the place, the event).

I refer to the event (of drawing) here not as a projection of the building's future but rather a projecting towards it, as prehension of its coming into being. The event implies extension, where the figure (the idea of building) becomes the composite of itself and its surroundings, and extension, the passage from one to the other through 'waves and vibrations that are vital to the event'. Sensation is the reaction of excitation or nervous stimulation that one senses in response to these vibrations produced by the qualitative variety of line within the drawing. Sensation offers the viewer an intense experience of the vitality that runs through the drawing/event as well as through their variations as a series. Each drawing is a series: it exists 
as a plurality of constitutive levels within the drawing, as different orders of the same sensation that depend on the vital power that traverses them all and that, for Deleuze, is synonymous with Rhythm. (37) The Rhythm invests the (haptic) visual level through the intrinsic intensities of the series - the gestural line: its shifts in weight, form, tempo, tonicity, duration, directionality, etc. But each drawing also corresponds to different orders within a series. Sensation is therefore synthetic in nature, having a 'sensing or sensed unity'. "I experience sensation only by entering the painting, by reaching the unity of the sensing and the sensed." (31) Deleuze investigates the operative forces at work in and between the levels by asking what constitutes this sensing or sensed unity. In his motor hypothesis it is (sensation as) arrest that synthetically recomposes movement. To illustrate this he gives the example of Duchamp's and Muybridge's decomposition of movement into sequences that we then recompose synthetically into movement. In the case of Gehry's sketches, it is the micro-movements of vibration that coalesce in the juxtaposed and interacting lines, that give the sensation of the forces of movement in formation. He states: "Movement does not explain sensation; on the contrary, it is explained by the elasticity of the sensation, its vis elastica." (36) By movement, he is referring to the motor forces of the spaces that isolate the Figure ${ }^{22}$ in Bacon's paintings. In the case of Gehry, I have referred to the forces at play in the site of his projects, in the preceding chapter. Movement recalls the manner of Lepecki's stillness as a movement inplace, a spasm, which reveals 'the action of invisible forces on the body'. It is the contraction and expansion of the Figure at the point where it merges with the field. We can also speak of movement as the translation between drawings that result from the deformation/transformation of the body or building (i.e. the figure).

Gehry's sketches for the unbuilt Lewis Residence project in Ohio (figs. 12-16) exemplify this experience of sensation. In the abundant series of drawings for this project, the depth and intensity of inquiry, of vital exploration, the sensation of gestural variation, are remarkable and exceptional, as Gehry himself indirectly concedes. In the first of these sketches we sense the inflection of forces of contraction and dilation that act on the body: a systole-diastole rhythm that seems to breathe in the surroundings and exhale a vitalized air that textures the field. The lines that oscillate along the contour ${ }^{23}$ activate and are activated by the spaces they inhabit and that are inhabited through them. Sensation is the vibration that

\footnotetext{
22 "The Figure is the sensible form related to a sensation." (31) I will come back to this below.

${ }^{23}$ I am not referring to contour as a line delimiting form: "A line that delimits nothing still has a contour or outline itself." (89)
} 
results from the dynamic state, the kinetic tension released into the pictorial field/body of the drawings through the lines that trace the architect's sensing.

The concept of diagram as advanced by Deleuze (2002), is foundational to this thesis.

The diagram is the operative set of asignifying and nonrepresentational lines and zones...that mark out possibilities of fact, but do not yet constitute the fact (the pictorial fact)...it is a germ of rhythm in relation to the new order of the painting...that unlocks areas of sensation. (82-83)

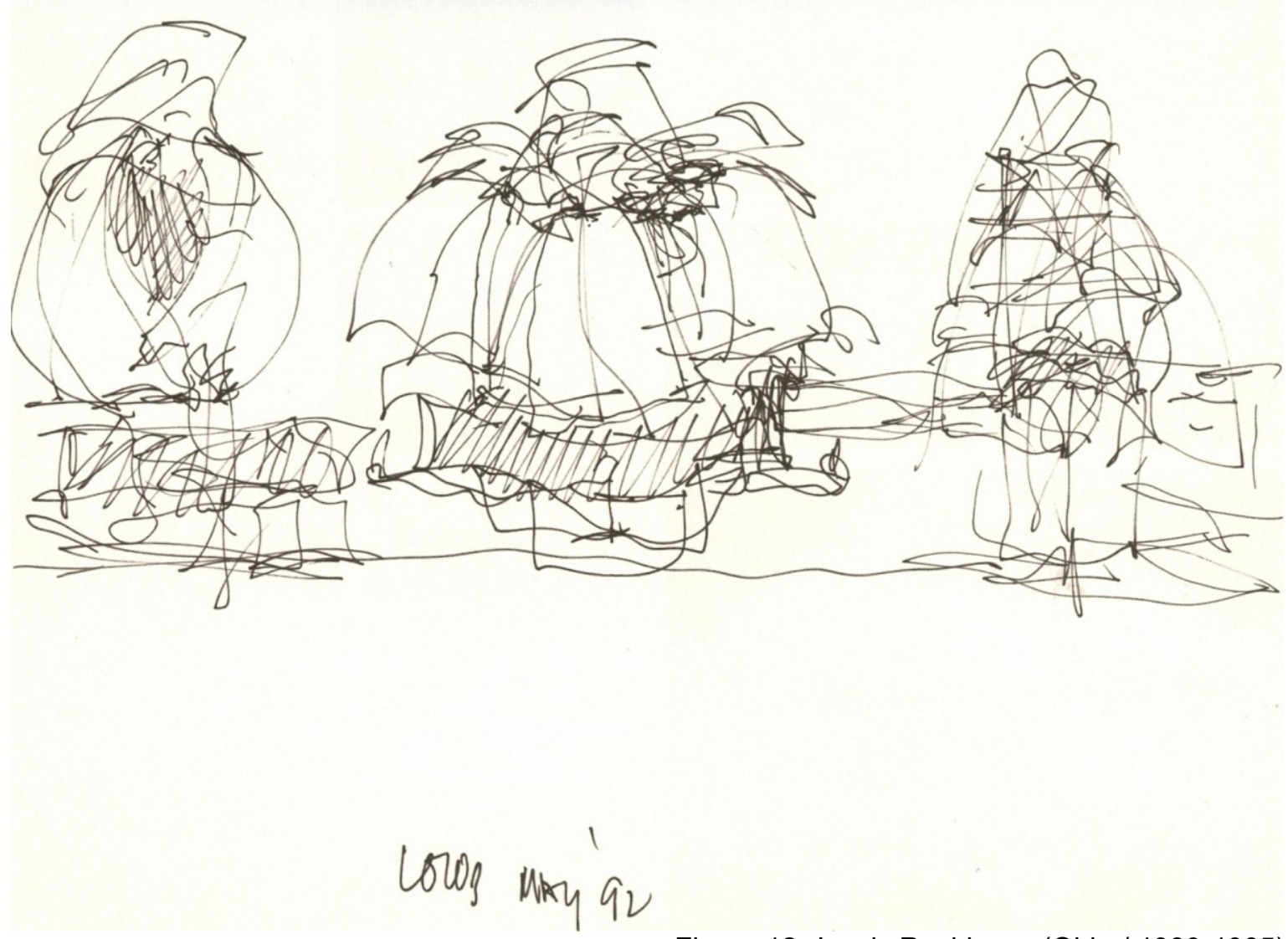

Figure 12: Lewis Residence (Ohio / 1989-1995) In Gehry Draws (2004, 131). 


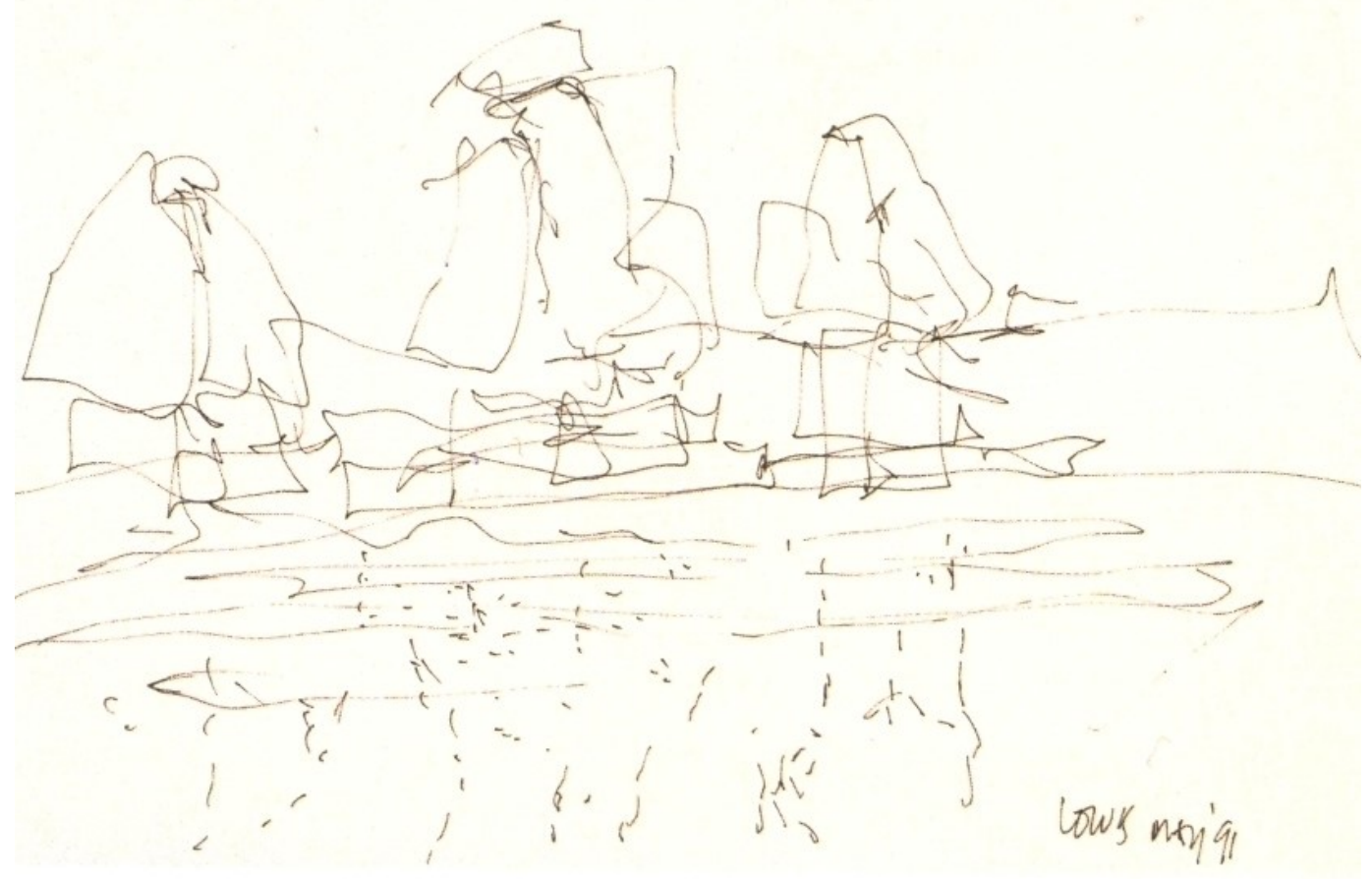

Figure 13: Lewis Residence In Gehry Draws $(2004,112)$.

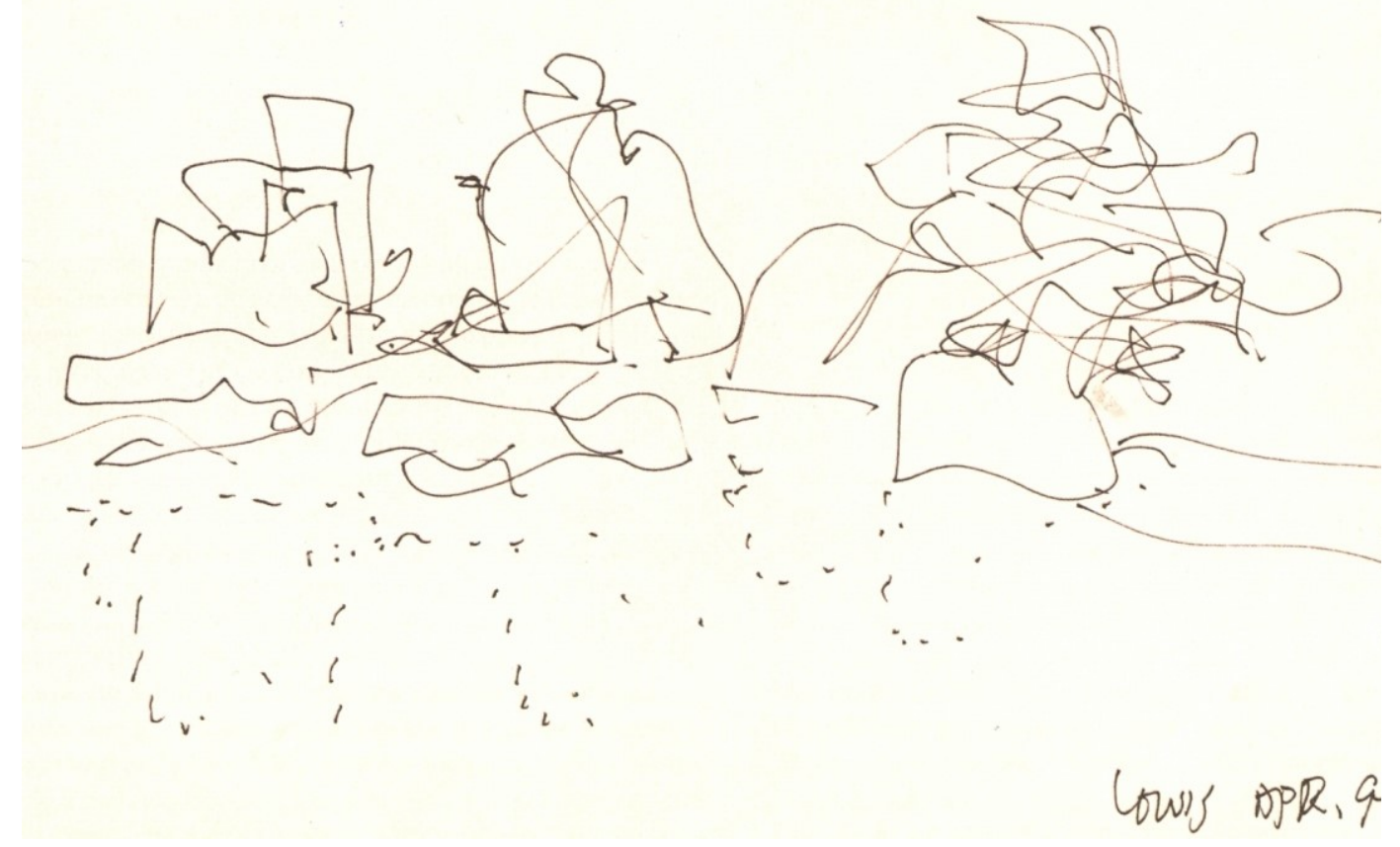

Figure 14: Lewis Residence In Gehry Draws $(2004,125)$. 
The diagram is made up of manual marks, traits that are accidental, free and irrational; they are neither significant nor signifiers but traits of sensation that act as agents of transformation. The hand intervenes on the optical organization (in Gehry's case, on the very structure of the plan, elevation or perspective), blurring it as if in a catastrophe or chaos. With respect to Bacon's paintings, the diagram intervenes on a figurative form (often from a photograph), scrambles it and imbues it with a new order of a different nature, that then emerges as a new Figure in the painting. (125) For Gehry, it is the architectural figure in its conventional representation, that is blurred by the diagram, or perhaps into a diagram, imposing a zone of indeterminacy or indiscernibility that transforms intention into extension and expansion. The diagram introduces virtual forces, which act as transformative agents by changing operative relations within the process of conception. The conjectural lines, traits and vectors no longer represent anything but their own movements, coagulating into a single expanding flow. Relations are felt through bodily sensation, beyond those of formal intentions and regulating parameters. Returning to our sketches, I allow myself to transpose Deleuze's insight into Michelangelo's painting of The Holy Family, onto Gehry's drawings. The Figure, he claims, is here caught in a sort of serpentine made up of necessary accidents mounting one on top of the other that coagulate and reveal:

the body beneath the organism, which makes organisms and their elements crack or swell, impose a spasm on them, and puts them in relation with forces - sometimes with an inner force that arouses them, sometimes with external forces that traverse them, sometimes with the eternal force of an unchanging time, sometimes with the variable forces of a flowing time. (129)

Gehry's sketches, however, are not yet Figures, they are of the diagram, the possibilities of fact, the agents of transformation that intervene at various stages of the design process in anticipation of the Figure.

The diagram is analogical, belonging to the right hemisphere:

Analogical language would be a language of relations, which consists of expressive movements, paralinguistic signs, breaths and screams, and so on. (93)

It is not an optical language but a manual power in which the hand is no longer guided by the eye. This power imposes itself upon the optical; it appears in all its 'indiscernibility and objective indeterminism', as a force of will from within, as an impulsive, intuitive, involuntary 
act of chance or automatism. It is what Deleuze calls the catastrophe or chaos. If there is an eye, Deleuze insists, it is the eye of the hurricane of which he finds expression in Turner's paintings. The eye of the hurricane "designates a rest or stopping point that is always linked to an immense agitation of matter." (111) If we turn to other sketches of the Lewis Residence (fig. 15-16), we find a sequence of 'eyes' or moments of arrest surrounded by an unbridled agitation: swirling eddies, crosscurrents jostling across narrow spaces, constrained within a frame. The agitation of nebular matter as a sort of mediation or condensation of outer and inner forces, transforms the center into an anacrusis, infusing the eye with a texture of gusty silence. The frame itself seems to emerge from the formative impetus of the intensifying coiling motion as if to restrain the catastrophe, to prevent the diagram from proliferating to a point of overload that would render it inoperative. Pure diagram operating in the interval between figure and Figure of which we can only sense the vital power: an 'absolute zone of indiscernibility and objective indetermination'.
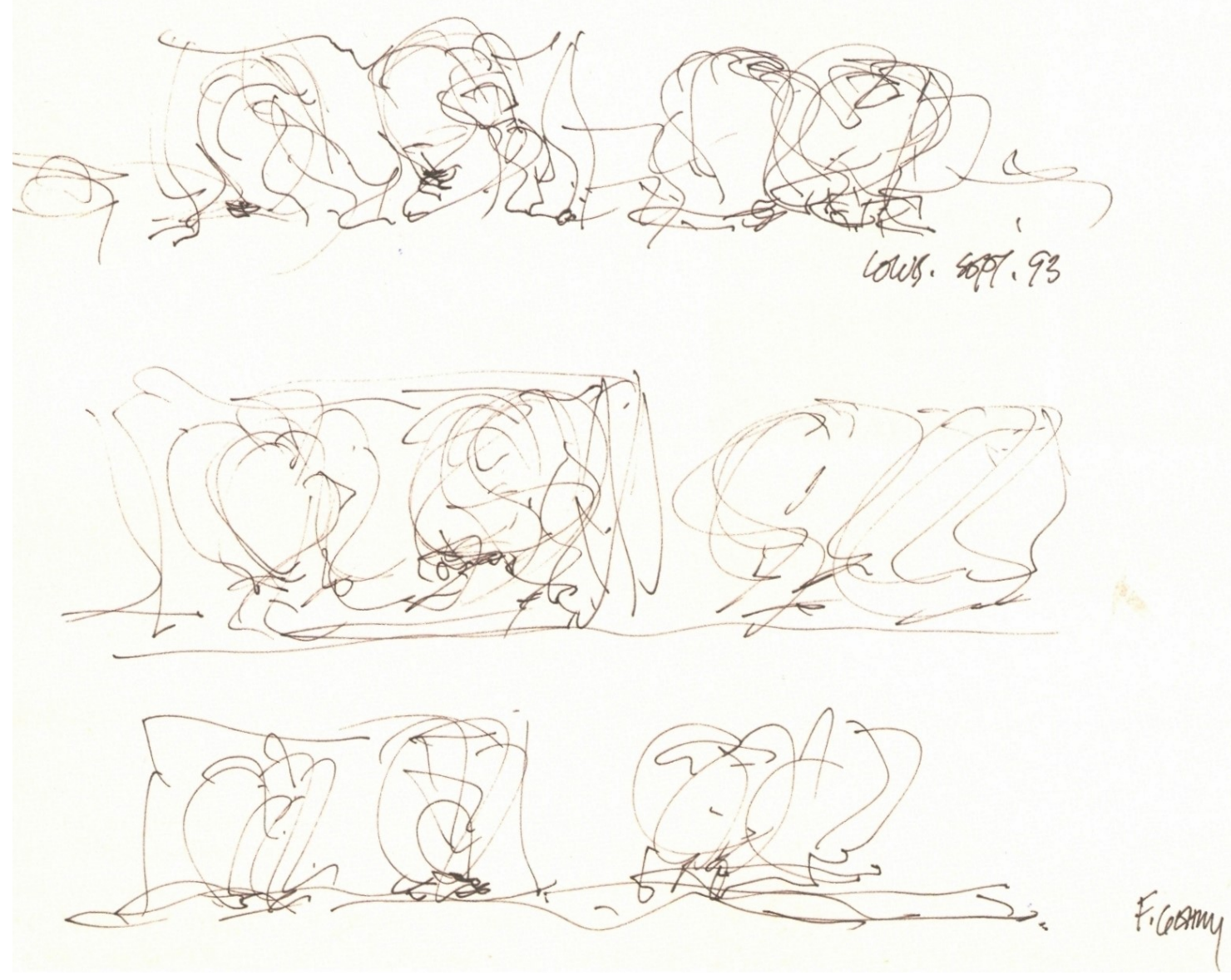

Figure 15: Lewis Residence In Gehry Draws $(2004,133)$ 

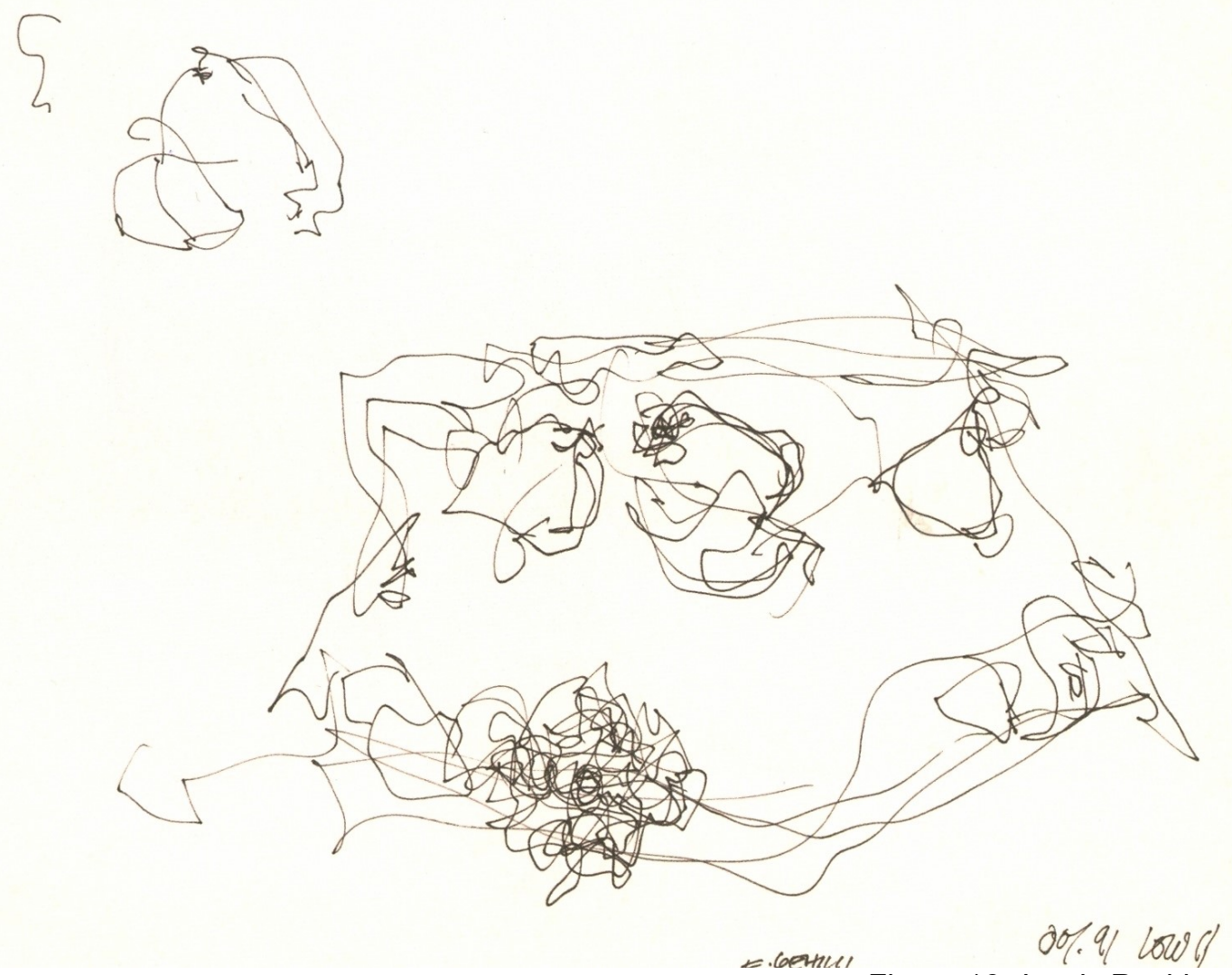

Figure 16: Lewis Residence In Gehry Draws $(2004,117)$.

Every drawing appears to be part of a synthetic diagram; each becoming operative within the transformative process by introducing its own particular set of virtual forces, operative relations and traits of sensation, that affects and is affected by other drawings and the series as a whole. Each impels the infinite potential germinations of the open series (also a diagram) by remaining perpetually permeable to change, new forces and relations. The diagram acts as a score for emerging possibilities within the process of conception, driven by the formative force of vitality affects that activate its intensities and energy. If we were to look at the Figures (or architectural projects ${ }^{24}$ ) that emerge, perhaps the diagram would remain imperceptible in the figurative sense, while its traces resound from within the overall form, generating its lifeline;

${ }^{24}$ Unfortunately, such an investigation is beyond the scope of this thesis. I simply wish to sow the seed for a potential observation. 
traversing body, architecture and environment with the cumulative impulsion of the diagram. I am not suggesting that his buildings are the literal expression of 'organic dance movements' as many contend concerning his projects. If we were to examine movement in his projects it would have to be through the forces that work from within and without, as I have adumbrated throughout this thesis.

\section{5}

\section{Drawing as Notation}

\section{Louppe on Scripting}

I have examined drawing from multiple perspectives that have generated nuances within an overarching vision. This vision has drawn from dance: from the difficulties that have enabled its discipline to grow and from the accumulated wisdom that has ensued. In this chapter I have addressed the question of writing the body into the process of conception in architecture, not as a means of inscribing movement into objective space but rather the affective resonance of the body into the flesh of architecture; a space temporarily swept clear of signifiers in favor of sensations. If dance has benefitted from the problem of tracing the ephemerality of movement and the dissolution of the body, as a condition not only of its practice, but also of the kinesthetic sentient body more generally, can architecture also gain from its insights? Drawing practices in architecture remain imprisoned within a formal and constraining language of nomenclature, an archival logic that predominantly negates the sentient body and that persists within institutionalized forms of drawing. They are mostly the projection of a state of isolation with respect to living matter. If we were to draw a parallel with dance notation it would bring us back to the $17^{\text {th }}$ century when Feuillet developed his categorical scripting system for the fixation and transmission of dance without the presence of the moving body. Notation then preceded dance and was "harmonized within the luminous planar space of Cartesian rationality, manifested in linear geometrism and the perception of the body as machine". (Lepecki 1004, 126) The notion of notation has since evolved to account for the intangible complexities in dance and movement. It is worth quoting a passage from Louppe (1994) in its entirety:

Choreography, for the contemporary creator, corresponds to a transformation of latent motor organizations, of the time and space that they contain, and of the play of exchange between these interior polyphonies and the objective spatio-temporal givens with which, among other things, the act confronts them. It is therefore above all a matter of interior 
score, moving and intimate. This score is within all of us: it is the ensemble of breathings, pulsations, emotive discharges or mass displacements which are focused on our bodies. It is the geography of the influxes diffused around us by the imaginary vision of space, it is the quality of the relations that we can have with the objective givens of the real - the very givens that movement 'sculpts', embraces and disperses according to its own axes of intensity. (16)

Gehry's sketches, as I have attempted to show, dip into this potentiality by uttering what conventional drawings cannot say, but "where another text shows through, another reading of living substance...The surface of the paper acts as a conjunctive tissue between, the body, its movement, and the space of projection where the inner score can unfurl." (16)

In Danses tracées, Laurence Louppe (1991) surveys the evolution of the practice of notation within the discipline of choreography. She outlines the transition in which notation moves from being a tool of analysis and transmission depicted through graphic signs to a means of "seizing states in which movement develops degrees, qualitative energies and tonalities". (10, my translation) She examines the origin of choreography as a scripting, noting or archiving of dance and sets this against contemporary understandings of choreography as an intimate partition of inner movement, as a 'geography of influxes' of emotional and gravitational discharges that releases our spatial imaginary and the quality of relations we sustain with the environment. She looks at notation as that in which movement is inscribed in the "memory of that which returns to us as a backlash of life":

Like a wave that is born of another wave, only the body can decrypt the echoes of a resonance that returns, in the matter of paper as a silenced percussion, of which we only need to awaken the blows. (24, my translation)

For Louppe (2010), the basis of memory is the experience of recording: leaving immaterial traces of sensations in the collective conscience for:

the quality of the instant does not depend on its ephemeral character but on the instantaneous perception of the sensuous intensity that inhabits it; and whose bodily emanation...can capture. (243) 


\section{6}

\section{Conclusion}

The allusion to notation is ubiquitous in my interpretation of the theories I have inferred from throughout the chapter. They constitute different thresholds into the relationship that sketching mediates between the kinetic body and architecture. Derrida's thought (concept) of trace as différance provides insight as to its infinite possibilities of movement towards other traces and absences that expand its signifying and imaginary potential. It enables sketching to move 'along ephemerality' and to employ the body as the source of tracing, scripting or movement towards experience and meaning. Nancy's idea of formative form sheds light on the process of deferment responding to the forces of formation that come conjunctively from the past (historicity) and move towards the future (otherness) as it traces itself. It is the essence of the trace's movement, of the act of dancing, writing, scoring and sketching. Deleuze's concept of diagram addresses the active and interactive effect of tracings (markings) as a disruptive movement of cumulative forces that operate from within the Figure. It intervenes on the figurative, the given, by transforming operative relations in the process of emergence of a new, denaturalized order. The diagram is the operative, transfiguring structure at play among and between tracings or scores. Notation, in the context of this thesis, consolidates all of these notions and it is in this unique manner that I contend Gehry's sketches figure as notations for his projects. 


\section{Chapter THREE Implications for Architecture Education}

This chapter circumscribes the problem of sensory disengagement and perceptual fragmentation as an outcome of modernity, and its impact on education. It briefly exposes the paradigm of ocularcentrism and the paradox of attention as the two primary sources of this ongoing crisis. It then examines the basis of embodied experience and spatiotemporal perception by looking at the nature and role of the senses and their relation to movement. The thesis also explores underlying phenomena that affect and are affected by corporeal movement in order to build an epistemological framework for understanding the significance of the body in conceptual processes in architecture. The insights brought to light through these various perspectives are weaved together to justify drawing's significance and its potential for transforming our corporeal engagement with architecture. It brings forth various potential points of entry into an epistemological re-evaluation of the role and pertinence of drawing, and by extension, the body in architecture education.

Juhani Pallasmaa criticizes the modern situation for its privileging of sight as the supreme form of knowledge and, consequently, emphasizes the primacy of the body (and of drawing) in perception, thinking and conception in architecture education. Jonathon Crary examines the problem from the perspective of attention as a fundamental condition of experience and creativity. This is followed by epistemological views of the body that vindicate the value of embodied approaches in education: Maxine Sheets-Johnstone argues that movement is a form of embodied thinking that yields natural kinetic bodily logos. Daniel Stern contends that amodal perception as a result of affective attunement with others produces implicit relational knowledge. This form of knowledge involves dynamic forms of vitality that can be traced back to movement and the perception of forces. Mark Johnson and George Lakoff establish the correlation between sensorimotor knowledge and our capacity to think metaphorically and conceptually. Elizabeth Grosz intervenes throughout, projecting these theories onto broader poststructuralist horizons, by interjecting the concepts of duration and virtuality. The chapter concludes by broaching the question of drawing as a heuristic tool in architecture education, taking gestural drawing and improvisation as potential springboards for explorations of embodied forms of knowledge. 


\section{1}

\section{Multi-sensory Perception in Architecture}

Pallasmaa's Critique of Ocularcentrism

In The Eyes of the Skin, architect and scholar Pallasmaa addresses the implications and consequences of the prevailing bias towards vision, and the suppression of the other senses in the teaching, practice and critique of architecture as a result of technological and consumer culture. He advocates the need to reconsider the body as the locus of perception, thought and consciousness and the significance of the senses in the experience, processing and understanding of the fundamental issues and complexities that underlie authentic architecture. In The Thinking Hand the author advocates drawing as a possible means of counter-balancing the prevalent problem of passive and purely retinal perception of space in architectural practices. He argues that the quality of architectural reality and imaginary depends on the embodied nature of this haptic vision. I will survey certain elemental dimensions of his thesis that expose central problems surrounding the pervasiveness of technology, at the basis of much controversy in architecture education.

Pallasmaa (2005) begins by emphasizing the need to question the nature of the Western perspectival eye and the epistemological privileging of sight as a supreme form of knowledge. He first points out the relevant historical connections between vision, knowledge, ontology and power that have contributed to this ocularcentric paradigm from ancient Greece to modernity. He sets the grounds that will situate his claims by illustrating the historical evolution of this visual paradigm in Western culture and its simultaneous development in architecture. He then surveys seminal philosophical concepts developed by key critics of ocularcentricism that will become the premise of his thesis.

One of the author's key arguments reflects Merleau-Ponty's claim that the Cartesian perspectivalist regime has contributed to the alienation and disembodiment of the subject. Pallasmaa argues that the very essence of embodied experience is shaped by hapticity and peripheral, unfocused (and unconscious) vision. Unlike perspectivalist scopic vision, which places the subject on the outside as mere spectator, peripheral vision enfolds the subject in space. An architecture of touch, he insists, is one of proximity, interiority and intimacy; an architecture of the eye on the other hand, is one of distance, exteriority and detachment. In The Thinking Hand (2009), the author, consequently, emphasizes the active and haptic nature of freehand drawing and its role in counter balancing purely retinal habits of perception in education. To draw an object, he claims, is to touch and feel its contours; the muscles of the 
hand, arm and body mimic the rhythm of the contours. A dialectic relationship links the inner, felt world of the perceiver to the external, imaginary or reality of space and matter in the act of drawing. Although I concur with Pallasmaa on the use of drawing as a potential embodied form of experience, I believe that by retaining the concept of drawing as a traditional form of observation and exploration, he falls short of fully exploiting the potential of kinesthetic experience and experimentation through drawing in ways more resonant with the kinetic body, and the context of a rapidly fluctuating technological world. For Pallasmaa (2009), drawing is a temporal process of successive perception as opposed to the momentary snapshot image of photography. But he ultimately seems to conceive of drawing as a form of image-making or representation that reflects the discontinuous cinematographic view of space that has been cultivated in architectural thought and representation from the onset of modernism. I will argue that if drawing is to find its place in today's world, it must be addressed rather, as a process that reveals the continuity of ever-changing situations and relations.

The author further concurs with Heidegger, that with the advent of modernity, technology and the collapsing of the world into images exacerbated the negative tendencies produced by the privileging of sight: the gaze itself flattened into a picture. Architecture education, he contends, primarily emphasizes design practices in which the conception of buildings is transformed into the production of images that tend to be devoid of existential depth, plasticity and temporality. He states:

Computer imaging tends to flatten our magnificent, multi-sensory, simultaneous and synchronic capacities of imagination by turning the design process into a passive visual manipulation, a retinal journey. (Pallasmaa 2005, 12)

Architecture consequently becomes immaterial; its "opaque transparency reflects the gaze back unaffected and unmoved; we are unable to see or imagine life behind its walls". (31) This technological effect (from the perspectivalist regime to the screen) constitutes one of the central arguments of disembodiment in architecture education. It contributes to a homogenization of spatial perception that seeps into the design process, and a narrowing of epistemological discourses on our relation to space. As a result, the potential idiosyncratic quality of student projects is often lost or dissolved and vitality forfeited. In the end, projects all breathe the same air of technological conformity. It has become a habitual way of seeing the world that is very difficult to dismantle even in the context of drawing pedagogy.

This critique is particularly pertinent to today's pedagogical reality because students generally spend more time passively submerged in their computer screens than they do 
actively exploring space or the sites of intervention with their own bodies and senses. When they do make it to the site it is with camera or video in hand, analytically recording optical images of fragmented space or, exceptionally, constructing perspective drawings. When they conceive and develop their projects, it is done in large part through simulation software. Their spatial perception, interpretation and conception evolve primarily in the realm of the optical image of the camera lens and the flat computer screen. Movement itself is constructed from mostly rhythmless sequences (or at best, sequestered flows) of two-dimensional representations that maintain the body on the outside, alienated from the possibilities of authentic sensorimotor response and interaction ${ }^{25}$. As Grosz (2000) also points out, digital technologies tend to 'divide relations into solids and entities' to make the world more manageable.

Digitization translates, retranscribes, and circumscribes the fluidity and flux by decomposing the analog or the continuous - currents - into elements or units...and then recomposing them...[but these] processes lose something in the process, although they reproduce themselves perfectly...what is lost...is precisely the continuity, the force, that binds together the real as complexity and entwinement. (181)

Buildings consequently tend to be conceived for the pleasure of the eye; architecture becomes object at the expense of place; exterior form is prioritized over the dynamics of experience. Instead of acting as objects, buildings should rather operate as spatial processes: not containers of objects but "facilitators of flows: volume without contour". (165) I believe that it is crucial for students of architecture to first explore and experience the vitality of dynamic embodied spatial perception in meaningful ways and to internalize this spatiotemporal process of embodiment so as to remediate or substantiate the disembodied habits of perception induced by perspectival vision and the homogeneously 'weightless, scaleless, abstract space' of computer images. Freehand drawing, as I will broach it below, has the potential to provide a multiplicity of pertinent temporal and embodied spatial experiences that extend beyond modes of representation.

In the second part of his book, Pallasmaa acknowledges that the adverse outcome of architecture, as a consequence of the impact of technological rationality, amongst other things, cannot be attributed to the historical privileging of the sense of vision alone. Rather, it is the

\footnotetext{
${ }^{25}$ Exploration through model-making has practically replaced drawing in studio practices. It certainly enriches the exploration process in many ways. However, it does not offer the same potential as drawing because it enforces the experience of object-making from the outside, lacking a certain interiority, a dynamic vitality, spontaneity and sensitivity in the process.
} 
separation of sight from other sense modalities and by extension, the sensory imbalance that ensues, that impoverished the perceptual system and reinforced the sense of alienation. But his discourse, throughout, implies a certain privileging of the tactile sense; he claims that all senses are extensions of touch and that the visual images, which reflect our mnemonic and imaginary faculties depend on primal experiences that are acquired haptically. The body is therefore the locus of our (haptic) memories and imagination; we remember a place because it has affected our bodies. The kinesthetic experience of architecture is not perceived as a series of retinal images but rather through haptic apprehension of the environment. Movement, balance and scale are experienced proprioceptively through the body as tensions in the muscles and articulations of the skeleton; architecture makes us aware of gravity, of depth, it strengthens our experience of verticality. Authentic architectural events are kinesthetic experiences in which the body approaches, confronts, enters, ascends, spirals, is suspended or restrained. To perceive is to learn how the environment structures one's possibilities of movement (Gibson's concept of affordances): to feel the ground under one's feet as flat or tilted, smooth or rugged is to perceive it as shaping or impeding one's possibility of movement. It is the very possibility of action, Pallasmaa contends, that differentiates architecture from other art forms. Spaces and "the elements of architecture are not visual units or gestalts; they are encounters, confrontations that interact with memory. In such memories, the past is embodied in actions." (63)

\section{2}

\section{Duration and Virtualities}

Grosz on Space as Duration

What Pallasmaa does not address, however, is the temporal dimension of movement or action that underlies embodied perception of space, and that constitutes the motor force of memory and imagination. The imbrication of time in the conception of space is crucial to exposing the full implications of kinesthetic embodiment in architecture. The concept of duration as developed by Bergson and built on by Grosz can fill this gap. Duration is, according to Grosz (2000),

a multiplicity of succession, heterogeneity, differences in kind and qualitative differentiations. It is continuous and virtual...Duration is not, through its continuity, homogeneous, smooth, or linear; rather, it is a mode of 'hesitation' bifurcation, unfolding, or emergence. (114) 
She argues that memory takes us to where the past is: in duration. And the virtual plays an important role in duration because it is bound both with the past and futurity. The past is suspended in memory as an inactive, ideational virtual, and the present is "laden with [these] virtualities that extend it beyond itself" into impending future action (and virtualities). This conception of duration is the near antithesis of that of space commonly understood as discontinuous, static, homogeneous, divisible and real. Grosz proposes that we rethink space in terms of duration and becoming. Memory seeks events where they took place in space and in time; virtual spaces are also suspended in the past and extended into the impending future. The spatial past is accessible in the present through motor mechanisms (as habits or images) that orient it to the future. Space, as duration, is a "moment of becoming, of opening up and proliferation, a passage from one space to another, a space of change, which changes with time". (119) Space as temporal is deeply embedded in (our awareness of) the kinesthetic experiential flows, always unfolding in a qualitatively dynamic manner.

I insist on this temporal dimension of space because it is what makes the experience of drawing so pertinent, beyond the purely haptic condition of the touching hand. Gehry's sketches embody this duration as both temporal and spatial. Spatiality forms as a qualitative extensity emerging through the motions that unfold and actualize it. The forces of duration, the motion of deferral are caught in the tracing of the trace that activates the space of the coming into being of architecture, as we have seen in chapter two. Exploration of spatial temporality has been generally overlooked in conventional pedagogical drawing practices and will form the conductive motor force of alternate approaches advocated in this thesis.

Grosz's spatial correlation to temporal duration is a result of the virtual. As we have seen, duration is bound with the past and the future as virtualities. Because these virtualities can never be exhausted or anticipated by the present, they provide the space-time of the new and unthought: the unfolding of multiplicity, complexity, and heterogeneity, the opening up to other spaces and events. This is what Grosz refers to as the 'logic of invention and experimentation'. (120) She proposes that we consider spatiality as the 'coexistence of multiple relations in succession', layers of spaces enfolded within themselves that can operate as the virtualities of the present 'here'. (129) These virtualities 'function through the production of novelties that remain unforseen' but that emerge from the virtual past. It is this virtuality that can produce difference by functioning 'in excess of design and intention'. (130)

As we have seen in earlier chapters, there is a sense in Gehry's sketches, of a probing of such virtualities. These virtualities seem to operate in excess of architecture, somewhere on 
the margins of function, practicality, use and history. They seem to seek allegiances with forces, affects, energies, sensations rather than form and purpose.

We cannot help but view the world in terms of solids, as things. But we leave behind something untapped of the fluidity of the world, the movements, vibrations, transformations that occur below the threshold of perception and calculation and outside the relevance of our practical concerns. (175)

Through his impulses and intuitions, Gehry seizes the minute relations beyond the pragmatic, he accesses vibrations and intensities hidden within architecture, he experiments the world from the fluidity and flux that eludes everyday demands. Drawing is here a space of virtuality where the new, the unthought can emerge unrealized; it is the means of perceiving space as extension, expansion, passage; it is perception as action-in-potential. Experiencing space through drawing as duration: as a passage from the virtual past into an impending future of potential spatiality, should be the aim of heuristic practices in architecture education. The proposed exercises (appendix A) have been conceived so as to activate perceptual relations (in the spatiotemporal sense) and to heighten awareness of their sensorimotor contingencies through felt gestural drawing. They attempt to transform the habitual flows and rhythms of spatial perception in order to compel students into virtualities of excess, beyond and below their habitual threshold of spatial perception. Such endeavors, as Crary argues below, call for states of suspended attention that enable sustained and transformational journeys into the unknown.

\section{3}

\section{Suspension of Perception}

Crary and the Paradigm of Attention

John Crary (1999) disengages the problem of modern perceptual fragmentation from questions of opticality, as Pallasmaa maintained, by examining the issue through the concept of attention. He claims that privileging the argument of visuality ignores the forces of specialization and separation that are a consequence of the crisis of attention in modernity. Crary looks at how social and political forces imposed from the nineteenth century on, on the phenomena of attention, have created forms of disengagement by enforcing isolation and concentrated focus on reduced amounts of stimuli, thereby creating and maintaining sedentary, docile bodies and orderly, productive subjects. He examines the impact of evolving 
forms of technology on the nature of attention over the last two centuries and the way in which it has lead to a restructuring of perceptual experience in terms of the nineteenth century solitary rather than collective subject. New technologies, Crary argues, have sustained a culture of spectacle not from the imperative of a seeing subject but rather by creating strategies of individualism, isolation and separation that 'inhabit time as disempowered'.

Television and the personal computer, even as they are now converging toward a single machinic function, are antinomadic procedures that fixate and striate. They are methods for the management of attention that use partitioning and sedentarization, rendering bodies controllable and useful simultaneously, even as they simulate the illusion of choices and 'interactivity'. (75)

Doctrines focused on vision, he argues, are linked to a broader reshaping of subjectivity that rely less on optical phenomena than on those of modernization and rationalization. But Crary's interest is primarily in establishing the issues of attention that link philosophical dogmas of vision and perception, to social and institutional constructions of experience and subjectivity. His thesis examines the paradoxical nature of attention: on the one hand it constitutes a potential means for the subject to transcend the limits of a subjectivity imposed by social and institutional power, and on the other, it subordinates him/her to the very control of those external agencies as indispensible to pragmatic survival. In other words, modes of attention (focused or distracted) can either bloom into a creative potential by producing intensive states of deep absorption, tapping into unknown and new territories, or it can lead to pathologies of identity or subjectivity. In the end, the author advocates a mediating position that veers toward a state of suspension in which resonates a tension, a stillness, the wonder of contemplation at once immobile and ungrounded, and at the same time, an interruption, a disturbance: "a perception that can be both an absorption and an absence or deferral". (10) This state of suspension will be the source of future pedagogical pursuits advocated for drawing.

Crary designates the modern educational institution as one of the spaces in which subjectivity is externally shaped and controlled: The teacher fixes the attention of the student on processes and objectives that he/she would not intuitively be attracted to thereby shaping through suggestive emphasis and training, patterns of attention amenable to the discipline's established norms. (63) Although Crary acknowledges that it is within these very spaces of control that "new thresholds continually emerge at which an institutionally competent attentiveness veers into something vagrant, unfocused, something folded back against itself", (77) I believe there remains a ubiquitous historical bias toward modes of selective attention that strongly prioritize disembodied vision in architecture education and that reinforce 
sedentarization and standardization of responses to our immediate environment, to answer to demands for productivity and sustainability.

Architecture curricula still largely focus attention on cognitive approaches and abstract thinking while dismissing embodied multi-sensorial awareness that escapes rationalization. Approaches that valorize this latter type of awareness could only, in my opinion, invigorate and enrich pedagogical pursuits. Such a means would shift attention away from existing focused exclusionary modes of thinking, to peripheral modes of perception attuned to the multiplicity of changing unformulable sensations that constitute our experience of the world. Or as Crary would have it: a suspended engagement, as had Cézanne, "in a motor and sensory attentiveness to the continual emergence and disintegration of constellations of relationships of which the self is a constituent element". (301) In order to achieve such a shift of attention, I contend that alternate forms of embodied thinking and practice must be introduced into the pedagogical context so as to dissolve long-standing biases and preconceptions. In certain contemporary dance and somatic practices, the body disengages itself from its predisposition to function and habit as well as from representation, and exposes itself to the potentialities of transformation and metamorphosis. In this sense, it has the potential to become a body of resistance against the logic of productivity: the fixity of the final product and the automaton of a capitalist society. Perhaps it is this very condition of embodied freedom (in creative drawing practices) that could destabilize and rupture ingrained habits and open a whole new field of potentialities in architecture education. Sheets-Johnstone examines the nature and logic of such an embodied freedom in the practice of improvisation. She establishes a direct correlation between movement and thinking that will enable the projection of the body into the process of conceptualization, in an effort to further dissolve the Cartesian mind-body dualism.

\section{4}

\section{Kinetic Bodily Logos}

Sheets-Johnstone on Movement

In her article Thinking in Movement Sheets-Johnstone (2009) claims that thinking and doing, perception and movement, are inseparable aspects of a natural kinetic bodily logos. "Movement is not a medium by which thoughts emerge but rather thoughts themselves, 
significations in the flesh"26. She questions the assumptions that thinking is invariably tied to language and rationality and dependent on a symbolic system, and contends rather that thinking in/as movement is a particular kind of rationality or kinetic intelligence. This thinking that responds to evolving situations, is a 'process, which develops its own logic or integrity' on the basis of an implicit bodily logos. She examines the paradigm of thinking in movement through the practice of dance improvisation. A spontaneous and unrehearsed form of dance experienced in its immediacy, improvisation is the 'incarnation of creativity as process'. The ongoing flow of movement experienced as an ever-changing present is a process of thinking in movement that is continually open to future possibilities that arise and dissolve in a fluid complex of relationships and qualities.

... [in improvising] I am wondering the world directly, in movement. I am actively exploring its possibilities and what I perceive in the course of that exploration is enfolded in the very process of my moving. $(31)^{27}$

She distinguishes improvisation as the creation of dance as process, from non-improvisation or the creation of dance as product. The former is 'thought in action', the latter, 'thought about action'. (39) Improvisation requires a phenomenological unity of body and mind, it must become the plane of immanence on which thought and body dissolve one into the other.

That the dancer is thinking in movement does not mean that the dancer is thinking by means of movement or that her/his thoughts are being transcribed into movement. To think is first of all to be caught up in a flow of thought; thinking is itself, by its very nature, kinetic. It moves forward, backward, digressively, quickly, slowly, narrowly, suddenly, hesitantly, blindly, confusedly, penetratingly. What is distinctive about thinking in movement is that not only is the flow of thought kinetic, but the thought itself is. It is motional through and through, at once spatial, temporal, dynamic. (30)

It is of course possible that thoughts emerge autonomously during the process, intruding on the ongoing flow. But these, she claims, are 'spin-offs' of thinking in movement rather than the result of a mental process. Movement does not designate thought but becomes the presence of that thought. Movement is a form of rationality or kinetic intelligence, borne of a kinetic bodily logos that is non-symbolic, nonlinear, non-propositional; it is a bodily-force "shaping and

\footnotetext{
${ }^{26}$ This quote was taken from another version of the article, published in 1981 in the Journal of Aesthetics and Art Criticism, 39, 4, 400.

${ }^{27}$ It is not only through dance improvisation that such possibilities can arise but to a different degree, in the movements and flows of everyday actions such as walking, as the Situationists, among others, have demonstrated.
} 
being shaped by developing dynamic patterns in which it is living"; it is a body that "knows what to do". (33) "Thought is grounded... in the tensional relations and orientations interior to living beings between affect and perception". (Grosz 2017, 188) It is liberated from representation, signification and 'given back its capacity to effect transformation', metamorphoses. It is an encounter with the outside in Grosz's (2000) sense, as a virtual condition of the inside or as the unthought. (68) Thought folds back onto itself but its source remains the body in movement as I have already discussed in relation to Lepecki's plane of immanence in dance.

An understanding of the concept of kinetic bodily logos is indispensible to seizing the very nature of sketching as thought in action in this thesis; and the potential of improvisation is paramount in the exploration of heuristic drawing practices in architecture education as well. The notion of formative force developed in chapter two is sustained by bodily logos as well as by the spirit of improvisation that extends beyond intentionality. The trace similarly is the marking of thinking in movement. In fact, every dimension of drawing I have explored so far is grounded in bodily logos. But what the concept introduces in the context of this chapter is an understanding of thought as movement, which can be projected into conceptual forms of thinking in the design process. Drawing-as-dance (and improvisation), as we shall see below, opens venues onto the nature of thinking, and perceiving of, and in movement, that can shift attention away from cognitive focuses to a more embodied awareness of experiential processes of drawing (and thinking) that sustain creativity in architectural conception. Next, I look at what induces the impulse to move once intention has been put on hold. Stern argues that vitality is the sense modality that constitutes the primary qualitative dynamic force impelling us into, and sustaining movement.

\section{5}

\section{Vitality and Affect Attunement}

Stern on Dynamic Forms of Vitality

I have referred to the notion of vitality throughout my essay, relying on a tacit understanding of the word in the context of drawing and dance. I believe it is worth attending more explicitly to the concept, so as to endow it with a more acute meaning. To do so, I turn to Daniel Stern's essay entitled Forms of Vitality. Stern (2010) considers dynamic vitality forms as the sixth 
sensory modality that 'senses the duration, speed and time-shape of the force making up felt events'. These vitality forms give temporal shape to embodiment as it is being enacted.

Vitality dynamics refer mainly to the shifts in forces felt to be acting during an event in motion, and thus focus more on the dynamic qualities of the experience, in particular the profile of the fluctuations in excitement, interest, and aliveness. (45)

The concept of vitality has many implications within this thesis; it is the motor force by which I have been able to access the specifity of Gehry's work from the perspective of dance, drawing and architecture. When I wrote of authentic architectural encounters in which the past is embodied in action (through memory) I am implying the workings of dynamic vitality. Stern states:

Dynamic forms of vitality provide another path...to access non-conscious past experience, including memories, dissociated experiences, phenomenological experience, past experience known implicitly and never verbalized. (11)

But vitality is also the means by which one can enter into the space of drawing and by which one can understand drawing as dance; architecture as dance; and Gehry's drawings as the embodiment of architecture in its vital sense. The very structure of this inquiry is grounded in the meta-modal nature of vitality forms: it attempts to combine different art forms to explore the regenerating effects of their combinations and therefore, depends on their cross-modal fluency to lead them beyond their individual forms.

'Correspondences' between art forms are necessarily created because of the meta-modal nature of vitality forms that assure a common ability to render similar, but not identical, experiences... when different art forms are juxtaposed, certain aspects do not translate well from one form to the next...[but] vitality forms are readily transferable between art forms in large part because of their meta-modality and potential speed of modulation. (78)

Each art form has developed its own technique to code or create the same forms of vitality, shared by all through the meta-modal phenomena. What they all have in common is their impetus to explore the dynamic dimension of human experience. (98)

Affect attunement is another concept that will prove pertinent, especially in relation to improvisation techniques introduced as the basis of potential heuristic drawing practices that 
conclude this thesis. We become aware of our vitality both subjectively and intersubjectively, through our affective attunement with others. In being attuned to others' felt experiences, we share dynamic forms of vitality, but across different modalities. Stern refers to this innate cross-modal fluency as a form of amodal perception. He claims that amodal perception is fundamentally affective and pertains to the force or patterns of relations experienced as vitality affects. Lived intersubjectively, affect attunement can be experienced unilaterally (I draw what I feel the dancer/model feels) or bilaterally (I draw with the dancer/model as she responds to what she sees I feel). Intersubjectivety is a 'time-intensity coupling' in which dynamic forms are crucial. In this context:

The concept of dynamic vitality forms brings together four converging lines of thought, namely intersubjectivity, cross- and meta-modality, the dynamic features of experience, and a phenomenological focus on subjectivity. (44)

Affect attunement creates and sustains a vital running dialogue of affective exchange that can lead to forms of implicit relational knowing: a process by which concepts and abstractions occur when one enacts an aspect of a relationship in a new way without it being reflected upon and verbalized. I contend that both dance and freehand drawing engage in dynamic forms of vitality that are somewhat curtailed in today's prevailing digital drawing processes, attitudes toward the experience of space, and pedagogical approaches. Could engaging in collaborative improvisation between dancing and drawing perhaps heighten the student's sensitivity to dynamic forms of vitality inherent in the process of dance and thereby generate intersubjective experiences of implicit relational knowing in the act of responsive drawing, that would move the student towards other understandings of space and flows of living form? How would these

other understandings of space then be absorbed in the design process? The subsequent section examines how kinaesthetic experience enables the conceptualization process and the formation of meaning in architecture.

\section{6}

\section{Body as Locus of Conception}

Johnson and Lakoff on Embodied Meaning

"Our experience of meaning is based, first, on our sensorimotor experience, our feelings, and our visceral connections to our world; and, second, on various imaginative capacities for using 
sensorimotor processes to understand abstract concepts." (Johnson, 2007, 12) Conceptual understanding and thinking, as a result of metaphorical extension is grounded on a tacit sensorimotor knowledge that emerges from our kinetic experiences. Such is the underlying premise of Jonhson's thesis. In The Body in the Mind, the author develops a theory of the imagination in which our cognitive structures are intimately linked to our bodily experiences. $\mathrm{He}$ argues that our fundamental concepts ensue from these experiences and are metaphorically extended and transformed into abstract concepts, become meaningful. In conjunction with Lakoff, Johnson elaborates on the physical experiential basis of metaphorical thinking and understanding, arguing that, and demonstrating how most if not all our primary concepts are rooted in spatialization metaphors. Grounded on the results of neuroscience, they seek to invalidate the fundamental assumptions underlying western doctrines that contend that thinking is literal, that metaphors are purely cognitive and that reason is disembodied and universal.

Of interest in Johnson's work, in the context of education, is the epistemological relevance of the body: how our body and kinesthetic experience contribute to processes of imagination, understanding and knowledge. He considers two types of imaginative structures that are central, and that I will briefly summarize for the purpose of my inquiry: the 'embodied' or 'image'-schemata and the metaphorical projection. Johnson (1987) defines the imageschemata as a "recurring, dynamic pattern of our perceptual interactions and motor programs that gives coherence and structure to our experience". (xiv) These schemas become meaningful structures through our experience of bodily movements in space, our manipulation of objects, and our perceptual interactions. For example, the verticality schema comes from our experiences of the up-down orientation: experiencing the level of water rising in a glass as you pour, going up the stairs, raising a flag on a pole, etc. The schema is a dynamic abstract structure for our kinetic experiences, and the images and perceptions of verticality they produce.

Metaphors are embodied imaginative structures by which patterns from one domain of experience (or image-schemata) are projected or extended to structure another domain of a different kind. In other words, our physical movements in given experiences are structured in a conceptual schema, as with the image-schemata, and that structure is projected onto another abstract situation via metaphor. (xv) He uses the example more is up as a primary metaphoric structure for understanding quantity in terms of verticality. For example: prices go up, grades go down, sales are rising, etc. These understandings are made possible because, as with the 
image-schemata, we have experienced the physical activity of verticality. As Johnson (2007) argues, metaphors and image-schema are the means by which we appropriate the semantics and knowledge structure of sensorimotor operations in order to understand abstract concepts and draw inferences from them. What we have described as metaphorical projections are, in fact, projections from the realm of corporeal onto the cognitive. "What is typically regarded as the 'bodily' works its way up into the 'conceptual' and the 'rational' by means of imagination." (xxi) They are also the central means by which we establish new connections; they are the basis of imagination and conceptualization. Metaphorical thinking is a rich and commonly used medium for creating architectural events that are experientially and semantically meaningful. They offer a way to transcribe bodily logos into the architectural project directly and in very creative, imaginative, and poetic forms. However, the bodily and experiential dimension of metaphor often goes unexplored and disavowed in architecture education in favor of pure semantics. I find metaphors particularly rich for architectural conceptualization because, as according to Lakoff (1980), "most of our fundamental concepts are organized in terms of one or more [primary] spatialization metaphors", grounded in physical, social and cultural experiences $^{28}$. These primary metaphors all relate to spatial orientations: up/down, in/out, close/far, back/front, deep/shallow, above/below, center/periphery, etc. (18) Metaphors built on primary spatial concepts and displaced into a design situation or context, prove to be quite conducive to conceptual transference, interpretation and extension in architecture. Metaphorical conceptualization grounded on corporeal experience is, I believe, also embodied in sketching practices that seek to explore the potentiality of the architectural event. Trace in sketching is, in a sense, a form of metaphor; it is a 'structure' of felt bodily experience (grounded on affective/haptic kinesthetic memory) projected into the architectural situation; it is the vital body's extension in line onto the surface of the paper. But drawing must first be understood and experienced as a process of thinking in movement that aspires to forming phenomenological relations between the pre-reflective and the reflective on the basis of the ecological $^{29}$ experience of one's environment. It is only then that it can begin to have a meaningful impact on the conception of architecture.

\footnotetext{
${ }^{28}$ Along with Sheets-Johnstone, I do not intend to understate the role of other elemental concept structures derived from affective/tactile kinesthetic experience, such as temporal concepts (sudden/gradual, accelerating/decelerating, etc.), force concepts (weak/strong), or quality concepts (soft/rugged, cold/warm, etc.) in architecture. I my understanding of live space, they are presupposed in spatialization concepts.

${ }^{29}$ I am referring here to Gibson's doctrine of ecological psychology.
} 
My point here is not to engage in a rigorous account of the workings of these structures as both Johnson and Lakoff, amongst others, have quite eloquently done. What I am moving towards, or striving for, is a recognition of the importance of corporeal awareness, of attending to the wealth of potential the body inheres, and an opening onto those very possibilities in architecture. Without becoming dancers, we can explore bodily insights through drawing. Allowing ourselves to be inspired by the receptive body of somatics, we can observe our corporeal selves; or by the creatively free body of improvisation, we might discover ourselves. Creative conceptualization partakes in a process that requires a spontaneous responsiveness to ever-changing contexts and situations and a capacity to act and react, improvising strategies from those responses. In the architectural context the ability to think metaphorically, to understand and create abstract concepts and develop poetic and meaningful experiences, as I have said, is fundamental. But if this skill is developed and applied in its purely cognitive and objective dimension, if students only learn to design from semantic conceptualization, through formal innovations, or for pragmatic and technical sustainability, wherein lies architecture's potential for attunement with its inhabitants? Can drawing with and through the enlightened, spontaneous, kinesthetic body forming relations and projecting into virtualities, also contribute to a more meaningful and felt understanding of metaphor, imagination and experience, but more importantly to a richer understanding of the creative potentiality of drawing itself as a 'metaphorical' interface between the body and architecture? Are not Gehry's drawings scores for embodied conceptualization, the agent of his dynamic vital imagination, and perhaps their resonance, the substance of his buildings? As Costa Meyer (2008) puts it in regards to Gerhy's sketching:

In their unfettered freedom, [his] sketches offer a glimpse of the imagination at work in the luminous, half-palpable realm where the vanishing thought leaves traces in its wake: the stuff of dreams. (101)

\section{7}

\section{Drawing as a Heuristic Tool}

\section{Projections}

Freehand drawing practices in architecture education have suffered a rapid and substantial depletion and decline, to which I have been witness, in the last decade. Current controversies and debates maintain the practice of drawing in suspension but its future seems precarious. 
I've often wondered whether this regression is self-generating: whether it is because the more students are exposed to limited drawing content, and conditions as well as skeptical attitudes, the more they question its significance. It is very difficult to comprehend, in light of the role and significance of the body and kinesthetic experience sketched out throughout this thesis, how its relevance can be seriously questioned. But drawing will only become indubitably pertinent when implemented in a sustained and substantial manner that enables it to reach a heuristic plateau from which its transformative potential can begin to seep into architecture in an enactive and embodied manner. I will conclude this essay by proposing potential venues from which such practices might stem.

The act of drawing a moving body, when engaging in gestural drawing ${ }^{30}$, is a direct haptic and mimetic or improvisational response to the tensions and efforts that generate the model's movement. In the architecture curriculum, the freehand model-drawing studio precariously remains one of the few places where the body is consciously lived and experienced as a vital moving entity through drawing. Here, the kinetic body is intentionally studied and its meaning brought to consciousness as the basis of our understanding of lived space. Drawing goes beyond mere visual representation by bringing the student back to his own bodily response time. His/her senses are solicited in attunement with the dancer/model's through kinetic empathy ${ }^{31}$. He/she strives to feel and capture the vitality, energy and intensity of forces, tensions and releases that underlie the model's movement in his/her interaction with space rather than seek to delimit form. He/she reciprocates with his/her own body interpreting and improvising through various mediums this body-space relation in human time and depth, and leaving traces of the intersubjective experience of shared vital movement in its act of appearance/disappearance. Drawing as residue becomes a coalescence of fluxes or forces ensuing from a continuity of instants past and simultaneously projected into imminent

\footnotetext{
${ }^{30}$ Unlike traditional gesture drawing in which students draw the model once the movement has come to a stop, I am referring to an approach I have been experimenting with in my courses, that privileges continuous movement. Students attempt to seize the flows, rhythms and/or continuity of movement that constitute the space of the body. Short interruptions of movement are addressed as intervals from which students anticipate or attune themselves to the incipiency of oncoming actions.

${ }^{31}$ Studies in neuroscience also suggest that through the phenomena of mirror-neurons "to see another person perform an action activates some of the same sensorimotor areas, as if the observer herself were performing the action." (Johnson, 2007, 161) See also Galllese, V. on the concepts of empathy, embodied simulation and resonance. Susan Leigh Foster (2011) also points out the anticipatory function of mirror neurons whereby "watching a dance [is] a continual conjecturing of possible arcs and flows". (167) Empathy, therefore, activates our ability to predict the actions of others (but in our own individualized and culturally specific manner): what will happen if they move in a certain way. Cunningham's idea of dance, for example, "based on his body's articulateness, envisions dance as opening the viewer up to new moves that he can make...[his moves] are "malleable indicators of multiple scenarios." (167)
} 
potentialities that activate the space. The lines that mark the surface invariably collide, cross and cumulate in junctions that absorb and transfer these forces in space-time. I contend that drawing (with) a live body immersed in the intensity of felt movement can bring forth and explore a tacit knowledge in insightful and new ways. Perhaps gestural drawing revisited and projected into the contemporary situation may have untapped potential as a heuristic tool in architecture education.

I have prepared the ground for alternate embodied drawing approaches by gradually introducing the idea of dance improvisation and of a somatic ${ }^{32}$ awareness that inheres in such a mode of exploration. I will summarize the essential nature of the dance improvisational process and the optimal state of mind needed to sustain it, as it might translate into the act of drawing. The dancer and scholar, Cooper Albright (2003) writes:

Improvisation is a philosophy of life...it is a way of relating to movement and experience: a willingness to explore the realm of possibility, not in order to find the correct solution, but simply to find out...a willingness to cross over into uncomfortable territories, to move in the face of fear, of what is unknown. This willingness is made possible by the paradoxically simple and yet quite sophisticated ability to be at once external and internal - both open to the world and grounded in an awareness of one's ongoing experience. 'Dwelling in Possibility' refers to this dual experience of being present 'here' in order to be able to imagine what could happen out 'there'... Dwelling is a heightened experience of inhabiting - fully and consciously - such that space becomes more than the sum of its parts, such that space makes things happen. (259)

Improvisation, Cooper Albright contends, seeks to release the minded body from habitual responses, expectations, and preconceptions through a suspended attentiveness and a somatic engagement that transforms the psychic organization. It is an act of relating and creating new relations that can reconfigure the very significance of relationships. (263) Improvisation is a means of being present in the moment, of experiencing freedom and the distilled energy that it produces and engages with. In the spirit of Crary's suspension of perception, it channels our awareness of the world and is simultaneously a detachment from it, enabling one to inhabit metamorphoses. The holistic state of mind induced by somatic awareness in improvisation Nancy (2015) refers to as the state of listening:

32 Somatics is based on the soma (the body as perceived from within). It promotes a heightened attention to proprioceptive information and inner experience. Somatic practices rely on a strong mindbody connection in their exploration of authentic movement and space-time presence. 
To listen is to be straining [in tension-intension] toward a possible meaning, and consequently, one that is not immediately accessible...[it] is always to be on the edge of a resonant meaning, a meaning whose sense is supposed to be found in resonance, and only in resonance. (18)

He further explains the significance of resonance in such a way as to bring us back to the idea of trace examined with Derrida:

Meaning...is made of a totality of referrals: from sign to a thing, from a state of things to a quality, from a subject to another subject or to itself, all simultaneously...in external or internal space, it resounds, that is, it re-emits itself while still actually 'sounding'...to sound is to vibrate in itself or by itself...to stretch out, to carry itself and be resolved into vibrations that both return it to itself and place it outside itself. (19)

To listen is to enter a spatiality that reciprocally penetrates one by opening up, and by being opened to, its reverberation and its expansion.

Bringing students that are intensely embedded in pragmatic, technical and scientific thinking processes and in the attitudes and philosophically narrow perspectives that these often entail, into somatically aware states of mind can prove quite challenging. But perhaps more difficult still, is convincing students that are versed in the frenzy of the vertiginous acceleration of information processing, to embrace stillness, darkness and silence, and to shift from the left to the right hemisphere. The one medium, albeit different in kind, that still seems to resonate and to link their worlds to that of drawing as advanced in this thesis is vital movement. Movement is, therefore, central in the heuristic practices I propose (appendix A); it is through embodied movement that stillness (in Lepecki's sense above) will be accessed; that sensations will occur, that gestures and flows will emerge; that body awareness will develop; that inner feelings will arise; that space will come to life. It is off movements that thoughts will spin; that relations will be made. It is also in collaborative movement that affect attunements will form. Drawing, I hope, will become the tracing of intensities, the mobilization of deferral, the metaphor of future possibilities. 


\section{8}

\section{Conclusion}

Having previously circumstantiated the kinesthetic, vital and embodied nature of Gehry's drawing practice as premise to a renewed conception of drawing in architecture education, this chapter outlined key pedagogical and epistemological foundations to further substantiate that conception. Through Pallasmaa's phenomenological outlook, the role of embodied sensorimotor perception and experience in architecture was evinced and the need to sensitize students to this reality, advocated. Crary proposed modes of attention conducive to transformative forms of experience that I contend can be actualized in drawing processes. Sheets-Johnstone linked the dynamics of thinking to that of moving, thus, conveying the nature of 'intelligence' at the heart of drawing. Stern grounded dynamic vitality in movement as it emerges in subjective and intersubjective forms of affect that sustain the act of drawing. Johnson and Lakoff then established the role of the body in processes of conceptualization, which also applies to architectural sketching. These theories together shape a discourse on the body that validates the necessity of reexamining our approach to architecture education. Drawing is but one potential means of changing attitudes and conceptions because it is already in itself a kinesthetic practice.

Seeking to expose and circumvent the shortfalls of modernity this chapter, therefore, proposes alternative attitudes and pedagogical approaches to architecture that acknowledge and advocate forms of embodied knowledge and kinesthetic attentiveness conducive to dynamic forms of vitality in the act of experiencing and conceptualizing architecture. It aspires to reveal a glimpse into the potentiality of drawing to embody forms of tacit bodily knowledge, in order to revitalize the role of drawing within the discipline. 


\section{CONCLUSION}

This thesis began by asking how drawing can be understood as an interface between dance and architecture. I conclude by positing, borrowing from Grosz, that drawing has the capacity to bridge these two discourses because it has also developed its own specificity in parallel with, and independently of the demands of both disciplines: it is situated on the outside: outside the disciplines, the pragmatics, technologies, politics and economics; outside their doctrines and established conceptions and expectations. By taking this position and freeing itself of the demands of both professions, it is empowered to draw, rather, from within the body, its desires, logos, histories, cultures, and potentialities. From this place, space is revisited as intertwined with duration; experience with movement; movement with sensation; sensation with affect; and the actual with the virtual.

Chapter one endeavored to show how drawing can play out the extensity and intensity of the sensorimotor body, enabling another understanding of building as vital body responding to, and generating the multiple fields of resonance, within and without, that make up the plane of immanence in architecture. Chapter two mapped out the mediating forces at work in the scripting or the coming into being of architecture. It attempted to reveal the nature of virtualities inherent in the act of tracing and the diagramming of transformative forces operating as sensations in Gehry's series of sketches. The final chapter examined the potential of duration as integral to a conception of space that embraces virtuality and excess in architecture. It designated the kinetic body as the very possibility of conceptualization and as the locus of knowledge, which can be explored through drawing. In the end, drawing aspires to be the pivotal experience of dynamic vitality and intensity that runs through all of these theories,

enabling them to operate as transformative forces or diagrams disrupting the stasis of architectural predispositions.

What this thesis ultimately aspires to disrupt is the well-entrenched impetus towards always more disembodied understandings of space. Students swept away in the immense maelstrom of digital and technological worlds are progressively inhibited from feeling the pulse of living matter, from relying on their own corporeal impulses and intuitions. From one year to the next (perhaps I could now say, from one generation to the next) of teaching practice, I have witnessed a progressive drifting further into the disembodied virtuality constructed for the vested interests of corporate entities. And the products of design practices reflect the 
consumer values these entities inhere ${ }^{33}$. What the thesis proposes, is bringing students back to a space of magical rapture, of enactively wondering the world with affect and passionate vitality, a world we could once say was that of our very idiosyncratic childhoods. But even that seems to dwindle from their repertory of possibilities, as their childhoods are precariously immersed in always more precocious digital universes. I believe that dance has much to offer as a window into our in-corporeal wealth and resources, which I have only begun to unveil in this inquiry; and drawing is the potential dance of the architect, one that is already inscribed in the process of design but that only needs to be revived.

Freehand drawing is part of a significant heritage that has sustained the practice of architecture from its very inception. That digital technologies have entered its realm does not revoke its role as a meaningful interface between corporeal sentience and built form. The practice of architecture as performance is a perpetual enmeshing of many planes of emergence of which drawing as residue of the body's motility and spatiality is a significant yet often disregarded component. Drawing, I propose, is a means by which we can ensure and substantiate the human corporeal reality that bestows meaning upon our contemporary architectural endeavors and their outcomes. Can rethinking drawing as dance, act and trace in the context of our contemporary situation, as a projection of our bodily experience and knowledge, perhaps revive the poetic performative potential of architecture and enhance its capacity to affect human values and lives?

33 This phenomenon is even more pronounced in interior design programs than in architecture. 


\section{References}

Bredekamp, H. (2004). Frank Gehry and the art of drawing. In H. Bredekamp \& M. Rappolt, (Eds.). Gehry Draws (pp.11-28). London: The MIT Press.

Buci-Glucksmann, C. (2001). L'esthétique du temps au Japon: Du zen au virtuel. Paris: Éditions Galilée.

Crary, J. (1999). Suspensions of perceptions: Attention, spectacle, and modern culture. Massachusetts: The MIT Press.

Cooper Albright, A. (2003). Dwelling in possibility. In A. Cooper Albright \& D. Gere, (Eds). Taken by surprise: A dance improvisation reader (pp. 257-267). Middletown: Weylan University Press.

da Costa Meyer, E. (2008). Frank Gehry: On line. New Jersey: Princeton University Art Museum.

Deleuze, G. (2002). Francis Bacon: The logic of sensation. (D. W. Smith, Trans.). Minneapolis: University of Minnesota Press. (Original work published 1981)

Didi-Huberman, G. (2006). Le danseur des solitudes. Paris: Les Éditions de Minuit.

Ednie-Brown, P. (2007). The aesthetics of emergence: Processual architecture and an ethicoaesthetics of composition (doctoral dissertation). Melbourne: RMIT University.

Eleey, P. (2008). If you couldn't see me: The drawings of Trisha Brown. In A. Lepecki, (Ed.). Dance: Documents of contemporary art (pp. 184-187). London: Whitechapel Gallery Ventures Ltd.

Fraleigh, S. (1987). Dance and the lived body: A descriptive aesthetics. Pittsburgh: University of Pittsburgh Press.

Gil, J. (2002). The dancer's body. In B. Massumi (Ed.). A shock to thought: Expression after Deleuze and Guattari (pp. 117-127). London: Routledge.

Gil, J., Lepecki, A. (2006). Paradoxical body. The drama review, 50 (4), 21-35. Massachussetts: The MIT Press.

Grosz, E. (2001). Architecture from the outside. Massachusetts: Massachusetts Institute of Technology.

Grosz, E. (2017). The incorporeal: Ontology, ethics, and the limits of materialism. NY: Columbia University Press. 
Johnson, M. (1987). The body in the mind: The bodily basis of meaning, imagination, and reason. Chicago : University of Chicago Press.

Johnson, M. (2007). The meaning of the body: Aesthetics of human understanding. Chicago: The University of Chicago Press.

Lafrance, N. (2008). Rapture: Body rhythm architecture. Sens production. New York: Rapture Press Kit. Retrieved Oct. 6, 2016 from: http://sensproduction.org/rapture.

Lakoff, G. \& Johnson, M. (1980). Metaphors we live by. Chicago: University of Chicago Press.

Langer, S. (1953). Feeling and form: A theory of art. US: Charles Scribner's Sons.

Laverty, S. (2003). Hermeneutic phenomenology and phenomenology: A comparison of historical and methodological considerations. International journal of qualitative methods, 2 (3), 21-35.

Retrieved Jan 15, 2017 from https://journals.library.ualberta.ca/ijam/index.php/IJQM/article/view/4510/3647.

Leigh Foster, S. (2011). Choreographing empathy: Kinesthesia in performance. NY: Routledge.

Lepecki, A. (2004). Inscibing dance. In A. Lepecki (Ed.). Of the presence of the body: Essays on dance and performance theory (pp. 124-139). Middletown: Wesleyan University Press.

Lepecki, A. (2000). Still: On the vibratile microscopy of dance. In G. Brandstetter \& H. Volckers (Eds.). Remembering the body. Body and movement in the 20th century (pp. 334-66). Ostfildern-Ruit: Hatje Cantz Publishing.

Louppe, L. (1991). Danses tracées: Dessins et notations des chorégraphes. Paris: Éditions Dis Voir.

Louppe, L. (2010). Poetics of contemporary dance. (S. Gardner, Trans.). Alton: Dance Books. (Original work published 1997)

McNamara, J. (1999). Dance in the hermeneutic circle. In S. Fraleigh, \& P. Hanstein (Eds.). Researching dance: Evolving modes of inquiry (pp. 162-187). London: Dance Books Ltd.

Merleau-Ponty, M. (1968). The visible and the invisible. (A. Lingis, Trans.). Evanston: Northwestern University Press. (Original work published 1964)

Merleau-Ponty, M. (1964). L'Oeil et l'esprit. France: Éditions Gallimard. 
Merleau-Ponty, M. (1962). Phenomenology of perception. (C. Smith, Trans.). London: Routledge \& Kegan Paul Ltd. (Original work published 1962)

Nancy, J.-L. (2013). The pleasure of drawing. (P. Armstrong, Trans.). New York: Fordham University Press. (Original work published 2009)

Nancy, J.-L. (2015). On listening. In A. Heble \& R. Caines, (Eds). The improvisation studies reader: Spontaneous acts (pp. 17-27). NY: Routledge.

Pallasmaa, J. (2009). The thinking hand: Existential and embodied wisdom in architecture. Chichester: John Wiley and Sons Ltd.

Pallasmaa, J. (2005). The eyes of the skin: Architecture and the senses. Chichester: John Wiley and Sons Ltd.

Pirson, J. F. (2011). Pédagogies de l'espace: Workshops. Bruxelles : Cellule architecture de la Fédération Wallonie-Bruxelles.

Rouquet, O. (1999). Mettre en movement les spirales du corps. Médecine des arts, 30, 33-40.

Sheets-Johnstone, M. (2011). The Primacy of Movement. Amsterdam: John Benjamins Publishing Company.

Sheets-Johnstone, M. (2009). Thinking in movement. The corporeal turn (pp. 28-63). Exeter: Imprint Academic.

Spurr, S. (2007). Performative architecture: Design strategies for living bodies (doctoral dissertation). South Wales: University of South Wales.

Spurr, S. (2009). Drawing the body in architecture. Architectural theory review, 14 (3), 322-332. Retrieved Nov. 7, 2015 from 10.1080/13264820903341670.

Stern, D. (2010). Forms of vitality: Exploring dynamic experience in psychology, the arts, psychotherapy, and development. Oxford: Oxford University Press.

Van Imschoot, M. (2010). Rests in Pieces: On scores, notation and the trace in dance. Retrieved Oct. 8, 2016 from http://www.make-up-productions.net/media/materials/RestsInPieces Myriam \%20VanImschoot.pdf

Williams, J. (2014). Introduction: What is poststructuralism? Understanding poststructuralism (pp. 124). NY: Routledge. 


\section{Appendix A}

\section{An Embodied Approach to Drawing in Architecture Education}

\section{Proposed Exercises and Projects}

In-corporeal Diagrams: Drawing from Dance to Architecture, examines the role of drawing and sketching in architecture education and attempts to reveal the importance of establishing alternate drawing practices in response to the proliferation of digital tools of conception in the field. It calls for heuristic practices that could enrich understandings of the creative potential of drawing as a conceptual interface between the body, architecture and the environment in design processes.

In tandem with this research, I have developed an archive of various drawing approaches and exercises that could constitute a pedagogical resource for drawing practices in architecture education, as a source for reviving our temporal engagement with space. The following exercises ${ }^{34}$ and projects are inspired in part by, and formulated primarily in relation to, methods of dance improvisation and practices that draw on somatics. Ultimately, it aspires to open venues into the nature of thinking and perceiving in movement that would shift attention away from habitual corporeal responses and cognitive focuses to more kinesthetic awareness of experiences and processes that could sustain and revitalize creativity in architectural conception.

\footnotetext{
${ }^{34}$ Anyone of the drawings produced from these exercises could then be reinterpreted in a threedimensional maquette or installation to continually reinforce the potential of translating drawing into architecture and vice-versa.
} 


\section{A.1}

\section{Seeing and Perceiving}

The Urban Context

Sitting in a busy public space and using line, stroke and point (no figurative or symbolic forms):

Draw in a continuous line, the movements of passing people (pedestrians, bicycles, cars, etc.) while paying attention to the different pulses or fluxes of each.

Draw the direction and distance of peoples' gazes (either a person's continuously shifting gaze, or a momentary glance of many peoples' gazes as they pass through the same space) as they wander through the space. You might first sketch out the outlines of the space as a framework in which to draw.

Choose an animated element in the environment (falling leaf, insect, flag, plant, piece of paper, smoke, water, reflections in a window, changing light, fork or pen in someone's hand, someone's hair, etc.) and study its movement through drawing. (Let your hand and body convey the movement, don't try to represent it.)

Draw the rhythms of urban blocks with short strokes, the rhythm of people, buildings, windows, or any other repetitive element; draw the street flow or elements of continuity with longer lines.

Wander through the city and look for spaces that offer different rhythms. (Distance between repeated elements will reflect the speed of drawing: tighter rhythms should be drawn faster, spaced rhythms slower - pay attention to this space-time relationship.)

Paying attention to your act of looking, draw freely and quickly what engages you at every instant. This can include various fragments of buildings, movements, scraps on the floor, a passing cloud, etc. This could be done as a blind drawing. (C. Webster)

On one page: draw the distant scene, close-ups and peripheral views without turning you head. 
Draw the space using different modes of attention: distracted looking, focused, sweeping glance, eyes jumping around, analytically, sensuously, etc.

Close your eyes and listen to the noises of the city. Imagine and draw elements of the scene from the sounds: travelling in open space, reverberating against surfaces or objects, muffled by crowds of people, etc.

Draw the space from different positions (lying down, suspended, upside-down, bent over, etc.)

Find ways to disable your drawing gestures (tie your hands together, lift your leg and draw underneath it, put your paper behind you and draw from behind, hold your sketchbook between your feet, etc.) Draw while your shoulder is touching your partner's shoulder without breaking the contact.

Bringing only water, watercolour paper, a brush and a scraper, navigate the city stopping at places that engage you. Using only your materials and available matter from the site, make a non-figurative drawing 'of the place' (mix earth and water to paint; use or scrape a piece of asphalt to draw with; rub your wet paper on a surface to leave a trace of its materiality, rub a dampened leaf into the paper; engrave the paper with a branch; have someone walk on, or drive over your paper; draw using large quantities of water and let the sun dry it out to leave the water's trace, etc.).

Using loose-leaf paper and a pencil go on a shadow tour of the city. Trace the most interesting shadows you encounter on various surfaces.

Take a walk through a familiar part of the city then draw (from memory) the main references/landmarks that enable you, in a glance, to recognize the area.

Draw the references that direct your navigation... what references indicate where to stop, cross turn, look up, etc. (avoid the obvious mechanisms such as circulation lights, 
pedestrian crossing, etc.). Try to identify the sensorimotor signposts such as the distance from the radius of a curve (i.e. I stop when I get to 9 inches from the curb), alignment with a post or with a building corner, an opening between two cars, a shadow line, the roof edge of a building, etc. (What part(s) of your body is solicited by this referencing event?)

Get a map of your neighbourhood. Trace a line between public and private spaces (walk around and enter public spaces of commerce to determine the border where public becomes private). Indicate the porosity of the border by varying the quality of your line (freely traversed, traversed by some, inaccessible, etc.).

Draw a 'section' of your path to school. A horizontal line establishes the ground line and a trajectory line traces the vertical and horizontal motions above or below that line. Try to grasp any modulation of walking efforts in your line. Determine an alternate trajectory (or traveling rhythm) that would make that line more interesting, travel it and draw it, noting the points of kinetic interest along the way. This does not have to be the most efficient route (it can move in and out of buildings or metro stations, for example). The graph should be a twodimensional one ignoring the horizontal changes in direction and depth.

Repeat this exercise regularly throughout the semester, always looking for ways to vary the line.

Go to a crowded place, event or festival. Navigate through the densest part of the crowd paying close attention to the nature of your every deviation, contact, obstacle, and opening as you slalom through the space. Then draw this experience using charcoal with a line that expresses the variation of intensities, flows, tempos and resistances encountered.

Repeat the experience through various crowd densities and energies, to compose the tempos and rhythms of your movement drawing. Pay attention to the surging, fading, pulsing, affective/haptic kinaesthetic quality of your experience. 
Determine a route in the city (from point A to B). Take the metro to travel this route. Sit with a drawing surface on your knees, hands deposited lightly on the paper with a pencil in each. Let your pencil record the movements and vibrations of the train. (W. Anastasi)

Repeat the exercise on the bus (by car, walking, etc.) for the same trajectory.

Sit on a pivoting chair (facing the back so as to rest your drawing surface on the backrest) somewhere in a room. Draw the room in a continuous fashion as you pivot $360^{\circ}$. Change positions in the space and repeat. Vary the speed or rhythm of rotation. Begin to roll more freely around the room as you draw. (Pay attention to space as always transforming relationships: changes in scale, distance from you, etc.)

Choose a place, indoor or outdoor, and draw the space without representing any architectural element or using architectural conventions. (For example, you could draw only the picture frames on the wall or objects in the space - without relying on perspectival relations; draw the space as if it were a lump of clay; draw the light without the surfaces; the sounds entering the space, the drafts or air currents through the space, etc.)

\section{A.2}

\section{Proprioception}

Body \& Anatomy

With eyes closed draw a continuous 8 motion in the air with your foot, as stretched out as possible. Visualize what you feel in your calf-ankle-foot; draw the tensions you feel; draw the connections between your tensions and the 8 shape.

Zoom into your toes; draw the connection/continuity of tensions within your foot.

Rotate your shoulder tracing the largest 0 you can (the arm stays limp), draw your shoulder/collar bone joint as you feel it; draw the felt connections between shoulder and 
shoulder blade. (You may touch your shoulder in movement with your other hand if you have trouble visualizing.)

Draw the tensions, sensations, and connections in your hand, arm, body, as it draws.

Sit or stand still in a comfortable position, your sketchbook resting close at hand. Concentrate on your body and trace all the sensations and micro-movements you can feel from within and without (pulsations, tingling, tensions, vibrations, contractions and dilations from breathing, etc.). Scan your motionless body carefully part by part with your mind's eye.

Continuously describe the process orally as you draw, describe what you are feeling in your fingers, hand, arm, body as you draw; the parts of your body that seem shut off from the movements, etc.

Grasp the first distracted (perhaps unrelated) thought that comes through your mind and talk about it as you continue to draw. Think of the last film you saw and narrate it. (How does this mind-body split affect your drawing?)

Alternately squeeze and release your partner's arm with one hand and draw, with the other, his bodily response to your touch (tensions, pulsations, etc.). Shift your attention from your touching hand to your touched hand. Draw the tactile feeling between your hand and his arm.

Repeat the exercise by placing your feet on his back and applying pressure. Draw the tensions and dilations in your feet and in his back. Draw the exchange (connection) between feet and back, toes and back, heel and back.

Engage in a contact improvisation of stillness with your partner and simultaneously draw the exchange of forces at the center of contact.

Select a series of your drawings and analyse them (what kinds of strokes, intensities, qualities, forms, etc. predominate?) Identify your gestural habits and dead spots. 
With a partner, mount a large sheet of paper on the wall. You are to examine the rotary and micro-rotary limits of your body articulations. Standing sideways with shoulder against the wall, your partner will trace the arcs of your articulations while maintaining the center of the radius pinned to the wall (he will pin your knee to the wall as he traces the arc of the tibia's movement, your hips as he traces the arc of your leg movement, etc.). Pay special attention to articulations that are less obvious: the rotation of your jaw, fingertips, skull rotation, neck rotation, and as many vertebrae rotations as you can move. You may also consider the extension of your breathing by tracing the movement of your chest and stomach. Certain articulations such as the shoulder may have more than one type of articulation (it may rotate relative to the arm, the collar bone and the shoulder blade).

Stand with your back or front to the wall and repeat.

With your partner study the rotations and micro-rotations of joints in a simple movement such as ascending or descending a stair, jumping, etc.

Find fifteen creative ways of 'measuring' a space with your body. Any prostheses must be used as a measure of force and not distance. (Count the amount of times you repeat a gesture across a space: rolling or spinning on the floor; hopping backwards; spitting a small object as far as you can; bouncing a ball off the walls and counting amount of times it bounces off the surfaces, sliding along the periphery or diagonally across a space; using the time it takes to utter a sentence while walking, as a unit of measurement; counting amount of times you cross the room while reading a specific text, etc.)

Draw the space as an expression of these movements.

Find a creative way to leave a qualitative trace of your body in a space (by spreading sand or paper on the floor or walls and moving on it to displace, wrinkle, tear it; soaking your clothes in water and moving around; blowing powder or coloured soap bubbles in the space, etc.).

Have your partner re-enact your movements by interpreting the traces. 


\section{A. 3}

\section{Visualizing}

Creating and Remembering Space

Delimit a space (square, circle, etc.) on the floor of the studio with a tape or cord. One student enters the space and mimes the gestures of moving within an imaginary architecture. (He bends and steps over the tape as if entering a window, turns and climbs stairs, stops and leans over to look down, walks and stops at the tape line looking out, steps over the tape onto an imaginary balcony, enters and steps down into an imaginary space, looks up as if into a skylight, etc.) As the student creatively mimes a space, other students draw this space, reading the forces and qualities of gestures of the student. (Pay attention to how movements inform us on space.)

Another student repeats the exercise but creatively suggests unconventional architectural spaces through unusual movements.

This project should be presented as one exercise option among others. It is to be done at any time during the session. You are to sleep with a sketchbook next to your bed. When you wake up to a dream, draw in plan the spaces or spatial fragments of your dream (areas that are ambiguous should appear ambiguous in your drawing). Choose an interesting dream and analyse the spaces trying to recall which real spaces they represent in your life experience. Be attuned to re-compositions of many spatial fragments into one dream space (some dream spaces may be constituted from the characteristics of many real spaces). How do the spatial fragments connect? What architectural elements are most recurrent (stairs, columns, doorways, etc.)? How did you navigate these spaces? How did you feel in them? What memories emerged with them? How do they differ from real spaces - how do they break the codes of architectural conventions?

Remember a space from your childhood to which you have not returned but can still access. This could be an old school, house, gymnasium, park, shed, attic, hiding place, etc.) Draw the space in as much detail as possible, using any type of drawing you find appropriate. Also note the sounds, smells, feelings you remember, the corporeal movements you engaged 
in, etc. Return to the space, survey and redraw it. Analyse the differences between your memory and the reality of the place. Where are the blind spots? What had been exaggerated? What was perceived falsely? What differentiates your childhood perception from your adult perception? Why did you use that type of drawing, what specificity links it to your experience?

\section{A.4}

\section{Improvising}

Working with the Dancer

Observe a sequence of movement of the dancer/model. Draw the shape of the dance (the overall sequence's spatial form) from memory (see Laban's icosahedron).

Observe the dancer again and attempt to draw the spaces of sequences within the overall dance as they overlap and flow into each other. Find the conductive flow (line) throughout.

Try to grasp the 'center of movement' that generates the forces of flow throughout. Draw the rhythm of this center (in isolation) as it moves (for example, are the hips and stomach generating the dance or is the torso?).

Draw the rhythmic flow from this center into the arms as it moves; from the center into the feet (does the floor push the centrifugal forces back towards the center or does the energy flow out of the feet and dissolve?).

Draw the extensity of the dancer's movements into space (the imaginary space around the model as she moves): respond to the forces of projection and reverberation of her movements in space. (Outgoing gestures should engender large spaces; introverted movements, closed spaces; directional movements, linear spaces; rotation movements, circular spaces. Shape, direction, size/distance, quality/texture, rhythm/reverberation, etc. should all be generated from the (forces of) movements.) 
(In other words, draw the reverberation/echoes of the dancer's gestures within the existing space like flows of reverberating water in an aquarium. The way the movement's forces, bounce against walls and objects, slide along surfaces, dissipate in space, etc.?)

Using mirrors around the model, draw all views of the body.

Using mirrors around yourself, draw yourself from different views. (Pay attention to the relationship of what you see before you and what is hidden behind you.)

Attempt the same exercises without mirrors, visualizing your (or the model's) back.

Draw from memory what you don't see around you. (What would your back see, the top of your head, etc.?)

As the model remains still, make a blind drawing of him/her while moving slowly around him/her. Repeat with another pose but begin to vary the distance between you, paying attention to the shifting scales.

A video projection of drawing in the making, as the student traces and interacts with the (potential) movements of the dancer/model, is simultaneously projected onto the walls surrounding the dancer so as to generate an improvisational exchange between drawing and dancing. (Drawing becomes a form of immediate scoring for the dancer and vice-versa.)

The improvisations could stem from spatial themes (passage, frontier, opening, rupture, etc.) or physical phenomena (compression, equilibrium, torsion, etc.) explored in design studios. They could stem from forms of vitality (fading, surging, swelling, pulsing, fleeting, bursting, etc.)

Line might become synonymous with wind, breeze, or breath: pushing, twirling, bending, brushing against the body of the dancer as she/he responds to its forces, directions, and aerial qualities. 
Improvisations could be constrained by pre-given instructions or by the incorporation of 'obstacles' (ex: translucent fabric 'banners' could be suspended randomly from the ceiling and be activated by wind sources to introduce movement to, and fragment the projected image; varying the intensity and amplitude of the affecting force on this third body of movement to further spatialize the act of drawing).

A dancer moves in space according to given directions (ex: move left foot and right shoulder). Student draws it with left and right hand respectively as a video of her drawing is projected onto wall. A second student, with her back to the first, responds to the drawing by also moving left foot right shoulder. (Rochelle Haley)

\section{A.5 \\ Drawing in Space}

Interventions

Choose a space in the school (staircase, wc, hallway, etc.) and create a choreography that will change the nature of movement through the space by stretching cords, nylons, or other linear elements across the space.

Choose a threshold (with or without a door) and modulate the act of entering and exiting. (Set written parameters for the movement: do not touch the cords, or only with your feet; push or pull on every nylon rope with hands and feet as you traverse them; re-anchor/position ropes in wall/floor as you move through them, etc.)

Choose a small space (bathroom cubicle, section of a staircase or corridor, threshold, etc.). Using line (in any medium: reflect on the possibilities of translating line in space), transform the felt qualitative nature of the space: modulate and/or infuse the perimeters with a vibratile intensity that activates the space.

Choose a film or text that has moved you and transcribe its qualitative nature in the space. 
In groups of two or three create and build an apparatus or object that will put into play your sense of gravity (such as a seesaw, a pivoting or suspension mechanism, etc.). Find a way to use this apparatus to trace (on the wall, floors, ceiling, etc.) its movement and your response to it, in such a way that we can read/sense the type of disequilibrium that it puts into play.

\section{A. 6}

\section{Scoring}

Writing Movement

Choose the most interesting route from point $A$ to $B$ into the school and travel it back and forth a few times. Devise a personal score of your navigational movements through the space (see examples of various notation systems). These could be markings, symbols, etc.

'Parallel' to this score develop another one that indicates the body part(s) that is most solicited by the movement experience.

In a third score devise a notation that evokes the quality or the sensations created by the movement (breathing, heartbeat, body temperature, light on eyes, air currents, etc.). These may include (abbreviated) words.

In a forth, indicate up to three related architectural elements per movement that are responsible for the movement or sensation.

Combine these scorings graphically to shape your 'text' of the experience. Place more emphasis on characteristics that dominated others or that were more intense, using line weight, size, etc.

Another scoring system could examine Laban's factors of effort in the experience of traveling the same route: 
Time: what is the tempo of your movements, accelerations and decelerations through the space?

Space: how are you attending to space? Is it a focused, direct attention or distracted, indirect; is it a close or distant attention?

Weight: what is your engagement with gravity? Is it forced, heavy and resistant or free and light?

Flow: what is the intensity of your muscular tonicity? Are you controlling the movements and creating tensions or is it free and released?

Create a choreography that relates to another, creative way of moving along the same route.

Working with a partner, have him interpret (with or without assistance) your score and perform it in the space. He may then suggest interpretations or variations on your score, etc.

Imagine changing or adding one architectural element in the space that would completely alter the way one moves through it. (If you can actually alter it, all the better.) How would it alter the movement or its quality?

Choose one of your (or another's) favourite architectural drawings (plan, elevation, section, etc.). Working with tracing paper:

On the plan or section, use your scoring system to study all the possibilities of movement through the space (this does not have to be functional: think in terms of various movement types _ acrobat, gymnast, skate boarder, dancer, etc.).

Devise a more interesting score and rearrange your space to enable it.

Choose another drawing and "scramble" it until it becomes a diagram (all it conveys are sensations of the immediacy of your gestures through line variation, as an expression of the space - how the space feels, pushes and pulls on you).

Revise your original drawing to incorporate the spatial vitality of your diagram. 


\section{A.7 \\ Duration}

Tracing Time

This project should last a whole session. Choose 6 or 12 drawing mediums and number them; obtain a pair of dice. Set up a sheet of paper or support of your choice that is to remain on the wall, floor, ceiling, window or table the entire time. Every day you will draw a line (in its broadest sense) that conveys the atmospheric weather non-figuratively.

The first roll of the dice will determine at which time you will draw the immediate weather (you can choose how to read the dice: one only or both, representing am or pm).

The second roll will determine which medium to use (1 to 6 or 12).

The third, the amount of minutes you will take to draw the line.

The fourth, the length of the line (the units should be decided relative to the size of support.)

(This could also been done with a three-dimensional line in space.)

Wait for a cloudy day. Using charcoal, a shammy, and an eraser, choose a cloud formation and draw its transformation. (Avoid drawing its form; concentrate on its movement, the forces affecting it, its dissolution, its formation.) 


\section{Bibliography (Appendix A)}

Buckwalter, M. (2010). Composing while dancing: An improviser's companion. Madison: The University of Wisconsin Press.

Collod, A., Challet-Haas, J., Brun, D. (2007). Dossier Laban. Centre national de documentation pédagogique en ligne. Paris: Ligne de sorcière. Retrieved Feb 11, 2017 from: http://lille3.fr/files/espaces/pers/30/P6730/partage/Licence\%20S2/Analyse\%20chor\%C3\%A9gra phique\%202/Laban.pdf.

Draw to perform: An international community for drawing performance. Accessed Jan 21, 2017 from https://drawtoperform.com/

Forti, S. (1974). Handbook in motion. NY: New York University Press.

Haley, R. (2015). The aesthetics of change: Dancing the line, The international journal of the image, 6 (4), 1-12. Retrieved January 16, 2017 from www.ontheimage.com

Molesworth, H. (Ed.). (2011). Dance/draw. Boston: Hatze Cantz: The Institute of Contemporary Art.

Shusterman, R. (2009). Body consciousness and performance: Somaesthetics east and west. The Journal of Aesthetics and Art Criticism, 67 (2), 133-145. The American Society for Aesthetics.

Shusterman, R. (2012). Somaesthetics in architecture, In Thinking through the body: Essays in somaesthetics (pp. 219-238). New York: Cambridge University Press.

Heble, A. \& Caines, R. (Eds). (2015). The improvisation studies reader: Spontaneous acts. NY: Routledge.

D. Petrovich \& R. White (Eds.). (2012). Draw it with your eyes closed: The art of the art assignment. NY: Paper Monument.

Webster, C. (2012). The journey and movement, repetition and time: Drawing my visual practice. Journal of visual practice, 11 (1), 27-47. Retrieved Jan 16, 2017 from: doi:10.1386/jvap.11.1.27_1 